\title{
Building an Understanding: What Motivates Teachers to use Science in Motion
}

\author{
Karen M. Spuck
}

Follow this and additional works at: https://researchrepository.wvu.edu/etd

\section{Recommended Citation}

Spuck, Karen M., "Building an Understanding: What Motivates Teachers to use Science in Motion" (2015). Graduate Theses, Dissertations, and Problem Reports. 6706.

https://researchrepository.wvu.edu/etd/6706

This Dissertation is protected by copyright and/or related rights. It has been brought to you by the The Research Repository @ WVU with permission from the rights-holder(s). You are free to use this Dissertation in any way that is permitted by the copyright and related rights legislation that applies to your use. For other uses you must obtain permission from the rights-holder(s) directly, unless additional rights are indicated by a Creative Commons license in the record and/ or on the work itself. This Dissertation has been accepted for inclusion in WVU Graduate Theses, Dissertations, and Problem Reports collection by an authorized administrator of The Research Repository @ WVU.

For more information, please contact researchrepository@mail.wvu.edu. 
Building an Understanding: What Motivates Teachers to use Science in Motion

Karen M. Spuck

Dissertation submitted

To the College of Education and Human Services

At West Virginia University

Education Doctorate

In Curriculum \& Instruction and Science Education

Patricia Obenauf, Ed. D., Chair

Ron Iannone, Ed. D.

Sam Stack, Ph.D.

Randall Wiesenmayer, Ph.D.

Bruce Smith, Ph.D.

Department of Educational Theory and Practice

Morgantown, West Virginia

2015

Keywords: Science Partnerships, Science Outreach, Teacher Beliefs, Teacher Initiated Practices

Copyright 2015 Karen M. Spuck 


\title{
ABSTRACT \\ Building an Understanding: What Motivates Teachers to use Science in Motion
}

\author{
Karen M. Spuck
}

Science education reform documents call for instructional practices that include scientific equipment and materials. Often, these types of resources are inaccessible for schools, especially those which are rural and socio-economically challenged, due largely to budgetary considerations. Science outreach partnerships are able to bridge the gap between what is called for in science education reform documents and the realities of many schools. Science in Motion is a science outreach partnership project located in rural Northwestern Pennsylvania, supported by state funds, that provides equipment, curricular materials, and professional development free of charge for area science educators. Teacher participation in this project is completely voluntary. Not a grassroots initiative, nor a top down mandated project, why do teachers decide to use this project? This study examined the volitional use of the Science in Motion project at Clarion University of Pennsylvania. Qualitative research methods were used to answer the following research question: what are the reasons for project use reported by teachers who use the project on a regular basis? Sub research questions were: what is it about the teacher that encouraged her/him to initiate Science in Motion services, and what is it about the teacher that encourages her/him to continue using Science in Motion services? Two focus group interviews as well as a paper/pencil questionnaire were used to collect data from teacher participants who use the project on a regular basis. A phenomenological lens was used to examine data. A grounded theory approach was used to analyze data. Research findings reveal teachers initiated use because: the project provided opportunities for teaching and learning that otherwise were inaccessible, the project was perceived as user friendly and easy to access, the project embedded professional development provided the support needed to encourage initial use, and the project resources were perceived as a means to facilitate teaching and learning goals and beliefs held by this group of teachers. Reasons for continued use included the project was found to be user friendly and the project maintained a variety of equipment, and updated labs and equipment on a regular basis. In addition, teachers were given an opportunity to have a voice in the project, selecting labs and materials as the project expanded over the years, which gave teachers a sense of ownership and empowerment. Assertions about this group of teachers were also developed. These teachers were found to be reflective about their teaching practices, and resourceful problem-solvers. They also maintain strong professional attitudes, and value life-long learning. The research participants believe maintaining a dynamic curriculum and continued professional growth keep the teaching processes exciting for themselves, which then sparks student interest excitement and motivation to learn. 


\section{DEDICATION}

This dissertation is dedicated to my grandmothers, Carolyn and Virginia. As the first woman on both sides of my family to earn a doctoral degree, I know they would have been so happy and proud of my accomplishment. 


\section{ACKNOWLEDGEMENTS}

In 1998, my journey began in Green Bank, WV where I attended a summer teacher institute. It was there that I met my adviser, Pat Obenauf. The experience inspired me to further my education. I am extremely grateful for the people I met at this institute and the experience that started me down the path towards a doctoral degree. I am particularly grateful for Pat, who shared her wisdom, guidance and quiet encouragement, and still does to this day.

I would like to recognize my WVU committee members: Dr. Ron Ionnane, Dr. Sam Stack, and Dr. Randy Wiesenmayer. Thank you for your support, insight and guidance along the way. I would also like to recognize Dr. Bruce Smith, my outside committee member and longtime Science in Motion director, mentor, master degree adviser at Clarion University, colleague and friend. Bruce has been a constant source of encouragement, support and guidance over the years. I am thankful for all he has done for me.

I am also grateful for Don Mitchell and the CPACT team for their ingenuity and vision. The Science in Motion Program is something that has made a difference for many science teachers and their students, and for me. The program gave me a forum and context in which to form this study. In addition, the Science in Motion staff across Pennsylvania are an incredible team of dedicated professionals who have been a source of support and inspiration along the way.

As the Science in Motion coordinator and mobile educator at Clarion University, I have had tremendous support from many university science faculty and staff over the years. Their encouragement and ideas have been instrumental as I have grappled with this process.

I would also like to recognize and thank the teachers involved with the project at Clarion University, and in particular those who participated in this study. They were very generous with their time and willingness to shared personal thoughts and insights which gave this study meaning and purpose.

And, I have had amazing support from countless friends and family who have helped me through this journey. In particular, I would like to thank my husband, Tim for being there for me, supporting me as I struggled through the challenges, and celebrating the accomplishments with me along the way. And also my parents, Larry and Ann, who have been a source of constant support. Mom, with her subtle and gentle encouragement, and Dad, who has been my biggest cheerleader, with his persistent encouragement and prodding. Thank you all so much! 


\section{Table of Contents}

ABSTRACT

DEDICATION

ii

ACKNOWLEDGEMENTS

\section{Chapter 1 INTRODUCTION}

Science Education Reform and Classroom Realities $\quad 1$

History of the Science in Motion Partnership Program 3

Science in Motion Lesson Illustration $\quad 8$

Focus of the Study

Clarion University of Pennsylvania Science in Motion $\quad 10$

Personal Narrative 11

$\begin{array}{lr}\text { Rationale } & 16\end{array}$

Statement of Problem $\quad 17$

$\begin{array}{ll}\text { Purpose of the Study } & 17\end{array}$

$\begin{array}{lr}\text { Research Questions } & 18\end{array}$

Limitations and Assumptions of the Study 18

Definition of Terms 19

Document Format 21

\section{Chapter 2 REVIEW OF THE LITERATURE}

Overview 22

Science Education Reform: Sputnik to Present 22

Disconnection between Science Education Reform and the Educational

System

Science Education Partnerships as a vehicle to meet Science Education

Reform

Partnerships and Instructional Resources 26

$\begin{array}{ll}\text { Partnerships and Professional Development } & 27\end{array}$

$\begin{array}{ll}\text { Partnerships and Science Literacy } & 30\end{array}$

Partnerships and Student Achievement 34

Partnerships and Student Attitude and Motivation 36

Science Education Reform, Partnerships and the Science in Motion

Program

Factors that Influence Teachers' Decisions to Implement New

Instructional Materials

Teachers and External Factors that Influence the Instructional Decision

Making Process

Teachers and Internal Factors that Influence the Instructional Decision

Making Process

Teachers and Beliefs

Teachers and Sustained Innovative Instructional Practices

46

Summary 
Chapter 3 RESEARCH DESIGN AND METHODOLOGY

General Summary $\quad 50$

Research Questions 51

Research Design 51

Method of Data Analysis $\quad 52$

Participant Selection 53

Research Instrumentation $\quad 54$

Interview Questions $\quad 55$

IRB Requirements 56

$\begin{array}{lll}\text { Chapter } 4 & \begin{array}{l}\text { PRESENTATION OF DATA } \\ \text { Introduction }\end{array} & 57\end{array}$

Overview of Teacher Selection Process 57

Data Collection Process: Paper Pencil Questionnaire Participants 58

Data Collection Process: Focus Group Interview Participants 58

Teacher Demographic Information $\quad 59$

Focus Group Interview Procedures $\quad 60$

Data Analysis Overview 61

Teacher Participation Data Overview: Question One through Question

Five 62

Question One: What was it about you that encouraged you to initiate

SIM services? 63

Perceptions about the SIM Project: "Levels the Playing Field" 63

Perceptions of SIM: Ease of Use 64

Perceptions of SIM: Familiarity with Staff and the Project Reaching

Out 64

SIM as a means to Enhance Teaching $\quad 65$

SIM as a means to Enhance Learning $\quad 66$

Teacher Professional Development 67

Teacher Self-Reported Personal Characteristics as Influences to Initiate SIM $\quad 68$

Question One Summary 69

Question Two: What are the factors that have encouraged you to
continue using SIM?

User Friendly Nature of the SIM Project 71

Professional Development $\quad 72$

Variety and Up-Dating of Laboratory Materials 73

Teacher Voice and Ownership $\quad 74$

Cost Savings and Budgetary Restraints 75

Student Engagement $\quad 75$

Life Beyond the Classroom $\quad 77$

Probing Questions $\quad 77$

$\begin{array}{ll}\text { School Administration } & 78\end{array}$

Parents and School Board $\quad 80$ 
School Culture

Question Two Summary

Question Three: Does Science in Motion help you meet your personal

Teaching Goal: Provide Engaging Experiences for Students

Teaching Goal: Real World Connections

Teaching Goal: Maintain a Dynamic Curriculum 99

Teaching Goal: Inquiry Teaching Strategies $\quad 91$

Teaching Goal: Professional Growth 93

Question Three Summary 94

Question Four: Does your continued participation with SIM reflect your personal feelings about your teaching of science? 96

$\begin{array}{ll}\text { Feelings about Pedagogy } & 96\end{array}$

Feelings about the Process of Instruction and Curriculum 97

Feelings about being a Professional Educator 97

Feelings about Student Readiness to Learn 98

Feelings about Student Learning and Motivational Experiences 99

Feelings about Teaching Goals: Science Literacy and Life Beyond the Classroom

100

Question Four Summary

Question Five: What is it about yourself that you believe causes you to continue to use the SIM project?

Beliefs about Learning: Personal Enjoyment

Beliefs about Learning: Life Beyond the Classroom 103

Beliefs about being an Educator: Learning is a Life Long Process 104

Beliefs about Teaching: Curriculum is Dynamic 105

SIM: Personal Connections $\quad 106$

Question Five Summary 108

Chapter 5 DISCUSSION OF DATA, FURTHER STUDY AND CONCLUSIONS

Introduction

Research Sub Question One

What is it about the teacher that encourages initial project use?

Teacher Perception of the SIM Project

Teacher Beliefs about Teaching and the Teaching Process

115

Teacher Beliefs about Students and the Learning Process

Research Sub Question Two

What was it about the teacher that encouraged her/him to continue using the project?

SIM is a Valuable User-Friendly Resource

SIM Expands the Curriculum

Ownership and Empowerment

Over-Arching Research Question: What is it about the Teachers that Encourages Use? 
Reflective Nature of the SIM Frequent User Teachers 122

Teachers and Their Professional Attitudes 124

$\begin{array}{ll}\text { Life-Long Learning } & 124\end{array}$

Resourceful Problem-Solvers 125

Teacher Beliefs about Students and Student Learning 126

$\begin{array}{ll}\text { Summary } & 127\end{array}$

$\begin{array}{ll}\text { Further Study } & 128\end{array}$

$\begin{array}{ll}\text { Teacher Users verses Non- Users } & 129\end{array}$

Teacher Users 130

Student Achievement 131

The Role of the Mobile Educator 133

The SIM Consortia in Pennsylvania $\quad 133$

$\begin{array}{ll}\text { Final Concluding Thoughts } & 133\end{array}$

A Letter to Stakeholders and Policy Makers in the U.S. 134

$\begin{array}{ll}\text { References } & 136\end{array}$

Appendices $\quad$ A. Participant Consent Letter 144

B. Human Research Protocol Only Minimal Risk Consent Form 146

C. Study Participant Demographic Questionnaire 150

D. Study Participant Demographic Data 153 


\section{Chapter I}

\section{Introduction}

\section{Science Education Reform Efforts and Classroom Realities}

In 1983, the publication, A Nation at Risk presented a shocking reality regarding the dismal state of science education in the United States (NCEE, 1983). In response, the American Association for the Advancement of Science (AAAS) published Project 2061: Benchmarks for Science Literacy with a vision of scientific literacy for all Americans (Rutherford, Ahlgren, et al., 1989). Soon to follow, in 1996, the National Research Council published the National Science Education Standards (NSES) urging K-12 science educators to make broad sweeping changes in pedagogy and curriculum, shifting focus away from content-centered curriculum and move toward a more process-centered curriculum (NRC, 1996). Almost a decade later the National Academies published, Rising Above the Gathering Storm: Energizing and Employing America for a Brighter Economic Future by request from the Federal Government to identify actions that could be taken in order to ensure a U.S. stronghold in science and technology. The recommendations included strengthening K-12 science education (NAS, 2007). This call for action was echoed again with a greater sense of urgency in the 2010 publication, Rising Above the Gathering Storm Revisited, Rapidly Approaching Category 5 (NAS, 2010). What sort of impact have these reform documents had on science education?

At best, the impact of reform efforts is slow to minimal. At worst, improvements in science education are non-existent. The National Assessment of Educational Progress (NAEP) science assessment results for grade twelve show no measurable changes in average scores when comparing results from 1996, when the NSES were released, with average scores from 2005 (NCES, 2012). Four years later, the 2009 NAEP science assessment results show only $21 \%$ of 
students in grade 12 performed at or above the Proficient level (NCES, 2012). Not only are the result disturbingly low for the nation as a whole, they also reveal an equity gap. When broken down by socio-economic status, the scores drop as the rate of poverty increases with only $4 \%$ of students in high poverty schools performing at or above the Proficient level.

The Trends in International Mathematics and Science Study (TIMSS) 2011 report the most successful schools are affluent and have access to resources for teaching science such as computers, technology and supplies (Martin et al., 2012). In low-income schools, teachers have limited resources and as a result, resort to mostly didactic modes of instruction (Thadani et al., 2010). When teachers are given resources to provide quality instruction, student achievement improves (Burruss, 2011; Herring, 2009; Lott, 2002; Mitchell, 1998; PDE, 1998; Thadani et al., 2010).

Curiosity and common sense aside, many of the advances in science are products of better and more advanced technological tools. The tools by which science, technology and engineering have been able to advance play a valuable role in science education. However, technology has grown and developed so quickly, education has been challenged to stay abreast of current trends (Dawkins, 2002; Ertmer \& Ottenbreit-Leftwich, 2010). Moreover, many of the tools used in science, technology and engineering are costly and out-of-reach for many school districts (Mitchell, 1998; Mulfinger, 2004; Rogers, 2000). None-the-less, technology has a major impact on the way we teach and learn and even think about education (Gaff, et al., 1997). In the science education community, it is now accepted knowledge that students need to experience science in order to have an appreciation and understanding of scientific principles. This aids in the development of science literacy. And often, experiencing science requires high tech tools that 
allow students to measure and interpret the world around them in meaningful, relevant ways (Ertmer \& Ottenbreit-Leftwich, 2010).

These shifts in science education and advances in technology have created challenges as well as obstacles which science educators and stakeholders struggle to overcome. Often schools do not have the financial resources to support quality science education (Mulfinger, 2004). There remains a gap between the vision of good science instructional practices and the reality of the average American classroom. This becomes pronounced in socio-economically disadvantaged populations, especially those in rural areas where school resources are limited and science education enhancement opportunities are few and far between. Moreover, many teachers are not even aware of the latest technological tools being used in current science research or how these tools relate to their content area (Ertmer \& Ottenbreit-Leftwich, 2010). Solutions to these challenges and obstacles can be realized when stakeholders come together to form partnerships (Mulfinger, 2004). The following paragraphs detail one such example.

\section{History of the Science in Motion Partnership Program}

In 1984, Dr. Don Mitchell, a young energetic chemistry professor at Juniata College, a small private school in central Pennsylvania, was puzzled as to why entering freshmen were not interested in studying chemistry, yet they were graduating up to 20 chemistry majors every spring. He organized a luncheon, inviting high school chemistry teachers from the school districts in the areas surrounding the college, to meet and share what they were doing in their chemistry classes and perhaps shed some light on why entering freshmen were not interested in majoring in chemistry. The meeting was so well received that the chemistry teachers and Dr. Mitchell decided to begin a new organization. 
In 1985, the Central Pennsylvania Association of Chemistry Teachers (CPACT) was formed. CPACT became a forum for chemistry teachers to share professionally with each other, and consequently, provided a support network. The teachers appreciated the professional networking, and the respect they received through this association. It also created a bridge between the high school community and the college community. The group established a rapport, with mutual trust and respect between the high school chemistry teachers and the college faculty member, Dr. Mitchell.

Soon, teachers began to invite Dr. Mitchell into their classrooms. During these visits it became clear why high school students had little interest in studying college chemistry. Upon his visits, Dr. Mitchell was dismayed; not with the teachers and their teaching, but with the lack of equipment they had in their classroom, along with their heavy daily workload.

After his classroom visits and the eye-opening reality of the CPACT teachers' working conditions, Dr. Mitchell asked the group to come up with a classroom resources wish list. CPACT teachers decided they needed equipment and lab activities for their students. Dr. Mitchell wanted to provide the equipment and curriculum in such a way, as to not increase their already overburdened workload. Teachers wanted an opportunity to be brought up-to-date with current trends in chemistry, but in such a way as to receive support throughout the school year while they were teaching. This grassroots effort led to the beginnings of a partnership program.

Dr. Mitchell, along with fellow CPACT members took their idea of a complete support system for high school chemistry teachers to the National Science Foundation (NSF). In August 1987, CPACT and Juniata College was awarded a five year, $\$ 500,000$ grant from NSF. The program soon became popularly known as the Chemistry in Motion Project. 
Between August 1987 and June 1992, the Chemistry in Motion Project targeted 80 high school chemistry teachers in 16 school districts surrounding Juniata. Teachers were introduced to the project through professional development during a summer workshop where they learned the theory and practical classroom application of the new state-of-the-art chemistry equipment and curricula available through the project. The implementation of the equipment and curricula throughout the school year was facilitated by a mobile educator who brought the equipment into the classroom and helped teach the lab activities alongside the classroom teacher. CPACT teachers took sabbaticals to fill the position of mobile educator. Participating teachers could tap into the Chemistry in Motion resources throughout the school year simply by requesting a teaching visit from the mobile educator.

What made Chemistry in Motion unique and very successful was the utilization of a delivery vehicle and a mobile educator who brought the equipment to the teachers and helped teach the labs. The project secured a large box- type truck. This truck was not a mobile laboratory, but a means to transport the equipment to the high school chemistry classrooms. The mobile educator brought teacher requested lab equipment and all necessary materials into the classroom and implemented the lab activity with the classroom teacher. These mobile educators also coordinated and conducted the professional development workshops for participating teachers.

Due to the success of the first NSF grant, in 1992 a second five year NSF grant was awarded. The additional monies were secured to expand the program into biology. Since the expansion of services extended to biology as well as chemistry, the name of the project was altered to be all inclusive. It was now known as the Science in Motion Program. As the program 
evolved, mobile educators were hired full time to drive the vans, teach labs, and coordinate professional development workshops.

By the time the second NSF grant was beginning to wind down, the project was securely embedded within the high schools surrounding Juniata College. In 1995, Dr. Mitchell began searching for funding to sustain Science in Motion. The program included multiple school districts, most of which were economically disadvantaged. Knowing these school districts would not be able to financially support the program, and as education is primarily a state endeavor, Dr. Mitchell began knocking on doors in Harrisburg, Pennsylvania; the state capital.

Dr. Mitchell presented the program to the Pennsylvania Department of Education as well as the Pennsylvania General Assembly, and they were listening. Upon completion of the second five year NSF grant, the Science in Motion program at Juniata College was provided funding by the commonwealth of Pennsylvania through special legislative appropriations. Dr. Mitchell believed that the future of the program depended on replicating the program strategically across the commonwealth. By 1999, several colleges and universities in Pennsylvania were aware of the successful Science in Motion program and the rumor of a statewide partnership. Dr. Mitchell used his political and geographical strategies to locate new SIM sites. These institutions included: Drexel University, Gettysburg College, Clarion University, Wilkes University, University of Pittsburgh at Bradford, Ursinus College and Westminster College.

In fiscal year 2000 - 2001, special state legislative appropriations earmarked \$2 million of the state budget to form a statewide partnership program modeled after the highly successful Science in Motion program. The newly formed Pennsylvania Basic Education/Higher Education Science and Technology Partnership Program, otherwise known as the Science in Motion 
Consortium came to be. Today, the consortium includes several colleges and universities across the commonwealth and provides services to over 200 school districts.

A statewide consortium supported by state funds, Science in Motion program goals included: a) access to high-tech, state of the art science lab equipment, b) laboratory activities aligned with state science standards, and c) professional development to train teachers how to use the high-tech equipment and embed the laboratory activities into their existing curriculum. Along with these SIM consortia goals, the emphasis of the program shifted to a focused on costeffectiveness by means of shared resources, and equity by providing resources to school districts that otherwise would be out of their financial reach.

SIM services remained the same across the sites with the basic format and premise of the original SIM model. Participating teachers attended summer professional development workshops learning how to use the new equipment and finding ways to embed the lab activities into their existing curriculum. These summer workshops were an important means for teachers to network professionally with both secondary science teachers and higher education science faculty.

Teachers who participated in professional development workshops could request a teaching visit, a team-teaching visit or a lab loan during the school year. Teaching visits were essentially embedded professional development experiences available through the program where the teacher takes on the role of learner in the classroom with her/his students. Teamteaching visits were also embedded professional development, but in the scenario, the teacher works together with the mobile educator teaching the lab, but may require guidance and support from the mobile educator during the lab experience using the high-tech equipment. Lab loan 
requests were available for teachers who were experienced using the lab equipment and were comfortable completing the lab activity without the aid of the mobile educator.

\section{Science in Motion Lesson Illustration}

The following illustration is intended to walk the reader through what happens during a typical Science in Motion visit by the mobile educator in the classroom of a science teacher. For this illustration, I will use Sue, who teaches tenth grade biology. This illustration is closely based on lessons that have actually taken place in Sue's classroom with me, the author acting as the mobile educator.

Sue would like to include a lesson on DNA Electrophoresis with her tenth grade biology class as they cover a unit on genetics. Sue doesn't have the necessary materials to conduct the lab investigation, but she knows DNA Electrophoresis is on the list of lab available through the SIM project. She sends me, the mobile educator an email requesting the SIM lab. Brief conversation exchanges are made to solidify the teaching visit via email. The day prior to the scheduled lab date, I travel to Sue's school, bring all the necessary equipment and materials to conduct the lab, and set up the lab for her in her classroom. We talk about logistics for the next day, including any special student or schedule concerns, as well as lesson flow. This discussion includes a conversation about Sue's comfort level with the equipment and what sort of role she would like me to play during the lesson. Sue is not comfortable with the lab equipment the first time I visit her classroom, and she would like me to take the lead and teach the lesson. In that case, Sue joins her students and works through the lab as a learner.

On the day of the lesson, I travel to Sue's school. Sue introduces me to her students, and I begin teaching the lesson. Sue has prepared her students by providing content background information. They are ready for the lab experience, but do not know how to use the equipment. I 
demonstrate and explain to Sue and her students how to use the electrophoresis equipment as they complete the lab protocol. After we complete the lab, I pack up all the equipment and return to campus. I follow up with Sue vie email, discussing the lab experience. The next time Sue requests the DNA Electrophoresis lab, her comfort level has improved and she requests a teamteaching visit.

During my next visit, as we move through the class period, Sue and I work together in the lab setting offering guidance as her students learn proper instrument use and technique. Once again Sue has prepared her students for the lab covering content background information for the lesson. Sue and I provide guidance and offer comments of support and encouragement as students grapple with the challenges of using the equipment for the first time. During this visit Sue may have questions about using the equipment, as she is still working on her comfort level and proper technique. Again, as the lab is completed I pack up the equipment and return to the university campus, following up with Sue via email. The next time Sue requests the lab, she requests a lab loan, where I bring everything to her and she completes the lab on her own.

During both teaching and teaming-teaching visits described above, the students are excited about conducting the lab investigation, and want to make a good impression on me, their guest instructor from Clarion University. Sue and her students show a great deal of excitement and appreciation as we conduct the labs. At the end of the class period, many students express their gratitude with words of thanks. As I listen to the conversations between the students, they often share they feel like a scientist as they conduct the labs. Sometimes students share with me this is the type of work they would like to do for a career. 


\section{Focus of the Study}

\section{Clarion University of Pennsylvania (CUP) Science in Motion (SIM)}

CUP joined the SIM consortium in 2000, when the partnership was initially funded by special legislative appropriations from the Pennsylvania general assembly as a statewide initiative. CUP is a small public university located in Northwestern Pennsylvania with a strong history as a teacher preparatory institution. The CUP SIM project became fully operational in the fall of 2001. The CUP SIM project is housed within science education and the College of Education and Human Services, which is unique to the partnership, as the other sites are housed within the chemistry department and the College of Arts and Sciences, and at one site, the provost office. While the CUP SIM project it is housed within science education, the project is physically located within the department of biology, and resides in the same building along with all of the science departments at the university. The physical location has been instrumental in developing close ties between the SIM partnership project and the science faculty at the university. There has been one director, and one mobile educator throughout the duration of the project to date.

\section{CUP SIM Service Area Geographic and Demographic Information}

The CUP SIM service area includes school districts within Northwestern Pennsylvania. In most cases the schools are located in rural communities, and are relatively small with school enrollments below 700 students. According to the National School Lunch Program and the Pennsylvania Department of Education (2012) on average, approximately $43 \%$ of the students who attend schools within the CUP SIM service area are eligible for free or reduced lunch programs (PDE, 2012). 


\section{Personal Narrative}

As stated previously, there has been only one mobile educator for the SIM project at Clarion University. That person is me, the author and researcher for this study. The following paragraphs share my story, how I became involved with the project, and how the experiences I've had lead me to pursue this study.

I have been a science educator since 1994. I taught mostly through lecture the first five years, which was the predominant mode of teaching when I was a student. As a student, I can honestly say I never truly had an authentic science experience, but I did have a passion for science, and biology in particular and I wanted to share that passion with others. It wasn't until 1998 when I attended a summer institute designed to engage teachers in the research process and learn how to teach using inquiry that I began to question my approach to teaching science. Through the institute I was introduced to the National Science Education Standards as well as other science education reform documents. The experience opened my eyes to better ways of teaching. My experience lead me to an understanding and appreciation of science as process that leads to discovery. I truly wanted to embrace this new way of learning and become a better science teacher. In fact, I was so inspired I decided to continue my education and enrolled in a Masters of Science Education program. After I was a teacher participant in the program, I returned a number of times to be a mentor teacher for this particular institute, which in hind sight, provided a foundation that prepared me for the Science in Motion mobile educator position that was just a short distance down my career path. I believe my experience as a mentor prepared me in many ways to work with teachers as a peer mentor/professional development facilitator. I learned how to help teachers move in a direction of growth and understanding as a colleague, being sensitive to their learning process. 
In 2000, I left my teaching job, and became a full time graduate student at Clarion University of Pennsylvania. As a graduate student and a graduate assistant, I had many opportunities and experiences to grow and develop as an educator. I also had opportunities to take graduate courses in biology, my content area. Through these classes I learned new technologies and techniques used in the lab setting. I also had the opportunity to engage in authentic science experiences.

As I was completing my graduate program at Clarion University, my adviser shared the news that a grant funded project was about to be launched in science education. The project called Science in Motion would be a resource available for secondary science teachers in the area surrounding Clarion University. The resources would be in the form of technology tools school districts could not afford paired with lab activities to enhance the teaching of science. Without hesitation, I knew I wanted to work with this project. I believed my prior experience as a classroom teacher and the knowledge I had gained in the science education arena along with the experiences with the latest technologies in the science lab primed me to help initiate this new project.

In the spring of 2001, as I was completing my masters in science education, I took on the position of mobile educator and program coordinator for the Science in Motion project at Clarion University. I was basically given a "blueprint" and assigned the task to build the project from the ground up. With much enthusiasm, I purchased equipment and adopted labs. I then took the news on the road, traveling to each school introducing myself and the project to the teachers in our service area. In the summer of 2001, we launched our first teacher professional development workshop, which was well received. The following fall, Science in Motion was in full swing. I began traveling to the various schools working in the classroom with the science teachers, 
teaching Science in Motion labs. To this day, as I write this narrative, I am still the Science in Motion project coordinator and mobile educator for Clarion University.

Over the years, I have conducted numerous workshops and taught many labs with the teachers in our service area. I have developed close professional and personal relationships with these teachers. I feel very strongly that I am here to help teachers provide engaging learning experiences for their students that otherwise would be out of their financial reach. I have also developed close working relationships with the science faculty at the university, where I first came to know many of these individuals as a graduate student. I believe the science faculty are a great resource for staying abreast of current trends in the science lab in terms of new technologies and research tools. The university faculty members in turn have witnessed students who come into their programs with experiences using these technologies because of the Science in Motion program, and as a result, experience success in their labs. These faculty members recognize the value of Science in Motion and have expressed gratitude. That is something that gives me a sense of personal and professional satisfaction.

When I began to think about my dissertation topic, I knew I wanted my research to focus on the Science in Motion project. I spent a great deal of time turning this over and over in my head, and looking to find a meaningful study. Many studies have been conducted by the Science in Motion Consortium in Pennsylvania as well as the sister program in Alabama that demonstrate student achievement as a result of participating in the laboratory activities. I wanted to design a study that could potentially add dimension to the existing body of knowledge. Key to my research questions is the fact that teacher participation in the Science in Motion program is completely voluntary. I finally came to hone in on questions that I believe are relevant, and very important questions to ask: What is it about the teachers themselves that has encouraged them to 
participate in the Science in Motion program and, what is it about these teachers that keep them using the program over the years? Interestingly, while discussing my research questions with one of the teachers I work with on a regular basis, she directed the same questions to me. Why did I originally want to work for the project and why have I stayed with it over the years? This teacher pointed out the fact that my job is not stable, as it is funded on a yearly basis. In fact, with budget cuts, I have gone from a full-time employee with benefits, to part-time and no benefits. She also pointed out the fact that I could be making much more money as a classroom teacher. Even when I was a full time employee, my salary was a fraction of what I could have been making as a public school teacher in one of the school districts served by SIM. What got me involved and what keeps me going?

As I contemplate what keeps me with Science in Motion, I have to say there are experiences I've had that have shaped what I believe is important as a teacher and for students to experience. As I began writing this personal narrative, I mentioned a teacher institute where I had my first authentic science experience. This experience was pivotal in my career. The process of learning was wrought with fear, frustration, and doubts about learning to use the research equipment and having something important and worthwhile to contribute. During this process I also experienced awe, wonder, "ah-ha" moments, excitement, inspiration, satisfaction and a sense of accomplishment with what I learned.

My learning experience included emotions, both positive and challenging. During the institute, there were scientists and mentors available to help guide you through the research process and be successful. This experience showed me a glimpse of what science is, and what teaching science should be. I experienced first-hand, personal connections with the learning experiences. As I struggled with the process, I received encouragement and guidance. As a 
result, I experienced deep understanding and appreciation. This had a tremendous impact on how I viewed teaching and learning.

If teachers are given the proper resources, and the proper support, transformational learning can happen in the classroom. I saw Science in Motion as a resource that could help students experience science in such a way to inspire and create a spark of interest and a desire to learn more. This is why I have been with the Science in Motion project for all these years. I want to help teachers bring science into their classroom that might inspire their students.

It gives me a sense of pride and joy working with the teachers and their students, seeing them light up when they experience success with a lab or learn how to use a new piece of technology. I believe it makes a difference for the teachers and their students, especially those who are socio-economically challenged. When I began to go into the classrooms and work with the teachers and their students, I felt a strong sense of purpose and satisfaction. I felt like I was making a difference. I have witnessed students becoming truly engaged in the experiences and excited about learning. I have also witnessed teachers getting excited about having the opportunity to provide engaging instructional resources for their students. Now 13 years into the program, I have college students and young adults come up to me and tell me they remember me from a Science in Motion lab they experienced in high school and share how that experience made a positive impact on them. That is an incredible validation factor for me.

Over the years, this sense of purpose and making a difference is something I feel passionate about and it has kept me with the project. I know what these teachers deal with on a daily basis, because I have been there. I know their jobs are very stressful, and their resources are limited. Through this project, I believe it is my goal to help them provide their students with 
meaningful learning experiences. Their gratitude, and the gratitude expressed by their students makes it all worthwhile.

\section{Rationale}

The SIM program was created out of a need to improve science education by providing cost prohibitive resources out of reach for most educators, especially those in rural, economically challenged school districts such as those within the CUP SIM service area. The original program came to be through a grass-roots effort between a chemistry faculty member at Juniata College, a small private college located in central Pennsylvania, and the high school chemistry teachers in the surrounding area. However, as the project grew, it lost its grass-roots status. As it evolved into a consortium, it became something foreign to the new teachers with access to SIM services, including teacher in the CUP SIM program. Program goals remain relatively unchanged, aiming to improve science education by providing scientific investigative tools, curriculum and teacher professional development. All of these resources are provided to science teachers in the service area free of charge on a voluntary basis. CUP SIM teachers have had access to the SIM partnership project resources since 2001. On average, approximately $25 \%$ of the teachers use the partnership resources on a regular basis. Not truly a grassroots program, nor a top-down mandated program, how then do teachers decide to use the program resources for their instructional practices? From a research standpoint, we know when teachers play an active role in curricular innovations and implementation, a so called "grassroots" or "bottom-up" approach, meaningful changes can and do take place in the classroom (Ellis, 1995; Jones \& Eick, 2007; McCarthy, 2009; Richardson, 1998). We also know when "top-down" approaches are attempted to implement changes in instructional practices, teachers can be resistant (Oloruntegbe, 2011; Richardson, 1998). How then do teachers decide to tap into resources designed to improve 
science education without being a part of the project development, such as those developed through "grassroots" efforts, or being instructed to do so?

\section{Statement of Problem}

Science education partnerships are vehicles through which reform efforts can be realized by providing resources for teachers to transform the ways in which they teach. Ultimately, the teacher decides what sorts of instructional materials and practices will take place in the classroom (Cuban, 1986; Ertmer, 2005; Luehmann, 2003, 2003; Luehmann and Markowitz, 2007). Several studies reveal teachers grapple with external pressures and limitations as well as internal issues within themselves as they decide whether or not to adopt innovative instructional materials and practices provided through programs similar to the SIM partnership model (Ellis, 1995; Ertmer, 2005; Ertmer \&Ottenbreit-Leftwich, 2010; Lowther et.al., 2008; Robblee, 2000; Rogers, 2000; Steyn, 2005, 2006). SIM is a voluntary partnership program which provides enhancement opportunities for secondary science educators to improve instructional practices. The program, based on three goals provides: state-of-the-art scientific equipment for secondary science classrooms, laboratory exercises aligned with state science standards, and professional development opportunities for teachers to learn how to use the equipment and embed the laboratory activities into their curriculum. Program goals specifically aim to provide instructional resources for teachers. Annual service records show science teachers in the CUP SIM service area use the partnership project on a regular basis. However, little is known about the reasons these teachers began using the CUP SIM project and continue to do so.

\section{Purpose of the Study}

This study examines the perceptions and beliefs of science teachers who use the SIM project in the CUP service area. Specifically, this study examines teacher reported reasons for 
CUP SIM project initiation and continued usage. Through this research, teacher perceptions regarding the CUP SIM project coupled with their beliefs about teaching and their teaching goals will help develop a greater depth of understanding in regards to project use.

\section{Research Questions}

This study examines the following questions:

What are the reasons for project use reported by teachers who use the project on a regular basis in the CUP SIM service area?

Sub questions are:

What was it about the teacher that encouraged her/him to become involved with the project? What is it about the teacher that encourages her/him to continue using the project?

\section{Limitations and Assumptions of the Study}

1. This research utilizes a focus group interview to collect data. This researcher is an integral part of the SIM project at CUP. Attempts to account for and control biases will be made throughout the study.

2. This researcher and the teachers involved in the study have developed personal friendships. The personal nature of these relationships may create a bias in this study.

3. Teachers who participate in this study volunteer to do so. Self-selected participation may create a bias in the data unrepresentative of the entire frequent user population.

4. Data will be self-reported. It is assumed that teachers will provide honest and thoughtful answers to the interview questions. Validity of responses will be attempted through triangulation using service records, as well as teacher evaluations of the CUP SIM project when available.

5. This data is not generalizable to the population of CUP SIM partnership program users. 


\section{Definition of Terms}

Instructional Practices: A combination of teaching strategies brought to the classroom by the teacher paired with learning activities students engage in to facilitate content mastery and objectives within the specified curriculum.

Lab/equipment Loan: A SIM lab/equipment loan occurs when a science teacher requests a particular SIM lab or a particular piece of SIM equipment. The ME prepares the lab and/or equipment, and drops off the requested materials to the teacher in their classroom setting. The teacher then teaches the lab on their own without the aid of the ME. Upon completion of the lab activity, the ME returns to the school to pick up the borrow lab equipment.

Mobile Educator (ME): A certified science teacher employed by the SIM program who is specially trained in the use of the high tech SIM science equipment and laboratory protocols. This teacher plans and conducts all SIM teaching, team-teaching and loan visits for the program. The mobile educator also coordinates and conducts professional development workshops, the procurement of lab equipment and the development of laboratory curricula.

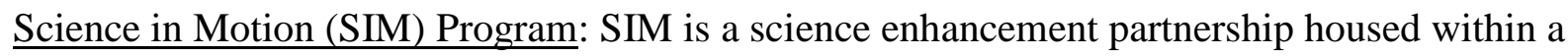
college or university with the goal to improve secondary science instructional practices. The program provides secondary science teachers with high tech science equipment, curricula, and professional development opportunities to learn how to use the high tech equipment, and embed the lab activities into their curriculum.

$\underline{\text { Science in Motion Consortia: }}$ The network of Science in Motion projects across the commonwealth of Pennsylvania. The consortium members include SIM programs at: Clarion University, Drexel University, Elizabethtown College, Gannon University, Gettysburg College, Juniata College, Susquehanna University, University of Pitt-Bradford, Ursinus College, West 
Minster College, and Wilkes University. The number and makeup of the consortia institutions has varied during the life of the program.

SIM service area: The geographical area which includes the school districts served by a SIM site. SIM Site: A Science in Motion project at an individual institution of higher education within the Science in Motion consortia.

Science Literacy: A broad definition includes the knowledge and skills in science, technology, and mathematics, along with scientific habits of mind and an understanding of the nature of science and its impact on individuals and its role in society (AAAS, Project 2061).

Teacher Evaluation: A standard form evaluation completed by the classroom teacher after completion of a SIM lab. These evaluations are voluntary, and are used to monitor SIM program satisfaction as well as to discover areas of needed improvement.

Teaching Strategies: Pedagogical activities selected by the teacher designed to engage students in the learning process.

Teaching Visit: A SIM teaching visit occurs when a science teacher requests a lab activity from the SIM program. The ME prepares the lab, and brings all the necessary equipment and consumables to the teacher in their classroom setting. The ME then teaches the lab while the teacher participates in the lab along-side his or her students.

Team-Teaching Visit: A SIM team-teaching visit occurs when a science teacher requests a lab activity from the SIM program. The ME prepares the lab, and brings all the necessary equipment and consumables to the teacher in their classroom setting. The ME and the classroom teacher work collaboratively to teach the lab. 


\section{Document Format}

Chapter I provides an introduction to the research study. Chapter II provides a review of relevant literature. Chapter III introduces research design and methodology. Chapter IV presents the data. And finally, Chapter V presents discussions and conclusions of the data as it relates to the literature. 


\section{Chapter II}

\section{Review of Literature}

\section{Overview}

Chapter two begins with an overview of science education reform efforts and documents since the launch of Sputnik in 1957 to the present. The disconnection between what is called for in reform efforts and what our educational system provides is discussed. This is followed with a discussion of science education partnerships, including the SIM model, found within the research literature. Specifically, research related to how partnerships overcome barriers to reform efforts by providing resources, professional development is present. Literature regarding how partnerships foster science literacy, student achievement, student attitude and motivation is presented. Research concerning science education reform efforts and the Science in Motion partnership program are then discussed. The literature related to teachers and how they make decisions regarding instructional practices in the classroom is then explored.

\section{Science Education Reform: Sputnik to Present}

There is a sense of concern and urgency felt within the science education community in the United States concerning the state of K12 science education. The flurry can be traced back to the launch of Sputnik in 1957 when the country felt pressure to keep up and beat the Russians in

the space race. Attention turned to science and technology and soon the U.S. boasted a successful mission to the moon. During the 1980's and 1990's, education and science education reform documents started to emerge, such as A Nation at Risk: An Imperative for Education Reform (NCEE, 1983), Project 2061: Benchmarks for Science Literacy (Rutherford, Ahlgren, et al. 1989) and the National Science Education Standards (NRC, 1996) which were discussed in Chapter I. Several years later in 2001 the No Child Left Behind Legislation Act shifted National 
attention to student achievement and accountability, mandating student proficiency levels beyond past expectations (No Child Left Behind [NCLB], 2002). This shift left science instruction largely in the dust, abandoned to cover the basics: reading, writing and arithmetic. High stakes tests where science was not represented often became the focus of instruction. As we entered into the twenty-first century, we see a re-emergence of science education reform documents such as, Rising Above the Gathering Storm: Energizing and Employing America for a Brighter Economic Future (NAS, 2007) and Rising Above the Gathering Storm Revisited, Rapidly Approaching Category 5 (NAS, 2010). In the 1990's, a new acronym, STEM (Science Technology Engineering and Mathematics) emerged from the National Science Foundation as a generic label involving these disciplines (Bybee, 2010). The acronym has also been adopted by the science education community. It is use to stress the need to improve STEM education. More recently the Framework for Science Education (NRC, 2011) and the Next Generation Science Standards (NRC, 2013) bring a revitalization and refocusing in science education reform, refining and echoing other previous reform documents such as the National Science Education Standards, and Project 2061: Benchmarks for Science Literacy.

\section{Disconnection between Science Education Reform and the Educational System}

Examining these events over time, a pattern emerges. Within the educational community, a crisis is identified where there is a disconnection between what our educational system is providing and what is called for in science education reform efforts (Cochran-Smith \& Lytle, 1990; Cole et al., 1991; Hurd, 1991). This disconnection can be understood as the intended curriculum and the actual curriculum (Murnane \& Raizen, 1988). According to Powell and Anderson, curriculum materials, the educational support system inside and outside school, and knowledge and beliefs of teachers are key to transforming what is currently happening in the 
classroom into reform based change (Powell \& Anderson, 2002). Science education reform documents identify specific ways in which the educational system needs to move in order to produce desired outcomes in student learning. Achieving this goal requires the entire enterprise to embrace change. This includes many stake holders, but ultimately reform must take place in the classroom in order to affect student learning. This leaves reform efforts largely in the hands of teachers. What do teachers grapple with in order to embrace changes called for by science education reform documents in their instructional practices?

The National Science Education Standards provide "changing emphases" which include: "Less emphasis on presenting scientific knowledge through lecture, text and demonstration to Guiding students in active and extended scientific inquiry" (NSES, 1996, p.52). Scientific inquiry often requires curriculum materials available for classroom use in the form of technology and scientific research tools. According to Powell \& Anderson, curriculum materials can be defined as, "the collection of textbooks, teacher's guides, and ancillary materials that are adopted for use in the schools for teachers to use while teaching science" (Powell \& Anderson, 2002, p. 108). However, access to these materials can be a challenge to overcome. Most school districts are not able to provide sufficient curriculum materials in the form of state of the art science research tools because they lack financial resources (Mitchell, 1998; Mulfinger, 2004). Rogers identifies external barriers to instructional technology including funding, instructional support, and lack of time (Rogers, 2000). Mitchell recognized the difficult daily schedules science teachers face as an obstacle to incorporating new technology into the classroom, and sought to develop a program to improve instructional practices without creating an extra burden on the teacher (Mitchell, 1998). The availability of resources and the ability of the classroom teacher to 
utilize these resources is a major challenge for the transformation effort of science education reform. What are solutions to overcoming these challenges?

The National Science Education Standards (NSES) state:

No one group can implement the Standards. The challenge extends to everyone within the education system, including teachers, administrators, science teacher educators, curriculum designers, assessment specialist, local school boards, state departments of education, and the federal government. It also extends to all those outside the system who have an influence on science education.... (NRC, 1996, p.9)

The NSES also address how this system is to evolve and change to transform the science education landscape with increased emphasis at the Federal level on:

Financial support for developing new curriculum materials aligned with the Standards, Support for professional development activities that are aligned with the Standards and promote system wide changes,

Coordination among agencies responsible for science education Support for activities and programs that successfully implement the Standards at state and district levels,

Long-term commitment of resources to improving science education (NRC, 1996, p.239) In addition, a changing emphasis at the state level includes:

Partnerships and coordination of reform efforts

Funds to improve curriculum and instruction based on the Standards (NRC, 1996, p.239) While, federal and state agencies should and do support science education reform efforts, Rita Colwell, Former Director of the Nation Science Foundation (NSF) calls upon the higher education community to take part in science education reform: 
We cannot expect the task of science and math education to be the responsibility solely of K-12 teachers while scientists, engineers and graduate students remain busy in their universities and laboratories. There is no group of people that should feel more responsible for science and math education in this nation than our scientists and engineers and scientists- and engineers-to-be. (NSF, 1999, Press release 99-012, para. 3)

\section{Science Education Partnerships as a vehicle to meet Science Education Reform}

It is clear from many perspectives that science education transformation requires a commitment from all stakeholders. When stakeholders come together to form partnerships, change begins to take place. Nelson and Landel report that partnerships are able to address and overcome barriers that hinder reform (Nelson \& Landel, 2006). What can be said about the nature of partnerships that enable science reform efforts to be realized? How do partnerships overcome barriers? These barriers include lack of access to resources and teacher understanding of resources, and how to implement changes in the classroom. Partnerships can and do provide access to resource which foster change in the classroom.

\section{Partnerships and Instructional Resources}

The very nature of a partnership is to bridge the gap between policy and practice.

Conducting scientific investigations called for in science education reform often requires the use of technology. What is often missing for teachers are the resources necessary to adopt a student centered, inquiry rich, authentic learning environment (Mulfinger, 2004). Rogers identifies availability and access to technology adoption and integration as an external barrier (Rogers, 2000). Partnerships address this need by providing resources for teachers in the form of science equipment, materials, and curricula (Felix et al., 2004; Lott, 2002; Moskal et. al., 2007). For example, the Alabama Science in Motion (ASIM) Partnership Program provides technology 
tools for science instruction at the secondary level in biology and chemistry. In a study conducted by Lott, teachers who use the program had a self-reported higher use of technology in the classroom when compared to teachers in a control group who did not have access to this partnership (Lott, 2002). An increased use of technology in the classroom was also reported by teachers who participated in another partnership study reported by Moskal et al. (Moskal et al., 2007). In order for teachers to embrace new instructional materials, these resources must also be accompanied by professional development (Loucks-Horsley et al., 1998). In order to be successful, and transformative, partnerships must provide effective professional development experiences for teachers in order to learn how to use the provided resources in classroom instruction (Moskal et. al., 2007).

\section{Partnerships and Professional Development}

According to Guskey, professional development can be defined as, "Those processes and activities designed to enhance the professional knowledge, skills, and attitudes of educators so that they might, in turn, improve the learning of students" (Guskey, 2000, p.16). The NSES also state, "Becoming an effective science teacher is a continuous process that stretches from preservice experiences in undergraduate years to the end of a professional career" (NRC, 1996, p.55). Science teachers are professionals, not merely technicians. This fundamental understanding is the backbone reflected in professional development (PD) changing emphasis found within the Standards found in Figure 1: 
Figure 1. NSES Professional Development Changing Emphasis

\section{LESS EMPHASIS ON}

\section{MORE EMPHASIS ON}

Transmission of teaching knowledge and skills Inquiry into teaching and learning

by lectures

Learning science by lecture and reading Learning science through investigation and inquiry

Separation of science and teaching knowledge Integration of science and teaching knowledge

Separation of theory and practice Integration of theory and practice in school settings

Individual learning

Collegial and collaborative learning

Fragmented, one-shot sessions

Long-term coherent plans

Courses and workshops

A variety of professional development activities

Reliance on external expertise

Mix of internal and external expertise

Staff developers as educators

Staff developers as facilitators, consultants, and

planners

Teacher as technician

Teacher as intellectual, reflective practitioner

Teacher as consumer of knowledge about

Teacher as producer of knowledge about

teaching

teaching

Teacher as follower

Teacher as leader

Teacher as an individual based in a classroom Teacher as a member of a collegial professional community

Teacher as target of change

Teacher as source and facilitator of change p. $72(\mathrm{NRC}, 1996)$ 
Since the publication of the NSES, a substantial body of research in professional development underscores the changing emphasis specified by the Standards. In A Framework for K-12 Science Education, in-service and on-going professional development that includes mentoring, scientific and engineering practices, and linked to teachers' needs and classroom practices is recommended (NRC, 2011). According to Darling-Hammond and Richardson: Research supports professional development that: deepens teachers' knowledge of content and how to teach it to students, helps teachers understand how students learn specific content, provides opportunities for active, hands-on learning, enables teachers to acquire new knowledge, apply it to practice, and reflect on the results with colleagues, is part of a school reform effort that links curriculum, assessment, and standards to professional learning, is collaborative and collegial, is intensive and sustained over time. (Darling-Hammond \& Richardson, 2009, p.49)

Teachers implement activities that become integral to the classroom, and are not perceived as additional tasks, noting that time management is an issue teachers struggle with on a daily basis (Lester, 2003). Time being a limiting factor is also noted in other literature as well (Mitchell, 1998; Rogers, 2000). Luehmann suggests teachers' subjective reality where time can be a limiting factor must be a consideration as educational reformers develop innovations for the classroom (Luehmann, 2002). Professional learning communities, the "new paradigm" address the challenges of time, through collaborative and collegial efforts which include job-embedded professional development, and continual dialogue promoting teacher learning, reflection and sharing (Darling-Hammond \& Richardson, 2009). In addition, sustained and intensive professional development is noted as having a positive impact on student achievement (DarlingHammond \& Richardson, 2009; Klieger \& Bar-Yossif, 2011). This is important because we 
know that teachers are more willing to try new instructional practices if they believe it will benefit their students (Emo, 2010; Guskey, 2002; Richardson, 1998; Mouza, 2006).

Partnerships are particularly poised to provide professional learning communities, and job-embedded P.D. opportunities. Huziak-Clark et al. examined the effects of a partnership where a collaborative model between scientists and science teachers was utilized to improve inquiry-based instruction. An embedded approach where team-teaching took place over a three year period did in fact increase the use in inquiry-based instruction in the classroom (HuziakClark et al., 2007). A similar program examined teacher use of constructivist teaching after a two year, embedded program, connecting scientists and classroom teachers. The data suggests teachers did increase their use of constructivist teaching, and these teachers reported gains in student achievement and critical thinking skills (Beamer et al., 2008).

Ultimately, student success experienced through gains in science literacy, student achievement, improved student attitude towards science and selection of STEM professions is the goal of science education reform efforts and science education partnerships. In what ways have student success as a result of participating in reform based partnerships been examined by researchers?

\section{Partnerships and Science Literacy}

The vision of science literacy was first presented in Science for All Americans. That vision is broadly understood as the knowledge and skills in science, technology and mathematics necessary to make informed decisions about science, technology and society. The knowledge and skills include understanding the nature of science, science concepts, and the process of scientific inquiry. This broad understanding of science literacy is the intended goal and mission of many if 
not all partnership programs aimed to improve classroom instruction. Over the years, numerous teachers who use the SIM partnership program have reported anecdotal evidence suggesting student gains in developing scientific literacy.

Phase One findings from the first Science in Motion NSF evaluation, at the time known as Chemistry in Motion, indicate an increase in student participation in science fairs (NSF award TEP-8751458). This evidence suggests students had access to materials and equipment to conduct scientific investigations, were motivated to conduct research and were engaged in science process skills and scientific inquiry skills. In the Pennsylvania Science Partnership feasibility study, teacher perceptions gathered through a questionnaire were used to assess the need of a statewide partnership program. Responses from teachers with access to a science education partnership programs were compared with responses from teachers without access to a science education partnership program. Significant differences were found in the responses to eight of the fourteen questions related to students and their development of science literacy skills (PDE, 1998). In a qualitative study conducted in 2005, teachers reported SIM provided a more meaningful richer learning experience for students, again suggesting students were engaged in the development of science literacy skills and knowledge (Spuck, 2005). In 2007 the SIM Consortium conducted a survey to assess the attitudes of teachers in regards to program impact on student learning. Teachers overwhelmingly indicated SIM was important to improving the quality of their science content and quality of their classroom instruction. These findings again suggest SIM having a positive impact on science literacy in the way of knowledge and skills development (PDE, 2008).

Other studies examining partnership programs and their impact on science literacy have been reported. Colley examined science process skills using the TIPS II as an evaluation method. 
Students who participated in this outreach partnership program had significant gains in science process skills as a result of the technology based learning unit (Colley, 2001). Lott reported students of teachers in the Alabama Science in Motion (ASIM) program had better science process skills after experiencing ASIM labs when compared to a control group (Lott, 2002). Bell et. al. examined high school students' understanding about the process of scientific inquiry after participating in a science apprenticeship program. These students experienced significant gains as a result of participation in the program (Bell et al., 2003).

Science literacy for all Americans can also be viewed as an issue of equity. Science for

\section{All Americans states:}

...economic circumstances must no longer be permitted to be a factor in determining who does and who does not receive a good education in science, mathematics and engineering. To neglect the science education of any is to deprive them of a basic education, handicap them for life, and deprive the nation of talented workers and informed citizens - a loss the nation can ill afford. (Rutherford \& Algren, 1989, p.200)

The NSES states:

All students in the K-12 science program must have equitable access to opportunities to achieve. (NRC, 1996, p.221)

The new Framework for Science Education states:

Providing more equitable access to the knowledge and practices associated with science and engineering-related occupations requires a more equitable achievement of science and engineering literacy...Today there are profound differences among specific demographic groups in their educational achievements and patterns of science learning.... (NRC, 2011, pp.11-12) 
The framework further states the differences in achievement can be linked to opportunities to learn because of inequalities. Evidence of socio-economic disparities in opportunities to learn is reflected in National Assessment of Educational Progress (NAEP) scores. Broken down demographically, the 2009 NAEP science assessment results for grade 12 students scoring at or above the proficient level are: $32 \%$ in low poverty schools (25\% or less of the student population eligible for free/reduced lunch), $17 \%$ in mid-low poverty schools (25-50\% of the student population eligible for free/reduce lunch), 9\% in mid-high poverty schools (50$75 \%$ of the student population eligible for free/reduced lunch), and $4 \%$ in high poverty schools (75\% or more of the student population eligible for free/reduced lunch) (NCES, 2009). Figure 2 contains these results in graphical form.

Figure 2. Percentage of $12^{\text {th }}$ grade students who performed at or above the proficient level in the 2009 NAEP science assessment, by school poverty level.

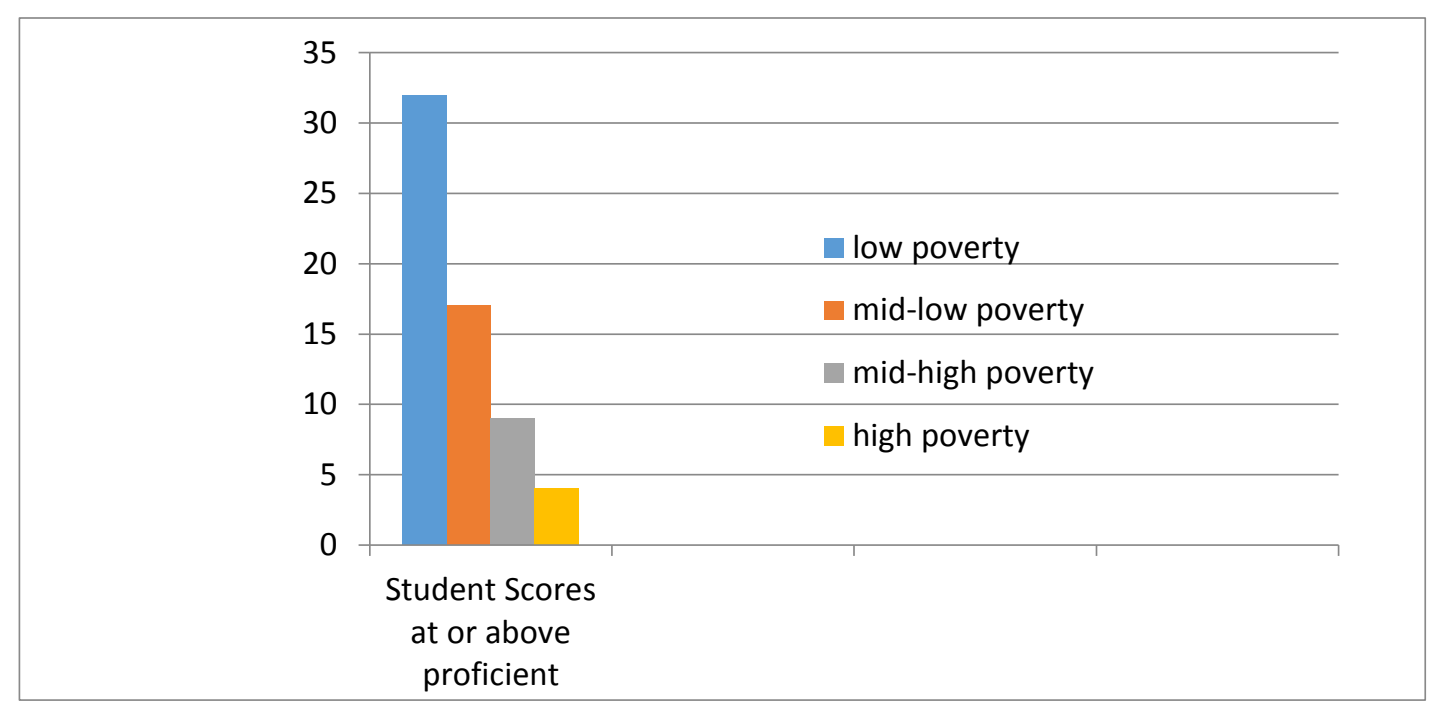

Data from National Center for Education Statistics 2009 
The drop in proficient scores as poverty increases is alarming and clearly demonstrates a need for intervention. The 2007 TIMSS 2011 International Results in Science report successful schools are affluent, and have access to resources for teaching science such as computers, technology and supplies (Martin et al. 2012). In low-income schools, teachers have limited resources and as a result, resort to mostly didactic modes of instruction (Thadani et la. 2010). When teachers are given the resources to provide quality instruction, student achievement improves (Burruss, 2011; Herring, 2009; Lott, 2002; Mitchell, 1998; PDE, 1998; Thadani et al., 2010).

Resources provided through partnerships and outreach programs can and do have a positive impact on student performance in low-income schools, addressing issues of equity. The partnership program, the Center for Social Organization of Schools at Johns Hopkins University provided materials, curriculum and professional development for teachers in low-income urban schools in Philadelphia. Students attending these schools were followed from the end of fourth grade through seventh grade. Students in participating schools experienced significant gains in science achievement compared to a control group (Ruby, 2006). Research conducted by Thadani et al. found their intervention of study which provided science outreach to demographically diverse urban schools disproportionally benefited students within the high-need schools (Thadani et al., 2010).

\section{Partnerships and Student Achievement}

Reformed based practices, when implemented by teachers in the classroom, can and do have a positive impact on student achievement (Roehrig \& Garrow, 2007). In a study conducted by Felix et al. where 35 grant awardees were evaluated, student success was measure by comparing students in the grant awardees group with a control group. The students in the award 
grantee group had a $74 \%$ student gain in knowledge, compared to $6 \%$ in the control group. Gain in knowledge was calculated by comparing standardized tests scores from a science proficiency exam, and the Scholastic Assessment Test (SAT) in math (Felix et al., 2004).

Three separate studies conducted on the Alabama Science In Motion program (ASIM), modeled after Pennsylvania's Science in Motion program demonstrated gains in student achievement. In one such study ASIM students scored higher on the Stanford Achievement Test9 (SAT-9) compared to students from control group who did not experience ASIM labs (Lott, 2002). Herring compared criterion reference test scores from student of the same teacher, before they used ASIM and students in the classroom when the teacher was utilizing the ASIM program. The students of these teachers after they began to use the ASIM program scored significantly higher than the students of these same teachers before they used the program (Herring, 2009). In yet another study conducted on the ASIM program, teachers reported ASIM contributed strongly to their students' understanding of biology and chemistry (Burruss, 2011).

For the Science in Motion program in Pennsylvania, an independent third party assessment showed significant increases in learning for the experimental group when compared to the control group in chemistry and biology (Mitchell, 1998). Similar gains are reported by other SIM studies conducted throughout the life of the statewide program. In 2003, after the SIM program became a statewide consortium, student achievement was assessed across all eleven SIM sites. Results showed significant differences between students who participated in the SIM program compared to students who did not have access to the SIM resources (PDE, 2006). In 2004, the SIM consortium conducted student achievement assessments on individual lab modules. Again, results demonstrated SIM students scored significantly higher on these 
assessments than the control groups (PDE, 2006). Similar data was collected again in the 20072008 school year yielding similar results (PDE, 2008).

\section{Partnerships and Student Attitude and Motivation}

Another measure of partnership success can be assessed by examining student attitude, and motivation. Many studies report anecdotal evidence to report a positive impact on student attitude (Felix et al., 2004; Krieble \& Salter, 2008). In a report from Long with the Virginia Tech Mobile Chemistry Laboratory (MCL), truancy rates dropped to near zero on the days when the mobile laboratory showed up for science lessons suggesting students had a positive attitude and a desire to participate in the MCL activities (Long, 2004). Other studies utilizing quantitative measures report positive gains in student attitude towards science as a result of participation in a partnership program designed to improve science education. The Hands on Science Outreach program, adopted by the University of Maryland Baltimore County and the Baltimore County Public Schools STEM Project utilized a pre-post questionnaire to determine student attitudes towards science. The findings revealed students reported a more positive attitude towards science after completing the program (Peyrot \& Ziolo-Royer, 2006). The TOPS (Teachers + Occidental=Partnership is Science) Program at Occidental College in Southern California developed an instrument to measure student attitudes and interest in science. Data from students who participated in the TOPS program show a more positive attitude and interest in science compared to a control group (Craney, Mazzeo, \& Kaye, 1996).

Career interests in STEM fields can be considered another measure of student attitude as a result of participation in a partnership program. The study, “Assessing Precollege Science Education Outreach Initiatives: A Funder's Perspective" examined student participants who then became science majors and compared these students with national averages. On average, $62 \%$ of 
the post-program students became science majors. The National average, as reported by the study, is $32 \%$, and the percentage for underrepresented minorities, which most of the participants were, to be 5\% (Felix et al. 2004). Mitchell reported an increase in chemistry majors at Juniata College after a five year NSF grant supporting the Chemistry in Motion partnership with freshmen enrollment boasting 27 chemistry majors, which accounted for 8 percent of the entering freshman class (Mitchell, 1998). Prior to the NSF grant, freshmen chemistry enrollment as a major course of study was non-existent.

\section{Science Education Reform, Partnerships and the Science in Motion Program}

SIM is a partnership program that provides resources, curricula and professional development for science teachers to improve instructional practices at the secondary level. The resources are typically cost prohibitive and out of reach for most school districts, and include research grade instruments such as those used in higher education laboratory settings. The curriculum available through SIM is aligned with state science standards. The professional development opportunities are provided in the form of workshops for teachers to learn how to use the equipment and practice laboratory protocols, and embedded professional development in the way of teaching and team-teaching visits. The program infrastructure is essentially a professional network connecting science educators within a fifty mile radius of Clarion University providing support and encouraging professional growth.

The program is a resource intended to be a vehicle for teachers to improve instructional practices in secondary science classrooms, however participation in the program is completely voluntary. Annual service records show approximately $25 \%$ of the teachers in the CUP SIM service area use the partnership resources on a regular basis. Not truly a grassroots program, nor a top-down mandated program, how do teachers then decide to use the project resources for their 
instructional practices? From a research standpoint, we know when teachers play an active role in curricular innovations and implementation, a so called "grassroots" or "bottom-up" approach, meaningful changes can and do take place in the classroom (Ellis, 1995; Jones \& Eick, 2007; McCarthy, 2009; Richardson, 1998). We also know when "top-down" approaches are attempted to implement changes in instructional practices, teachers can be resistant (Oloruntegbe, 2011; Richardson, 1998). Richardson claims that teachers are resistant to mandated change but willingly engage in self-initiated change (Richardson, 1998). Carless argues ownership has a strong influence on the likelihood an innovation will become established in teachers' instructional practices (Carless, 1999). How then do teachers decide to tap into resources designed to improve science education without being a part of the project development, such as those developed through "grassroots" efforts, or being instructed to do so by upper administration or state mandates? How do teachers engage in self-initiated instructional change?

\section{Factors that Influence Teachers' Decisions to Implement New Instructional Materials}

According to Powell and Anderson, curriculum materials, the educational support system inside and outside school, and knowledge and beliefs of teachers are key to transforming what is currently happening in the classroom into reform based change (Powell \& Anderson, 2002). What we know about science education reform efforts and partnership programs as vehicles to bridge the gap between what is called for in reform documents and the realities of many science classrooms all hinge on the teacher. Teachers ultimately decide what sorts of instructional practices will take place in the classroom (Cuban, 1986; Ertmer, 2005; Hargreaves as cited by Carless, 1999; Luehmann, 2002, 2003). Research reveals teachers grapple with several factors as they decide whether or not to adopt innovative instructional materials and practices provided through programs similar to the SIM partnership model. The factors that play a role in the 
instructional decision making process can be broadly understood as external pressures such as school culture, curriculum, accountability, access to resources and time, as well as internal issues such as teacher knowledge, self-efficacy, and pedagogical beliefs (Ellis, 1995; Ertmer, 2005; Ertmer \&Ottenbreit-Leftwich, 2010; Lowther et.al., 2008; Robblee, 2000; Rogers, 2000; Steyn, 2005, 2006).

\section{Teachers and External Factors that Influence the Instructional Decision Making Process}

External factors are those that exist beyond the individual teacher's control and include school culture, curriculum, accountability, resources and time (Carless, 1999; Ellis, 1995; Ertmer and Ottenbreit-Leftwich, 2010; Spitzer, 2004). Research shows school administrators' attitudes and beliefs have a major impact on school culture. Spitzer examined a school where the administration supported the implementation of innovative technology instructional practices and a school where the administration was not as supportive of those practices. Overall, teachers in the schools with administrative support reported a higher frequency of use than the teachers with an unsupportive administration (Spitzer, 2004). Steyn identified a transformational leadership style as playing a key role for implementing change in the classroom by encouraging teacher commitment to change (Steyn, 2005).

Pressure to cover certain topics in the curriculum can also impact teacher decision to implement new teaching strategies, which supports the idea that curriculum accountability factors play a key role in teacher pedagogical decision making (Duschl \& Wright, 2006). Sonmez and Haury found that teachers were more likely to implement an innovative instructional practice when the innovation aligned with their curriculum (Sonmez \& Haury, 2011). ChanLin et. al. examined factors that influence teacher use of technology in teaching and 
found curricular factors to be an important component in the decision making process for teachers as they integrated technology in the classroom ( ChanLin et. al., 2006).

External factors, resources and time are considerations for teachers as they choose to select innovative instructional practices. Teachers must have access to instructional resources to consider them as an instructional tool (Carless, 1999; Ellis, 1995). Teachers implement activities that become integral to the classroom, and are not perceived as additional tasks, noting that time management is an issue teachers struggle with on a daily basis (Lester, 2003). Time being a limiting factor is also noted in other literature as well (Mitchell, 1998; Rogers, 2000). Luehmann suggests teachers' subjective reality where time can be a limiting factor must be a consideration as educational reformers develop innovations for the classroom (Luehmann, 2002). Professional learning communities, the "new paradigm" address the challenges of time, through collaborative and collegial efforts which include job-embedded programs, and continual dialogue promoting teacher learning, reflection and sharing (Darling-Hammond \& Richardson, 2009). In addition, sustained and intensive professional development is noted as having a positive impact on student achievement (Darling-Hammond \& Richardson, 2009; Klieger \& Bar-Yossif, 2011). This is important because we know that teachers are more willing to try new instructional practices if they believe it will benefit their students (Emo, 2010; Guskey, 2002; Richardson, 1998; Mouza, 2006).

\section{Teachers and Internal Factors that Influence the Instructional Decision Making Process}

Internal factors that influence teachers' decision making processes when considering an innovative instructional practice include knowledge, self-efficacy, and beliefs. Taken from a framework developed by Shulman (1986) Ertmer and Ottenbreit-Leftwich state: "Teacher knowledge includes knowledge of the subject (content knowledge, CK), knowledge of teaching 
methods and classroom management strategies (pedagogical knowledge, PK), and knowledge of how to teach specific content to specific learners in specific context (pedagogical content knowledge, PCK)" (Ertmer \& Ottenbreit-Leftwich, 2010, p. 258). In science education reform based partnerships, teacher knowledge includes familiarity with scientific equipment and tools, understanding of science concepts to be explored using the equipment along with pedagogical methods appropriate to facilitate student learning (Ertmer \& Ottenbreit-Leftwich, 2010). Teachers must possess these types of professional knowledge, and also have a degree of selfefficacy or confidence to incorporate an innovative strategy into classroom instruction. In fact, according to Bandura, self-efficacy beliefs are the strongest predictors of human behavior (Bandura, 1986).

Darling-Hammond and Richardson provide evidence that support professional learning communities as a means for teachers to learn about, try out and reflect on new instructional practices (Darling-Hammond, 2009). These types of experiences can help teachers develop the self-confidence which leads to sustained instructional changes (Darling-Hammond, 2009). The SIM embedded professional development provided through teaching visits and team-teaching visits to the classroom by the mobile educator provides the support teachers may need to reach this confidence level, encouraging them to include an innovative strategy such as the lab activities and equipment provide through the program. In the SIM Teacher Attitude Survey conducted in 2007, teachers' comments did indicate the mobile educator was an important part of the SIM program, suggesting the embedded professional development component provided by classroom visits may have facilitated the development of teacher self-efficacy and encouraged program implementation (SIM Annual Report, 2008). 
In order for teachers to initiate change in instructional practices, teachers need evidence that a different approach will benefit them and their students (Emo, 2010; Guskey, 2002; Mouza, 2006; Richardson, 1998). Beamer et al. found that teachers actually increased their use of an innovative instructional practice because of gains in student achievement (Beamer et al., 2008). Reform based science education initiatives by nature include student-centered instructional practices. In a qualitative study conducted by Courson, teachers who successfully implemented a biotechnology partnership program believed the program would benefit their students and were willing to take a risk on the curriculum innovation (Courson, 2002). A closer examination of teacher beliefs is necessary in order to gain a deeper understanding of why teachers are willing to change or alter their instructional practices.

\section{Teachers and Beliefs}

"To understand teaching from teachers' perspectives we have to understand the beliefs with which they define their work" (Nespor, 1987, p. 323).

What teachers believe and feel has a considerable impact on the instructional decision making process (Bandura, 1986; Ertmer, 2005; Hargreaves, 1998; Nespor, 1987; Pajares, 1992). Nespor suggests the role of beliefs in teacher decisions regarding defining tasks and organizing knowledge may actually have a more important role that knowledge itself (Nespor, 1987). What then do we know about beliefs and how teachers use beliefs to make instructional decisions?

Green (1971) makes the distinction between explaining behavior and giving reason for behavior. To ask for an explanation of a given behavior, justifications for the behavior or giving reasons for the behavior may be the response. These types of responses are generally based on external rules or set of norms. For teachers who are considering whether or not to implement a 
new instructional practice, external rules or set of norms may be considered school culture, curriculum and issues of accountability, previously discussed as external factors that play a role in teacher decision making regarding instructional practices. On the other hand, giving reasons for a behavior solicits causes for the behavior. These types of responses are those of explaining the behavior and are based on beliefs (Green, 1971). Explanations for behavior based on beliefs are internal issue a teacher considers while considering whether or not to implement a new instructional practice. According to Green, judgments are truth claims in the absence of conclusive grounds, and value judgments are truth claims grounded in some fashion, but also are made based on personal preferences. Further, Green describes the appraisal process by which teachers make discriminating judgments of value such as those when teachers decide to use an innovative instructional tool.

Pajares argues teachers hold educational beliefs that shape their content and pedagogical knowledge, self-efficacy, and views of their students (Pajares, 1992). Nespor states beliefs are used to define tasks. Beliefs and knowledge are used together to come to a decision about the task at hand. To understand the decisions teachers make about tasks, we must examine their teaching goals (Nespor, 1987). This idea in appliqué can be found in research conducted by Zhao and Cziro who found teachers use technology because it allows them to achieve their teaching goals more effectively (Zhao \& Cziro, 2001). Courson found teacher implementers of a biotechnology program held personal teaching goals and their pedagogical practices which included the biotechnology program were congruent with these goals (Courson, 2002).

Exploring the literature which examines teachers and the decision making process in regards to implementing new instructional tools and materials, in addition to teaching goals, we do see evidence that beliefs are being used in this process. For example, when examining 
computer usage by teachers, Becker found teachers who believed more strongly in constructivist pedagogy were more likely to implement computers as an instructional tool, noting the computer activities were more conducive to meaningful learning activities for their students (Becker, 2001). Squire found that teachers selected instructional tools and resources that were consistent with their pedagogical beliefs and were perceived as potentially engaging for their students (Squire, 2003). In regards to technology and teacher beliefs, Niederhauser and Stoddart found teachers used technology in a fashion consistent with their beliefs about instructional practices as well as curriculum (Niederhauser \& Stoddart, 2001).

And finally, in an exploration of teacher beliefs and their decisions to implement innovative instructional practices, one must examine the phenomena described in different ways, but in essence is the spark, or impetus to initiation change within the teacher. Green argues wonder is at the root of motivation and should be included in the activities of teaching. It is the ability to be amazed or marvel which sparks the desire to learn (Green, 1971). In a similar fashion, Palmer speaks of identity and integrity in teaching, where teacher, students and subject are connected. In this scenario the teacher is truly present and engaging as to inspire and motivate their students (Palmer, 1998). Hargreaves presents teaching as emotional labor where the process of teaching is full of passion and where emotions are inseparable from moral purpose (Hargreaves, 1998). Ellis reports change requires a personal commitment from teachers (Ellis, 1995). How then does this state of wonder, being in the moment, state of emotion, and commitment influence teacher decisions to implement and sustain innovative instructional practices?

A quote from a teacher, Mr. Volker found within the research article, "Discourses about a teacher's self-initiated change in praxis; storylines of care and support” (Ritchie \& Rigano, 2002) 
enables one to begin to understand the spark or impetus experienced by teachers in the change process: "We should be changing from within, amongst ourselves, talking about how we teach and how we work" (Ritchie \& Rigano, 2002, p. 1079). Changing from within suggests being in touch with internal factors, both knowledge and beliefs. Sharing with other teachers demonstrates a sense of professionalism. Sharing with other teachers provides validation, support, and creates a safe place to grow professionally. In the research it was found that Mr. Volker took the initiative to engage and grow professionally because he was reflective about his teaching, and connected with his students. He took the time and courage to come to realize that his instructional practices were not engaging for his students, and then sought out new instructional practices in order to ensure his students were learning in a meaningful, enjoyable way that sparked interest within. Mr. Volker demonstrated a commitment to his profession by initiating change. Other research demonstrates teachers' who are committed to developing professionally experience a state of emotional arousal which creates a state of readiness and activates action (Yu, Leithwood \& Jantzi, 2000). Courson found teacher implementers of the biotechnology program were driven to explore new teaching tools because of their deep sense of professionalism. These teachers were compelled to seek out instructional tools and strategies that would be challenging and share their love of science with their students (Courson, 2002). Emo found teachers who initiated instructional change did so out of a need to add to their own enjoyment of their work suggesting a need to keep instructional practices exciting and engaging for them and in turn, their students (Emo, 2010). In the same study, Emo also reported a significant number of teachers reported a need to be part of a social-professional outlet as a reason for implementation. Voogt noted professional engagement was an important factor for 
teachers who were involved with the implementation of information and communication technology (Voogt, 2010). Professional engagement suggests a level of teacher commitment.

As discussed, internal and external factors a teacher experiences in careful consideration with teacher knowledge and teacher educational beliefs, and teaching goals influence teacher decisions to implement innovations in their classroom. The spark or impetus which ignites a desire within a teacher may begin the journey of change. What then encourages them to sustain their use of the innovation?

\section{Teachers and Sustained Innovative Instructional Practices}

As previously discussed, the research literature overwhelmingly indicates evidence of student success is a major factor in teacher change. Time and energy are major considerations for teachers as they decide to implement a new instructional practice in the classroom. Luehmann suggests teachers' subjective reality must be a consideration as educational reformers develop innovations for the classroom. In their subjective reality, teachers must juggle what is important with what works, what might be too much of a risk and what will motivate students. All of these play a role in the decision making process and ultimately sustained use of the innovation (Leuhmann, 2002). What then does the literature reveal about teacher subjective realities?

In order for teachers to take what they have learned and implement strategies in instructional practices, they need an opportunity to learn within the context of their teaching setting (Plummer \& Zahn, 2010). Huziak-Clark et al. examined the effects of a partnership where a collaborative model between scientists and science teachers was utilized to improve inquirybased instruction. An embedded approach where team-teaching took place over a three year period did in fact increase the use of inquiry-based instruction in the classroom (Huziak-Clark et 
al., 2007). Job embedded professional development opportunities have been specifically identified as facilitating sustained teacher change (Darling-Hammond \& Richardson, 2009). Clearly, giving teachers an opportunity to practice innovations within their instructional settings fosters lasting change. What do we know about the length of time a teacher engages in embedded professional development and how that influences lasting change?

Several studies suggest it takes teachers five to six years before they gain enough expertise to use technology in ways congruent with what is advocated by reform (Sandholtz at al., 1997). Other research suggests the time period it takes for teachers to acquire enough skill to be considered effect integrators using new technologies in their classroom is about three to five years (Brinkerhoff, 2006). Darling-Hammond and Richardson report it takes teachers engaged in professional development 30-100 hours over a time period lasting 6-12 months to have a last impact on instructional practices (Darling-Hammond \& Richardson, 2009). While the period of time it takes to master a new innovation may vary, especially those that include technology, it is clear that there is a stretch of time needed for teachers to gain a level of expertise and confidence and this can be facilitated through embedded professional development and other supportive professional experiences.

\section{Summary}

Many reform documents call for a transformation of the science education system in the United States. It is clear from many perspectives that a transformation requires a commitment from many stakeholders. When stakeholders come together to form partnerships addressing science education reform initiatives, meaningful change can take place.

Science partnerships are able to overcome obstacles to science education. These obstacles include access to instruction resources in the way of scientific research tools, and how these tools 
can be used in the science classroom. Partnerships provide; professional development opportunities for teachers to gain skills and knowledge, time to embed innovative instructional strategies into their curriculum and classroom practices, and networks to tap into professional learning communities which foster support and nurture professional growth. Ultimately, when partnerships come together, students experience positive gains in understanding and acquisition of science literacy, achievement, attitude and motivation, and interest in science beyond high school.

SIM is a partnership program that provides resources, curricula and professional support for science teachers to improve instructional practices at the secondary level. The resources are typically cost prohibitive and out of reach for most school districts, and include research grade instruments such as those used in higher education laboratory settings. The curriculum available through SIM is aligned with state science standards. The professional development opportunities are provided in the form of workshops for teachers to learn how to use the equipment and practice laboratory protocols, and embedded professional development in the way of teaching and team-teaching visits. The program has created a network connecting science teachers across distances. These networks are in essence, professional communities where teachers communicate and learn with each other developing professional connections and relationships. The program addresses many science education reform issues, and obstacles to excellent science education. The program is a resource intended to be a vehicle to improve instructional practices, however participation in the program is completely voluntary.

Many reform efforts, including partnerships rely on the willingness of the teacher to be realized. Teachers hold the key to reform. Teachers decide to use innovative strategies based on external and internal factors. External factors such as time, access to resources, school culture 
and pressures of accountability play a major role in teacher decision making. Internal factors include knowledge, self-efficacy, and beliefs. Teachers embrace change when they believe the new instructional practice will enable them to be a better teacher, and ultimately when they believe their students will experience success. 


\section{Chapter III}

\section{Research Design and Methodology}

\section{General Summary}

The Clarion University of Pennsylvania (CUP) Science in Motion (SIM) partnership project has been providing reform based science education resources for science teachers within a service area of approximately fifty miles surrounding Clarion University of Pennsylvania since 2001. This service area includes 18 school districts within five predominantly rural counties in Northwestern Pennsylvania (NWPA). Program goals specifically aim to provide instructional resources, curricula and professional development for teachers. The program is available for science teachers in the service area free of charge on a voluntary basis. Annual service records show science teachers in the CUP SIM service area use the partnership program on a regular basis. However, little is known about the reasons the teachers who use the program on a regular basis began using the CUP SIM project and continue to do so. The purpose of this study was to examine the reported reasons science teachers in the CUP SIM service area selected to initiate project use and continue to do so.

This chapter presents the research questions and describes the research design and data

analysis methods. Information regarding research participants is presented within this chapter as well. The development of the research instrument is also described. And finally, this chapter briefly discusses the Internal Review Board (IRB) for this study. 


\section{Research Questions}

This study examined the following questions:

What are the reasons for project use reported by teachers who use the project on a regular basis in the CUP SIM service area?

Sub questions are:

What was it about the teacher that encouraged her/him to become involved with the project? What is it about the teacher that encourages her/him to continue using the project?

\section{Research Design}

Qualitative studies are the most appropriate method of research to gain an in-depth understanding about the lived experience of individuals and groups of individuals. According to Gay \& Airasian, "Qualitative research seeks to probe deeply into the research setting in order to obtain understandings about the way things are..." (Gay \& Airasian, 2000, p. 16). This study examined the reasons why teachers select to use the CUP SIM project. The lived experiences of teachers form the foundation of this study. Because this study examined the real world situations of the science teachers in the CUP SIM service area, a naturalistic inquiry design strategy was adopted in order to collect data that was not contrived or manipulated in any way.

It is important to also note that this researcher is an integral part of the CUP SIM project. I have been the project manager and mobile educator throughout the life of the project at CUP. According to Charmaz, "We are part of the world we study and the data we collect. We construct our grounded theories through our past and present involvements and interactions with people, perspectives, and research practices" (Charmaz, 2006, p. 10). Being a part of the project might have potentially caused my perspective to be biased, but it also brought a wealth of knowledge, 
experiences, and history that helped develop a depth of understanding which, after all is the purpose of a qualitative study and this study in particular.

To address the research question and sub questions, two focus group interviews as well as a paper pencil questionnaire were used to collect data. According to Patton, focus groups provide rich, in-depth data and are typically comprised of 6 - 10 people (Patton, 2002). The focus group interviews took place on the CUP campus and took approximately five hours to complete. The paper pencil questionnaire contained the same questions posed to the focus group interview teachers, and were given to participants to complete on their own. Participants for the focus groups as well as the paper pencil questionnaire participants were comprised of teachers who use the CUP SIM program on a regular basis. Participants were given the opportunity to select either to participate in the focus group interview or the paper pencil questionnaire. Participant selection and interview questions are further discussed in detail within this chapter.

\section{Method of Data Analysis}

Focus group data was audio and video recorded. Focus group interviews were transcribed. During the interview process, detailed notes were taken by the researcher to aid in the analysis process. A phenomenological lens was used to examine focus group interviews and paper pencil questionnaires. Interview data was micro-analyzed and coded. Hyper Research software was used as an aid to analyze data. Triangulation of data from a variety of sources was used in the data analysis process. These sources included researcher interview notes, participant post interview and paper pencil questionnaire responses, and SIM service records.

Research methods where themes, patterns and assertions emerge through data analysis are in line with grounded theory (Patton, 2002). A grounded theory approach was used to analyze data. In this data analysis process, the first step involved open coding and inductive 
analysis where patterns, categories and themes were discovered as the data was handled. These emergent patterns, categories and themes were then used to deduce and generate assertions from the data that addressed the research questions.

\section{Participant Selection}

This study examined CUP SIM project usage through the lens of science teachers in the service area who use the project on a regular basis. Purposeful sampling methods were used to select participants. According to Patton, "Intensity sampling provides information-rich cases that manifest the phenomenon of study" (Patton, 2002, p. 243). Intensity sampling was used to select teachers who use the program on a regular basis, and were more likely to provide information rich responses. It was this researcher's opinion that the richest information would be collected from teachers who have had access to the CUP SIM project for the longest period of time. This researcher was also concerned about the effects of program down-sizing due to recent budget cuts over the past four years and hence the possible impact on newer teacher participant responses. Participants were selected that had access to the project prior to these events in order to paint a more complete and accurate picture of project use in its entirety. Therefore, participants were selected who had been teaching or taught in CUP SIM schools prior to 2010.

The criteria for a teacher who uses the project on a regular basis included teachers who have requested or request CUP SIM labs at least four times per year, or who use or had used a particular lab on a yearly basis. The lab requests could be in the form of a teaching visit, a teamteaching visit, or a lab loan. The CUP SIM project provides services to grades six through twelve, and provides materials for biological sciences, chemistry, earth and spaces sciences, and physical sciences. Teacher participants represented the grade levels and subjects which are serviced by CUP SIM. 
Teachers who met the purposeful sampling criteria were contacted via email and/or telephone and asked if they would be willing to participate in this research. Teachers who were willing to participate were provided a letter describing the study and their participation, and asked to sign a consent form. The Participant Information Letter is located in Appendix A. The Consent Form is located in Appendix B.

\section{Research Instrumentation}

Teacher participants were asked to complete a demographic questionnaire providing background and current teaching information. The questionnaire was distributed to teacher participants via email and/or U.S. postal service after the consent form was signed. A copy of the Study Participant Demographic Questionnaire is located in Appendix C. Demographic data collected from participants is located in Appendix D.

To develop research questions that solicit information rich responses, qualitative interviewing strategies were explored. Patton suggests it is important to develop instrument items that are truly open-ended in nature, ask singular questions, and are worded clearly (Patton, 2002). Question options provide by Patton that were considered for this research include: behavior/experience, opinion/values, feeling/emotions, knowledge, and background. These options were considered in the framework of past, present and future (Patton, 2002).

What the research tells us about how teachers make instructional decisions played a key role in the design of the instrument to address the research questions. It is reported in the literature that teachers select instructional practices based on internal and external factors (Rogers, 2000). Internal factors include knowledge, beliefs, and self-efficacy (Ertmer \& Ottenbreit-Leftwich, 2010). External factors include school culture, and issues of accountability, time and access to resources (Carless, 1999: Ellis, 1995; Ertmer \& Ottenbreit-Leftwich, 2010; 
Luehmann, 2002). Interview questions were design to solicit teacher responses addressing these key factors of the decision making process.

Patton's suggestions in regards to developing qualitative research questions, as well as literature on teacher decision making in regards to self-initiated changes and implementation of innovative instructional practices were used as a framework to develop interview questions. And finally, previous research conducted on the Science in Motion program was taken into consideration while developing interview questions. Specifically, the research considered included the Feasibility Study conducted in 1998 (PDE, 1998), a qualitative study conducted in 2005 (Spuck, 2005) and the Teacher Attitude Survey conducted in 2007 (SIM Annual Report, 2008). Interview questions were reviewed by four individuals who teach and/or have conducted research in the education arena. The interview questions were then piloted with four teachers who taught in the CUP SIM service area, and were regular users.

\section{Interview Questions}

The research question states: What are the reasons for project use reported by teachers who use the project on a regular basis in the CUP SIM service area? Sub questions are: What was it about the teacher that encouraged her/him to become involved with the project? And, what is it about the teacher that encourages her/him to continue using the project?

To address these research questions the following items were developed:

1. What was it about you that encouraged you to initiate SIM services?

2. What are the factors that have encouraged you to continue using the SIM project?

3. How does SIM help you to meet your personal goals as a science teacher?

4. How does your continued participation with the SIM project reflect your personal feelings about your teaching of science? 
5. What is it about yourself that you believe causes you to continue to use the SIM program?

Interview questions were shared with the participants one week prior to the focus group interviews in order for teachers to have an opportunity to begin reflection and generate in-depth responses. Teachers were given an opportunity to reflect upon the interview and provide additional feedback after the interview was complete. Paper pencil questionnaire participants were given three weeks to complete the questions.

\section{IRB Requirements}

The West Virginia University Internal Review Board requirements were taken into consideration for this research. The data for this study was comprised of teacher reported reasons for project usage. The data was collected through focus group interviews and paper pencil questionnaires. Additional demographic and teacher background data was collected. The identities of the participants were kept in strict confidence and all collected data will be destroyed after five years, meeting IRB requirements. This type of study presented a minimal risk to participants, and falls within the exempt category for research. 


\section{Chapter IV \\ Presentation of Data}

\section{Introduction}

The purpose of this study is to examine perceptions of science teachers who use the Clarion University of Pennsylvania (CUP) Science in Motion (SIM) project. More specifically, this study examines teacher reported reasons for CUP SIM project initiation and continued usage. In this study, teacher perceptions about their experiences with the CUP SIM project were gathered through qualitative data collection techniques using a paper/pencil questionnaire and two focus group interviews. Teachers were invited to participate in this study based on program usage.

This chapter consists of the following: 1) overview of the teacher selection process; 2) description of the data collection process for the paper pencil questionnaire (PPQ) teachers as well as the focus group (FG) interview teachers; 3) teacher demographic information, 4) focus group interview procedures 5) data analysis overview; and 6) teacher participant data for questions one through five.

\section{Overview of Teacher Selection Process}

Upon successful completion of my thesis proposal, I began the internal review board (IRB) approval process. After successful IRB approval, I contacted teachers who met the criteria for this study, inviting them to participate. The criteria to participate in the study includes those science teachers in the CUP SIM service area who use or have used the project on a regular basis during the existence of the program. Regular basis is defined as using a piece of lab equipment for a particular lesson or unit on a yearly basis, or using at least four different labs on a yearly basis. In total, twenty teachers were contacted. This group of individuals includes middle school 
science teachers, as well as high school biology teachers, chemistry teachers, physics teachers, and earth and space science teachers, representing all the disciplines and grade levels which receive SIM services. Of these science teachers, some are actively teaching, while others have left their teaching positions due to retirement or have entered an administrative position within the education field. Of the twenty teachers contacted, a total of fifteen teachers responded and agreed to participate in this study. However, one of the teachers dropped out of the study due to personal reasons, leaving a total of fourteen teacher participants. These fourteen teachers represent approximately 36 percent of the average number of teachers who have used the CUP SIM project throughout the life of the grant project.

Teachers who agreed to participate in the study were given an opportunity to select a participation preference; either a PPQ, or a FG interview. Seven teachers selected to participate in the PPQ, and seven teachers selected to participate in a FG interview.

\section{Data Collection Process: Paper Pencil Questionnaire Participants}

The PPQ teachers were sent an IRB consent form to complete via email. When these teachers completed and returned their consent form, I added my signature and date, made a photo copy of the form and sent the participants a copy of their consent form to keep for their records. After the consent forms were signed, the demographic data form and the PPQ with the interview questions were sent via email to the PPQ teachers. Teachers were asked to complete and return the demographic data and PPQ within two weeks. A reminder email was sent after one week, two days before the due date, and on the day the forms were to be completed and returned. The initial deadline was extended due to teacher requests for additional time. The forms were completed and returned within one week after the initial requested due date. After all the forms were returned, I contacted four of the PPQ teachers individually via email for clarification of a 
response, or to elaborate on a response they had given. Complete demographic data for the PPQ teachers can be found in Appendix D. A summary of the demographic data is found in Table 1.

\section{Data Collection Process: Focus Group Interview Participants}

Two separate FG interviews were scheduled one week apart and took place on the Clarion University campus. A Doodle Poll was used to select mutually agreeable dates for the teachers and the researcher. Upon arrival, teachers were greeted by the interviewer and given an opportunity to mingle. During this time, the teachers were asked to complete an IRB consent form and the demographic data form. After participants completed the IRB consent form, I signed and dated the form, and made a photo copy of the form for the participants to keep for their records. Both interviews took place between 9:00 A.M. and 2:00 P.M., with breakfast as well as a buffet lunch provided by the Science in Motion project. The interviews were videotaped, and audio taped. The interview logistics were facilitated by a graduate assistant within the Education Department. Four female teachers participated in focus group interview one (FG1), and one male and two female teachers participated in focus group interview two (FG2).

\section{Teacher Demographic Information}

As part of this study, teacher participants completed a demographic questionnaire. The questions asked are: 1) how many years have you been teaching/taught, 2) what is your current teaching status, 3) what higher education degrees have you earned, 4) which grade levels are you certified to teach, 5) which subjects are you certified to teach, 6) are you involved or have ever participated in grant projects other than SIM, 7) have you had experiences with outreach projects other than SIM at CUP, 8) do you have an experience doing research, 9) are you involved with any professional organizations, and 10) are you or have you been involved with leadership, or 
extra-curricular activities? Table 1 below provides a summary of the demographic information for all teacher participants.

Table 1

Teacher Demographic Information Summary

\begin{tabular}{|l|l|}
\hline Teaching Experience & $13-31$ years \\
\hline Teaching Status & $\begin{array}{l}\text { Actively Teaching: 10 teachers } \\
\text { Educational Administration: 2 teachers } \\
\text { Retired: 2 teachers }\end{array}$ \\
\hline Highest Degree Earned & $\begin{array}{l}\text { Bachelors: 5 teachers } \\
\text { Masters: 9 teachers }\end{array}$ \\
\hline Grade Levels Taught & $6-16$ \\
\hline Certifications & $\begin{array}{l}\text { Biology } \\
\text { Chemistry } \\
\text { Earth/Space Sciences } \\
\text { Physical Sciences } \\
\text { General Sciences } \\
\text { Middle School Science }\end{array}$ \\
\hline $\begin{array}{l}\text { Involved with other grant projects not associated } \\
\text { with CUP }\end{array}$ & 7 teachers \\
\hline $\begin{array}{l}\text { Other experiences with CUP beyond SIM (outreach, } \\
\text { PD or course work) }\end{array}$ & 11 teachers \\
\hline Experience with research & 7 teachers \\
\hline Involved with professional organizations & 12 teachers \\
\hline $\begin{array}{l}\text { Involved with professional responsibilities and duties } \\
\text { beyond the classroom such as leadership positions or } \\
\text { extra-curricular activities }\end{array}$ & 14 teachers \\
\hline
\end{tabular}

\section{Focus Group Interview Procedures}

The focus group interview questions were brought forth in sequence, one at a time, followed by a period of time for teachers to provide responses. Probing questions were used during the interview process to encourage additional responses related to the interview questions. Each FG had a unique personality. FG1 provided lively discussion, freely giving detail and insight into their perceptions on SIM project use. FG2 teachers were more reserved, but also engaged in detailed discussions about their responses when probed. The conversations in both focus groups touched on a variety of topics and issues these teachers experience in their 
classrooms, their schools and their communities as they ruminated on each question. It is noted that responses related to each question were not entirely addressed discretely in order, but took on more of a spiral effect where comments and conversations for one question addressed interview questions yet to be brought to the table, questions already discussed, and at times multiple questions at the same time. When I felt the conversations had strayed a bit too far away from the interview questions, I gently brought them back to task. At the end of discussions on each question, I reiterated what I heard from teachers during the conversation to make sure teachers had been given ample opportunity to share their thoughts with the group. After the interview, I contacted each teacher to give them another opportunity to share any additional thoughts that they may not have shared during the interview process due to a lack of comfort, or perhaps a thought they had had after they had time to reflect on the interview process. In addition, individual teachers were contacted to clarify a particular response, elaborate on a response, or answer a question left unattended during the interview process.

\section{Data Analysis Overview}

Focus group interview data was transcribed and data analysis of both PPQ responses as well as FG interview data was conducted using a grounded theory constant comparative approach. Data from the PPQ participants, and each FG interview was analyzed separately first. These discrete data sets were then analyzed in total. It is noted that the responses solicited through the focus group interviews were developed to a greater depth through conversation between the participants, while the paper pencil questions tend to be short discrete responses. FG data and PPQ data was coded line by line and entered into Hyper Research software. Code categories emerged and themes were developed. These categories and themes were used to organize and present the data in a cohesive manner. A grounded theory approach was used to 
develop assertions which address the research questions of this study. The discussions related to data analysis are presented in chapter five.

\section{Teacher Participant Data Overview: Question One through Question Five}

Following this brief introduction and overview is the presentation of data collected from teacher participants for each of the interview/PPQ questions. The data is organized within categories which emerged as each of the questions are discussed. Questions one through five are presented below. 


\section{Question One: What was it about you that encouraged you to initiate SIM services?}

Teacher responses to question one speak of SIM as a perceived resource that provides opportunities for teaching and learning, as well as professional growth. Below are teacher responses regarding initial project use presented in the following broad categories: perceptions about the SIM project, SIM as a means to enhance teaching, SIM as an opportunity to enhance learning, professional development, and teacher self-reported characteristics as influences which encouraged initial use of SIM services.

\section{Perceptions about the SIM Project: "Levels the Playing Field"}

Every teachers who participated in this study, without exception spoke of SIM as a valuable resource. More specifically, teachers spoke of initiating project use because they perceived SIM as an opportunity to provide learning experiences via instructional resources that, otherwise would be inaccessible due to the materials being cost-prohibitive. Below are teacher responses regarding SIM perceived as a valuable resource that in essence addresses issues of equity by "leveling the playing field":

SIM levels the playing field in that I can do some of the things that the rich school districts do. And so our students in little rural North Western PA can have some of the same experiences and opportunities as you know, somebody who lives in a rich school district near a city. (Laurie)

We just don't have the budgets, and that's when Science in Motion came out, and I was like, you've got this, this, and this, really? I can use this? All I have to do is call and I can get that? (Sue) 
I worked for the Catholic school and a serious lack of materials led me to SIM. SIM allowed me to continue my hands on teaching methods even when materials were scarce. (Patty)

SIM provided additional classroom materials that my regular budget could not support. (Kevin)

SIM had materials that allowed me to offer learning experiences for my students that I couldn't afford any other way. (Chuck)

One teacher shares that by using the SIM classroom resources, she is able to use her allotted school budget on other supplies, effectively stretching her budget:

By borrowing the equipment and supplies from SIM, I was able to use the money saved to purchase other lab supplies that were needed. (Tessa)

\section{Perceptions of SIM: Ease of Use}

Teachers spoke of the SIM project as being user friendly and easy to access as reasons for initiating SIM services. The delivery aspect of the project was attractive to teachers:

SIM has materials, and it comes to you! (Chuck)

With you bringing all the materials, I thought “Oh, I can do this!" (Barbie)

SIM was perceived as a resource that could make teaching easier:

If we didn't have that available, like, would I do that, would I have the time to do that or the money to do that or the resources to do that? (Sue)

\section{Perception of SIM: Familiarity with Staff and the Project Reaching Out}

Teachers note familiarity factors which encouraged them to initially become involved with the project. Some teachers were already acquainted with the SIM staff, which encouraged them to become involved: 
I think the fact that I already knew you and the people here. I think that's a draw for me. Just the familiarity with the people involved is comfortable for me to do. (Laurie) In addition, the project reaching out to teachers with introductory professional development workshops was appealing to teachers:

I think that it was mainly the mobile educator that I think got me involved with the whole thing because I didn't know anything about it, and you showed me the things that were available and that was so cool. (Barbie)

The initial contact was very well done. It was very well organized, it was effective. Everything was bam, bam, bam, here it is, here's why it's good. It was well presented. So instantly, I was like, wow this is great. I want to come back and use this because this is a great experience. (Brian)

\section{SIM as a means to Enhance Teaching}

Teachers report they initiated SIM services because they perceived SIM as a means to enhance their teaching of science. Enhanced teaching is mentioned in a variety of ways. Teachers discuss the need to provide engaging activities to facilitate student understanding of content:

I teach mostly middle school kids, so engaging activities, engaging them with content is key. (Brian)

The use of advanced science equipment as a resource to provide meaningful inquiry is desired:

I wanted to provide my students with authentic classroom investigations using advanced science equipment. (Mary)

Teachers spoke of SIM as a perceived means to enhance their ability to teach using inquiry instructional methods: 
There were so many times, if I had this to show you, this is what we would do. Well guess what? Now I have these things. (Sue)

I try to make teaching more inquiry based, using things that have evidence that they work with the kids. So, I'll use whatever I can find that will help me get the concepts across to the kids. (Laurie)

\section{SIM as a means to Enhance Learning}

As part of the other side of the teaching - learning continuum as one might expect, teachers report they initiated using SIM because of the impact they felt these opportunities would have on their students. Enhanced learning is often stated within the context of student engagement, motivation and providing positive learning experiences:

They are so excited when I bring something in. (Leslie)

It's more for the connection for the students. The excitement for the students. (Sue)

I enjoy bringing new stuff to my kids and hopefully the excitement will be there for them. (Laurie)

You know you have hands on where you sling things out and the kids are like "Whoa!" They're so engaged. (Brian)

I'm always looking for ways to engage my kids in neat stuff. (Kevin)

Enhanced learning opportunities for students is also mentioned in terms of learning the content with a greater depth of understanding. This included developing and improving critical thinking skills as well as science literacy:

Now I can actually put that back together and critically think, and make kids, you know, work the content instead of just talking about something. Kind of make it more alive. (Sue) 
You have to understand this material in order to get something out of it. It's not, we're not teaching it just because you have to take a test. (Barbie)

Perceived enhanced learning via SIM experiences is mentioned in terms of a competitive edge:

The other thing is that it keeps the kids knowing. They're going to be competing in the world with other kids. (Lucy)

\section{Teacher Professional Development}

Professional growth and development is mentioned as a factor which encouraged initial SIM services. Below are teacher comments regarding their desire to grow professionally:

I'm always going to as many professional development activities as I can to try and bring new things into my classroom. (Laurie)

I think as a teacher you have to be willing to continue to learn, and that was the opportunity that this provided. (Marcy)

I always say that I'm a life-long learner, so yeah, professional development is definitely an important thing. (Barbie)

I cannot imagine going through a day without learning something. And, pushing myself the furthest I can possibly go. You know you don't have too many opportunities to do that. (Sue)

Professional development is vital I think, especially for a long teaching career. (Brian) In addition to the professional development workshops offered through SIM, embedded professional development offered through the project via teaching and team-teaching visits by the mobile educator was something teachers found attractive. Below are teacher comments regarding the embedded professional development aspect of the SIM project: 
I would not have done this on my own because I don't like to fail in front of my students. (Barbie)

And, having you come into the classroom and running the lab the first time provided a level of comfort. That helped with the learning curve. (Chuck)

So I was willing to say, hey I don't know how to do this stuff, so (the mobile educator) you have to stay! (Lucy)

The teaching visits is something really great about the SIM project. They would come and teach. The great thing about Science in Motion is that there are people that support you and teach you. (Sue)

\section{Teacher Self-Reported Personal Characteristics as Influences to Initiate SIM}

Teachers talk about themselves in terms of their personal characteristics and what is important to them as they reflect and share their thoughts regarding why they initiated SIM services. Teachers share thoughts concerning their personality:

I really think it's your personality. It's your personality, and everybody here has a similar personality. You care about your kids. It's not just a job. (Lucy)

I mean knowing my personality, if I hadn't known you once I found out about it I know would have used it. (Laurie)

Teachers speak of things that are important to them and their desire to be positive role models for their students as reasons for initiating SIM services:

I think as a teacher you have to be willing to continue to learn, and that was the opportunity that this provided, and I think in some ways that provides a good role model for my students. (Marcy) 
Teachers talk about a sense of professional responsibility as they discuss why they started using SIM. Professional responsibility statements reveal a desire to be an excellent educator: I just want to be the best teacher I can be and use things, techniques that have some evidence that they work with the kids...I want to be better, and so whatever I can find that will help me to be a better teacher and help me get these concepts across to the kids... When it comes down to it, I feel like we're at the front line and, what we do is not the most glamorous job in the world, but it is really important, and so I want to do the best I can. (Laurie)

I think this it's probably a characteristic I have. I just want to be the best that I possibly can be. (Marcy)

Being an excellent educator was discussed in terms of a professional attitude: It's almost like avoiding atrophy. What actual scientists do to research things, and I've struggled with this. And talk about professional development, that's where it's like reconnection with, 'Oh this is what science is.' Because we're kind of in a weird wedge. We sit in between your state standards and your accountability. But then we also know what science is. (Brian)

\section{Question One Summary}

Teacher responses to question one reveal their perceptions about the SIM project, what they perceive SIM can do to enhance the teaching and learning process, and provide in terms of professional development. And finally teachers discuss their personal attributes as reasons for initiating SIM services.

Unanimously, teachers report they initiated SIM services because the project provides laboratory equipment and activities that are otherwise not available to them and their students, 
essentially expanding and enhancing instruction. Teachers speak of the project itself as being an impetus for initiating use. The SIM project was perceived as something well organized and presented, and the resources relevant. The SIM staff was perceived as enthusiastic, knowledgeable, and encouraging. The project resources were perceived as easy to access for their classroom use.

Teachers report they initiated SIM resources because the equipment and laboratory activities were perceived to enhance teaching in terms of providing advanced equipment, and authentic inquiry based laboratory activities.

Along the teaching-learning continuum, teachers report initiating SIM services because they want to provide engaging activities for their students that will encourage motivation, and a positive attitude. They also perceived the SIM project as a means to develop a greater depth of understanding within their content area, and develop and encourage science literacy and critical thinking skills.

Teachers share about their desire to continue to grow professionally as a reason why they initiated SIM services. The embedded professional development aspect where the mobile educator facilitates the lab with the teacher in the classroom was an important factor for teachers as they decided to initiate SIM services.

Finally, teachers discuss their motivation to initiate SIM services was, impart due to personal characteristics. Teachers report that SIM is perceived as a resource in line with teaching goals, learning goals for students, and their willingness and desire to continue to learn and grow professionally. Their desire and drive to meet their goals encourages them to take the initiative and use the SIM resources. 


\section{Question Two: What are the factors that have encouraged you to continue using SIM?}

As teachers share about factors that have encouraged continued use, they bring to the table their thoughts about the SIM project drawn from their experiences. The following paragraphs detail explicit reasons reported by teachers for continued SIM use. Probing questions regarding external factors: school administration, parents and school board, as well as school culture were asked during question two focus group interview discussions. Below are responses from the participants, regarding question two.

\section{User Friendly Nature of the SIM Project}

The user friendly nature of the project is noted by teachers as a factor for continued use. Comments from teachers touch upon user friendly aspects including time frame in which resources can be accessed and availability of the equipment:

The time frame in which you can get things is pretty reasonable. Any time I want anything, it's usually available or on its way to me from another school. (Leslie) If we want something today, like those slides that I forgot to order for at least three years in a row. I was able to call, and here they are, and we got them right away. (Brian)

The dependable reliable nature of the project:

Stability and reliability. I mean, you've been there when we needed you. Being able to simply email and say, 'I need this, Okay?' You know, that's huge. (Brian)

I know I can call you and say, 'Hey, I need this!' (Laurie)

The ease of project use was a factor for teachers:

The most important factor for me to continue using SIM is the ease of requesting the equipment and the delivery and pick up. It is really easy and convenient. The equipment and supplies are always well organized and bagged up when delivered. (Tessa) 
It is so easy to request and use. (Patty)

I continued to use SIM because of the deliveries and pick-up aspect of the project. (Linda)

It provides hands on to kids, and it comes to you! (RS)

\section{Professional Development}

As teachers share reasons for their continued use of the project, professional aspects they have experienced surfaced. Teachers were encouraged to continue using SIM because of the support they receive from the SIM staff:

I wasn't really comfortable with the equipment because I didn't know, step by step what to do. So the first time you came in to do the lab, and I was still a bit leery with doing it on my own. So a second time you came in, and now I can do it on my own. I'm much more comfortable because you allowed me to learn via you. (Leslie) It is beneficial to have the equipment, materials and consumables provided, but the technical support is also essential. If you don't know how to conduct the lab the SIM staff is willing to teach you. (Mary)

Staff is very easy to work with and they are willing to teach concepts or show students how to use equipment. (John)

Teachers also share it was the professional community and ability to network which encourages them to continue using the project:

SIM is a good way to make connections too, getting a chance to talk to other teachers. (Barbie) 
You learn from the content that's offered by the professional development facilitators, but you also learn ideas from the teachers, from each other, and that's very beneficial. (Marcy)

It's really one of the strengths, you know what you said about being with other teachers. You get so many ideas from everybody. You know, just to have a forum, and SIM provided that forum. I'm really amazed at the resource that SIM is for teachers and the community. (Lucy)

Teaching is very isolating. SIM gave me the chance to talk about science and teaching. It helps with the isolation, making connections and hearing what other teachers are doing. (Chuck)

\section{Variety and Up-Dating of Laboratory Materials}

Several teachers discuss up-dating of laboratory activities and equipment along with variety as reasons they continue using SIM after initial participation with the project. Each year the project is up-dated, adding new equipment and laboratory activities, essentially increasing the variety of equipment and activities while keeping up with the latest technologies and science activities:

I can tell you why I used it. Because it was updated. It had new things there. You kept up with the times, so that I could keep up with the times. (Lucy)

And also the amount of resources available because of the updating. (Leslie)

The factors that kept me going? The variety. I like the variety. (Barbie)

SIM reflects the subject and keeps it relevant with current events. It keeps students connected. It's relevant. (Chuck)

I continued to use SIM because of the up-to-date equipment. (Linda) 


\section{Teacher Voice and Ownership}

Teachers specify their participation regarding the selection of new laboratory materials and activities is a reason for continued project use. Each fiscal year, monies from the grant are used to purchase new equipment. The SIM staff solicit suggestions for new lab materials from the teachers. This participation gives teachers voice, which encourages continued use:

Perhaps something else I could add is the fact that SIM would ask teachers in the spring what new equipment they would like to have SIM purchase. I always thought that was great. It empowered me to think of really cool stuff I wanted and put that forward.

(Kevin)

If you wish to conduct a particular investigation the SIM staff will help you acquire it. It may mean borrowing it from a different SIM provider or purchasing it when the funds becomes available. (Mary)

You bought those high temperature probes I requested. You didn't have them before and then when you finally got them, I was so excited to have those. (Lucy)

The project also accommodates teacher special requests for materials and equipment not currently available during the school year, if funds are available:

I wanted to try and do a lab not on the SIM lab list, and the mobile educator said, well let me see if I can get the equipment. Then, you were able to get it, and I said, okay let's try it! (Barbie)

I specifically asked the mobile educator, can we do this? She actually bought the materials for the lab. It gave me the opportunity to think that I had ways to move myself up. But I never would have pursued this unless I had really been thinking, what if you 
could do this for me? I think it's the 'What else can we do?' that gets the thinkers thinking some more. (Sue)

Teacher participants indicate SIM providing materials which allows them to teach upper level science courses keeps them with the project:

There's no way I could possibly buy the equipment for some of those labs that you need to do, that you are required to do. SIM has allowed me to have AP Biology. (Laurie) Our school district did not have the necessary lab equipment for the AP Biology labs. (John)

\section{Cost Savings and Budgetary Restraints}

Teachers also touch upon the idea that SIM provides teaching and learning opportunities otherwise out of budgetary reach:

It's also because of the cost savings. We don't have to purchase the equipment, so then our students get to complete the labs. (Marcy)

Our budgets keep getting slashed, so I might be using more labs! (Sue)

It's great for the kids and it doesn't cost you anything. (Lucy)

Sim has provided very helpful tools. We couldn't provide these experiences ourselves. (Brian)

\section{Student Engagement}

Teacher responses include student engagement as a reason for continued use of the project. Student engagement is described as providing hands-on activities and those that can spark interest:

It provides hands on to kids. (Chuck)

Students really enjoy the equipment and labs. (Patty) 
I'm always looking for opportunities to engage my students in neat stuff. (Kevin)

Student engagement that leads to learning the content is mention:

Yeah, because the students are just into the learning activities, but to take that and then move into the direction of the content...You know and, and get the kids to understand like there's these really engaging things but then there's this body of content. (Brian)

Student engagement is mention in terms of pride experienced by their students as a result of participating in a SIM lab:

We are constantly shuffling things back and forth, and the students take pride in that. (Leslie)

The kids like it when you bring in something and they love the little sticker, 'This is from Clarion University.' It makes them feel important that they're using equipment from the university. (Laurie)

During FG1, the following conversation takes place where teachers share SIM experiences help develop science process skills and spark interest:

I really feel working with the SIM equipment is a worthwhile thing to do. (Sue) There are those process skills that they need to develop if they're interested in science... (Marcy)

Exactly! (Sue)

...they get it in the lab (Marcy)

Yeah, yeah it is. (Lucy)

It gets them... (Leslie)

Interested! (Marcy) 


\section{Life beyond the Classroom}

Teachers share student success beyond the classroom have encouraged them to continue using the SIM project. Some of these success are in regards to college readiness:

A couple students that took the AP class using some of the materials that you'd given us, now they're in college taking biology and they contacted me, 'We just did this lab. I just aced it because we already did it and I knew exactly what to do.' (Barbie) It's really exciting to me when they do go to college and they come and they say 'We did this in my college class and I already knew how to do it.' These are some skills that they can take with them and I wouldn't be able to do this on my own. (Laurie)

Student impact beyond the classroom also includes opportunities which open the doors and help prepare students for science careers:

We did stream studies down by our school, (the SIM mobile educator) showed us how to do the lab. And I had one boy who was in $7^{\text {th }}$ grade. We went out, and he just loved it. He was like 'Hum, I'm going to do this for a career.' And now he's doing something out West with Parks and Recreation doing stream studies. (Barbie)

It's nice to hear from them and hear what they've done. They get all excited like, 'Oh I did this. Aren't you proud of me?' you know. I actually had a student and he sent me the first part of his doctoral thesis. And in it he says, 'I want to thank my teacher, Laurie for inspiring me to go on.' (Laurie)

\section{Probing Questions}

During both focus group interviews, probing questions were posed to solicit further thoughts and information from the teachers regarding reasons why they continue using the project over the years. The literature review regarding teachers and how they make instructional 
decisions in the classroom guided the development of the probing questions. The probing questions are: does your administration have an impact on your decision to continue using the project, does your school board or parents of your students have an impact on your decision to continue using the project, and does school culture have an impact on your decision to continue to use the project? An explanation for the meaning of school culture was given to each focus group to provide clarity for the participants. Below are teacher responses from each probing question.

Probing Question: School Administration. During discussions in both focus groups, participants were asked specifically if their administration had any impact on their continued use of SIM. Administration is understood and commented on in terms of superintendents and principals. Teachers in both groups report their administration is either supportive or neutral about their decision to use SIM as a classroom resource. However, one teacher in FG2 made comments suggesting she might encounter some resistance if she is not able to demonstrate how a SIM lab fits specifically within her curriculum.

Here are the responses from FG1 reflecting thoughts that indicate the administration is supportive of SIM project use:

My superintendent is fairly new. She was familiar with SIM so she was very accepting. She was really supportive of the program. (Leslie)

My principal is pretty supportive. (Sue)

The administrators always were stopping by to see what it was that I was doing. You go with the attitude that it's helping the kids. If you go with that attitude then how can the administrators fight that? It's great for the kids, it doesn't cost you anything! (Lucy) 
We just got a new head master, and he's very supportive. The previous head master was extremely supportive. Again, I think it's because of the cost savings. (Marcy) Below are responses from FG2 teachers. Two of the teachers felt their administration was either neutral or supportive:

My administration, they're supportive of me getting anything that's free. They pretty much leave you alone to do what you need to do. They're supportive of anything I can add to my classroom that's not going to cost them money. (Laurie)

Our administrator is very good, actually all of them have been. There's nobody on our staff that's a new faculty member that teaches science, so I think we get a lot of leeway to do what we think is necessary which is really nice. (Brian)

$\mathrm{CO}$, in FG2 shares the only comment suggesting the administration or school culture is restrictive with the labs she can provide in her classroom:

Unless the lab that I'm doing somehow relates back to that curriculum map, the days of fun labs are done. So the lab has to match something that's in my curriculum. A lot of times in the past, if I thought a lab was really cool that you had brought in, I would share it with all my classes just to give them the experience, and they thought it was great. Those days are done. If it doesn't match the curriculum map, then I can't do it. (Barbie) As CO continues along this thread she shares how she has found a creative solution to this problem:

Yeah, it's tightened the reins on what we can do and we can't do. That's why I do a lot of the after school activities. It's like, okay, we're doing the SIM lab. It doesn't matter what curriculum I'm using after school, I can do it. If I have kids that want to stay after 
school, great. Just whoever wants to stays after and wants to do it. The kids do it because they want to. (Barbie)

Probing Question: Parents and School Board. In FG1, participants were specifically asked if parents or the school board had any impact on their decision to continue using the SIM project. Responses in FG1 regarding parental influence reveal they may indirectly encourage continued use by providing encouraging feedback when children share with their parents a positive experience completing a SIM lab in science class:

As for parents, I think they would be supportive of what we do. And the kids are definitely very excited and they go home and talk to their parents. (Sue)

Yeah, parents will see you some place and they'll say, 'Oh, so and so really liked what you're doing in your class.' So, really, I got support from the parents. The kids, they talk to their parents. They're going home being excited about school. (Lucy) When we came to campus to have a SIM experience, my students cultured African monkey brain cells. Jenny, who is on the girls' soccer team, had practice that night. She came back into class the next day. She says, 'I asked the kids what they were doing in their advanced bio class at our sister school and they're doing such and such. And they asked what I was doing, and I said we cultured African monkey brain cells today. And they were like, 'What?' So, just, you know, opening that communication between different schools within the same district. She was really excited to share that with them and they were really excited to hear it. And she said, 'You know, it's not every day you can do something like that.' So then that makes its way back home and then parents, when they see you, 'Oh, Jenny was really excited to hear or tell me about what you did.' You know, yeah, the kids talk. (Leslie) 
Responses in FG2 suggest parents have little or no impact on their decision to continue using the project:

Well, I don't know about SIM but I know some of the parents, they either have a really poor attitude and school is worthless. And then I have parents on the opposite end who want their kids, you know, they think they should be going to Harvard. We have to get them ready for that, so you know, what can we do for them to make them better. So I guess that's where, SIM would come in definitely. (Barbie)

There's very little parental involvement. I really get very little feedback from parents. As far as what I do in my classroom, nothing. So that really doesn't play any role in my using the equipment or not. (Laurie)

I don't know that there's any input from parents on how I use SIM. (Brian)

The school board was not perceived as having any real influence over their decisions to continue with the project in FG1:

Well, the school board and the superintendent are directly tied in my district. They don't tell me not to do things. (Sue)

Probing Question: School Culture. Probing questions regarding possible influences from school culture were addressed within both FG1and FG2. In FG1, the probing question regarding school culture was coupled with a question regarding leadership. The teachers were asked if they are or had been a department chair. Teacher responses in FG1 begin with reflections from Lucy:

I was the department head. But, you could be a department head and not have any real influence on anybody. I think that it all depends on who the people are that you have. (Lucy) 
Later during the discussion, Lucy continues sharing her thoughts, and as she does, she reveals how she did find support from teachers within her building, suggesting a positive impact from school culture:

I remember a math teacher who was teaching Boyle's and Charles's Laws with math problems. We were at lunch and she said, 'What are these laws? I don't even understand them.' I said, 'Well, come on down to class.' And so I always do the crushing of the can and all that other stuff. So, she came in and she says, 'I understand it now!' And she said, 'I can teach it so much better.' And then the art department had clay, so we did the Roku, and I had my AP Chemistry kids make their own elemental copper so they could put that copper on their Roku plate. (Lucy)

This comment was different from her first comments, thus initiating further probing:

So you have a supportive school? (Interviewer)

Um-hmmm (Lucy)

But you are a big school. (Interviewer)

But no, I said individuals. (Lucy)

Sue shares her thoughts on school culture. She believes the school culture is dominated by testing and relatively unsupportive, however she does receive positive feedback from her principal:

I think the testing is changing the culture and that has changed a whole lot of how we look at things. I think it affect your psyche. Over time it's really difficult. And you could get beat down. It undermines even though my principal is very positive and reassuring and says, 'You're doing a great job.' (Sue) 
Lucy taught within a relatively large school. Sue teaches within a large school as well. Their comments are very different compared to the comments about school culture from Leslie and Marcy, who both teach in relatively small schools. Responses from Leslie and Marcy suggest they feel their individual school cultures are supportive in many ways, and continuing with SIM may be one of those ways in which they feel supported and encouraged:

I am the only full-time science teacher, so it's really a pleasure when the math teacher will help where there are multiple connections that cross the curriculum. So it's nice being in a small school because we all know we wear many hats, but we come together and that helps to get things accomplished for the students. (Marcy) My school is really like a family. It's very easy to form connections. Everyone is supportive of me and I'm supportive of them and we make cross curricular ties all the time. So we're all connected and very supportive of each other. It's very easy for us to get together at the end of the day and talk. We have no department heads or chairs because there are so few of us. (Leslie)

\section{Question Two Summary}

Question two solicits teacher responses which reveal reasons why they stay with the project after initial use. Teacher responses fell into the following categories: factors regarding experiences with the SIM project, and student engagement. Probing questions during the FG interviews touched upon external factors: school administration, parents, school board, and school culture.

Teachers continue using the resources because they are readily available and easily accessible. Turn-around time between a teacher requesting resources from SIM and lab availability is perceived as very reasonable. Teachers also appreciate the user friendly delivery 
and pick-up aspect of the project. SIM staff in terms of familiarity is noted. In addition the mobile educator providing classroom support is perceived as essential while teachers are learning new techniques associated with SIM lab equipment and protocol. Resources being available at no cost is a major factor. The variety and up-dating of equipment keeps teachers with the project. Teachers enjoy the variety and having access to up-to-date technology for their instructional practices, keeping their teaching relevant.

As the project continues to expand and grow, adding instructional resources, teachers enjoy and appreciate having a voice within the SIM project. Teachers are given the opportunity to be part of the process, selecting and adding new materials and labs to the project on a yearly basis, as grant monies are available. Teachers having a voice gives them a sense of ownership and empowerment. In addition, the project allows them to expand their curriculum and offer upper level science courses.

Ultimately, student learning is the purpose of instruction, and teachers note they continue with the project because of their students. Teachers want to engage their students in hands-on science which will spark interest in the learning process. Further teachers continue because they want their students to develop science process skills, be exposed to learning experiences that may lead to career interests and ultimately impact students beyond the classroom. SIM has been a resource that enhances the learning experiences and touches upon these goals.

Probing questions regarding administration reveal most teachers feel their administration is either supportive or neutral in their decision to continue with project use. One teacher indicates she is bound by the district curriculum as she selects laboratory activities for her classes, noting that at one time they were less restrictive. However she is able to provide the laboratories after school. 
Teachers in FG1 didn't feel their school board has much of an impact on their decision to continue project use. The school board probe was omitted in FG2.

In FG1, parents are perceived as being encouraging as students share positive experiences with SIM labs. In FG2, two of the teachers reveal parents have no impact on their instructional decisions. One teacher shares some of her parents have no interest in education, while others have high expectations for their children to attend college. Those with high expectations may have an impact on her decisions to continue with SIM.

Regarding school culture, teachers in FGI share, overall, they feel supported in their use of SIM, but teachers in the larger schools may need to seek the support they need through interacting with those educators who are like minded. Teachers in the smaller schools felt a stronger sense of support. In FG2, comments regarding school culture which was coupled with administration reveal teachers feel supported, unaffected, or restricted.

As teachers discussed probing questions regarding school administration, school boards, parents, and school culture, none of the teachers felt strongly in a positive or negative way that these external factors have a major influence on their decisions to continue using the SIM project. 


\section{Question Three: Does Science in Motion help you meet your personal goals as a science}

teacher?

Responses to question three reveal specific personal goals teacher participants hold which are facilitated or enhanced through the SIM project. Every teacher in the PPQ and FG2 initially respond to question three with an unequivocal "Yes" Science in Motion does help to meet personal goals as a science teacher. Teachers then identify their personal goals, and explain how the project facilitates these goals. In the FG1 interview, teachers begin by sharing their personal goals, with “yes” being understood. Personal goals specifically identified broadly include: provide engaging activities for students, provide real world connections for students, maintain a dynamic curriculum, inquiry teaching strategies, and professional growth. The following paragraphs detail teacher responses to question three.

\section{Teaching Goal: Provide Engaging Experiences for Students}

Teachers identify a desire to provide engaging experiences for their students as one of their personal teaching goals. Within this broad category, teachers specifically identify a desire to inspire and facilitate student interest in science and learning:

I want students to get excited about science and have a great interest in learning science. (Tessa)

I need kids first and foremost to be interested in what they are doing. (Brian)

The students love the labs. SIM activities increase their enjoyment, their learning. (Marcy)

Show me something new, so I can find a way for my kids to like it. Let them have the element of surprise. (Barbie)

I want to inspire students. (Chuck) 
My goal as an educator is for my students to develop a love for science that will make them want to learn more. (Patty)

For some teachers, the SIM project is perceived as a vehicle to provide engaging opportunities that they and their students wouldn't have otherwise, which is a personal goal: The equipment brought new opportunity to me and my students and that was something as a classroom teacher I always looked for. (Kevin)

One of my personal goals is to allow students to have those experiences that they wouldn't have otherwise and may never again. SIM allows me to give kids those experiences. (Laurie)

Yes. To be able to use the equipment that they otherwise wouldn't be able to use. We certainly can't afford it with our budget. (Leslie)

SIM is perceived as a way to provide engaging activities which may encourage personal connections with learning and possibly pursue careers in science. During FG1, initiated by a probing questions, teachers share their desire to provide engaging opportunities in order to show their students they care about them as individuals. They also share their desire to show their passion in an effort to inspire students to find their own passion in life:

One of your personal goals is that you make a lasting impression on your students. What do you want them to remember? (Interviewer) That you cared. And when I say that, it's not caring microscopically about who they're dating, what they're doing, all that stuff, but you care about their future. You care that they're going to become a productive part of society. (Lucy) 
It's also important that they understand they could be passionate about something.

I mean, truly, that we are all passionate. I mean, I am passionate. I love biology. I have incredible passion. I just want kids to see my passion. (Sue)

And then, they might develop a love for science. (Marcy)

Yeah, passion. I mean, that's really what it is. (Lucy)

And even beyond science. (Marcy)

Yeah, it doesn't have to be science. (Lucy)

Later during the interview, Lucy shares more about passion and how her passion can be used to motivate students:

And also, some of them that would never have gone into science, go into your classroom and see something that you did and they see your passion, and their like, 'Wow' and they go in that direction, and you're amazed. And that's when you run into them and they say I'm doing something in science and I say, 'Really?' (Lucy)

Leslie talks about her passion and her desire to encourage her students find ways to think creatively:

I think part of the reason I use the program so the kids sort of know my passion for the content and I can show them that I am going outside of our school, so that they aren't afraid to step outside there little box, and pull different resources. (Leslie)

In a similar fashion, Patty believes the excitement she experiences has a positive impact on her students:

I enjoy learning and using the equipment myself. My excitement is then transferred to students which affects student learning. (Patty) 


\section{Teaching Goal: Real World Connections}

Teachers identify a desire to make real world connections for their students as a personal goal and share how SIM helps them achieve this goal. Teachers believe real world connections increase student interest, and make learning relevant:

SIM has helped me bring in equipment. Students are able to make real-world connections which increases their interest level. (Tessa)

Connect learning with the real world to keep current. Keep students connected. Keep learning relevant. (Chuck)

I did the SIM Heart Rate lab. I used to be a paramedic, so I taught my kids about the EKG sine wave, and what happens when there is a blockage in the heart. The students were like, Oh, I didn't know that! I didn't know this is what happens when you hear the 'lub-dub' (Sue)

Teachers believe real world connections expose students to opportunities beyond the classroom and want that for their students:

SIM allows them to see, 'Oh I could go into this or I could go into this,' so they realized that it isn't just this little tiny rural area and they have to stay. They can move on. By showing them all these different labs, they could think of something they could go into. SIM allows them to see, 'Oh, I could go into this or I could go into this.' (Lucy) And sometimes coming back to school to visit, they'll say, 'When we did this, that's what lead me to get interested in this, and now I'm studying this because of what we learned.' (Marcy) 
One teacher shares a story about her students and the paths they have chosen as they graduate due in part from SIM experiences and their real world connections:

The Science in Motion program has really increased the number that go into science. One of our past principles, when I first started, used to bring back previous graduates. $\mathrm{He}$ would ask: 'Where are you now?' and 'What did we do to prepare you?' And what was lacking in the very beginning was always science. And since I started working here, bringing these resources into the classroom has tremendously helped. I'd say, fifty percent are going into a medical profession or science. I don't think that they would be where they are, I would hope that they could be where they are, but I think SIM really helps sway their decisions, makes science more attractive. (Leslie)

Laurie reveals that her goal is to prepare her students for their future, whatever that may be: I am constantly being asked, 'Why do we need to know this?' and my answer to them always is, I don't know. I don't know what you're going to do with your life and neither do you, even though you think you do. I don't know why or if you will ever use this or if it'll come in handy, but I am preparing you for your future. (Laurie)

\section{Teaching Goal: Maintain a Dynamic Curriculum}

Teachers specifically mention different aspects of their curriculum as they discuss their personal goals. Teachers seek ways to expand, and improve their curriculum:

Yes, Science in Motion helps me reach my personal goals as a science teacher, by providing interesting labs for students which helps teachers to stretch academically. (Linda)

Yes. SIM allows me access to materials which give students better lab experiences. (John) 
Some teachers note their desire to change their curriculum:

Every year I do something differently. It's never the same. And the Science in Motion materials help me to do that. I can try something new. And sometimes, it's just looking at the list and saying, 'Hmm, I'd like to try that. I wonder if?' Just that sometimes it'd set a spark that starts me onto something. (Marcy)

In response to Marcy, Leslie links a dynamic curriculum with teacher and student interest:

I agree with that, with looking at the list, with the heart rate lab that someone had mentioned. I had no idea about it, but I was interested. It applied to what we were talking about. And yes, just keeping the curiosity open and having that transfer onto the kids is important. (Leslie)

\section{Teaching Goal: Inquiry Teaching Strategies}

Teachers report, either explicitly or implicitly, that a hands- on, inquiry approach to teaching is their preferred instructional style. As an instructional teaching goal, Science in Motion helps them meet this goal by providing laboratory activities:

I am an inquiry teacher, so I like to have a lot of hands-on. And, I think all of the materials that are available and the type of labs, they lead to so much. (Sue)

I want my students to get excited about science and have a great interest in learning science. One way that I learned over the years is to have hands-on, minds on projects such as lab activities. SIM has helped me bring in labs. (Tessa)

I believe in hands on science. (Patty)

During FG1, a discussion regarding inquiry methods took place. Specifically, their desire to provide learning opportunities that may have more than one correct answer. This instructional teaching goal helps them to achieve a learning goal they have for their students which is to 
develop science literacy and critical thinking skills. This is achieved in part by exposing students to learning experiences where multiple answers are possible, or multiple ways to achieve the same answer are accepted. The SIM project helps them to reach these goals by providing laboratory equipment and activities that support the development of science literacy and critical thinking skills. Below is the conversation regarding inquiry methods:

I am an inquiry teacher, so I like to have a lot of hands-on, but I don't like to do too much hands-on stuff where there's only one answer, or that you can't lead to something, you know, bigger. (Sue)

Well, when I first started teaching, I thought there had to be one right answer. But the longer that I've taught, the more I've gotten to be more like you (addressing Sue). You want those situations where there's multiple possibilities. And that sometimes makes the students a little crazy. But when they see that you're okay with that, you're accepting of that, then they're going, 'Okay, this classroom is all right.' To have a different interpretation, if it's logical, and it makes sense. (Marcy)

If they can validate it and back it up. And that's what you want kids to be able to do. To be able to use the information that they have and the data that they have and be able to make a logical argument for it. And that's what you want to push kids to do. (Sue) We run into a lot of that, I don't know if you use Study Island? Students get a wrong answer and then say, I thought that was right. And then I look at it yes it is right. There's a possibility that we might have more than one possible answer here. So you know they are getting used to not only having one answer to a problem. (Leslie) Stoichiometry. Okay, I always do it with the brackets set up and you fill in, and the kids would find ways to set up the problems and they'd set it up differently and get the 
same answer. And I always let them if they could prove it to me, and they have really creative ways! And I'd say, 'Show me how you got this?' and they would! When I started out I was real structured, and then I got laid back. And it was amazing. Just show me how you did it, so, yeah. (Lucy)

\section{Teaching Goal: Professional Growth}

Teachers share their desire to continue to grow and develop professionally as one of their personal teaching goals. In SC's statement above regarding keeping her curriculum dynamic, she actually begins with her desire to continue to grow professionally:

Well, I want to be a better teacher, and I think as a teacher you have to be willing to continue to learn and that was the opportunity that SIM provides. It helps me continue my education. (Marcy)

The professional development part of SIM helps me with aspects of my teaching as well.

To learn something new, a new lab, a new piece of equipment and how it works and what was available for me to use and that sort of thing. (Laurie)

Teachers share other aspects of the SIM project and professional development. One teacher credits the SIM project reaching out to her, facilitating professional growth:

The communications from the SIM staff alert me to educational opportunities, grant opportunities, guest speakers and various other science opportunities. This is greatly appreciated because with my loaded class schedule I do not have time to find these on my own. (Mary)

During FG2, the SIM project reaching out with professional opportunities is discussed:

When you're talking about personal goals too, it's kind of interesting because your emails that you send, usually you send something, and you're like, 'Hey, I just want to send you 
an email,' and they're not very regular and that actually is a good thing and it's usually something kind of cool and you're like, 'Hey, check this out' you know, and I'm like, 'Oh, wow, I should try that, you know.' (Brian)

The emails from you might not even give content, but it keeps you abreast of what's happening. I actually circle number two after you already went on and wrote, 'The mobile educator keeping in touch.' It's one of the things that probably, like if you never contacted me, you know, I might forget about it. (Laurie)

And in the same way, if you contact me all the time, you know, like some people do, you just start to avoid them. (Brian)

\section{Question Three Summary}

Teachers either explicitly or implicitly respond to question three with affirmation that SIM does help them reach their personal goals as a science teacher. SIM helps teachers reach personal goals related to what they want for their students, their teaching practices, and professional growth.

Personal goals related to students and student learning include student engagement and real world connections. Teachers have a strong desire to bring outside resources into the classroom. SIM provides these opportunities for teachers to incorporate engaging activities which teachers believe increases student interest, motivation and personal connections. In addition these engaging activities expose students to possible career paths in science. In FG1, a discussion about engaging activities reveals teachers want to share their passion for science, and in doing so encourage their students to find their passion in life be it in science, or some other path. The SIM project via instructional resources enable teachers to provide students with real world connections, which inspire student, and connect learning in the classroom with the world 
in which students live beyond the confines of the school building and the school day.

Personal goals related to teaching include a dynamic curriculum and inquiry instructional strategies. Teachers report they use the SIM program to expand and improve their curriculum. Some teachers report they enjoy the excitement of using new and different activities each year. SIM facilitates this by providing new labs and equipment on a yearly basis. Teachers either implicitly or explicitly report inquiry is an instructional teaching goal and SIM provides the hands-on materials which enable them to do so. These hands-on activities lead to interest, enjoyment and learning. Within FG1, during a conversation about hands-on activities, teachers prefer to engage students in activities that have more than one correct answer, with the goal to develop science literacy skills.

And finally, teachers report professional growth is one of their personal teaching goals. Teachers who participated in this study want to improve themselves as educators. SIM encourages professional growth through teacher workshops, and the embedded professional development via a teaching or team-teaching visit by the mobile educator. Teachers also report SIM reaching out in a user friendly fashion encourages them to use the project as a professional development tool whether it be a SIM workshop, or other professional opportunities SIM announces to the teachers in the service area on an irregular basis. 


\section{Question Four: Does your continued participation with SIM reflect your personal feelings}

about your teaching of science?

Teachers share thoughts regarding their continued participation with the Science in Motion project as it reflects their personal feelings about their teaching of science. Specifically, teachers share their feelings about: pedagogy, the process of instruction and curriculum, professional attitudes, student readiness, student motivation and inspiration, and specific teaching goals which include science literacy and life beyond the classroom.

\section{Feelings about Pedagogy}

Teachers share they feel inquiry is an important instructional technique. Teachers relate how Science in Motion facilitates inquiry teaching methods by providing resources. Some teachers specifically note that these resources would otherwise be out of reach:

I believe that science instruction should be student-centered and inquiry-based. SIM provides the resources necessary to teach this way. (Leslie)

I want to continue to use inquiry, and that's exactly the type of materials and lessons that are available through SIM. I will continue to participate because it gives me the ability teach the sorts of lesson that I want to, the more inquiry based lessons. (Laurie) I personally believe that students should experience science. I think that it is a hands on subject and should be taught/learned through actually doing/experiencing it. (Patty) Literally everything should be hands on. Inquiry; it's the most important thing to do with the thinking and the questioning, and the challenging. (Linda)

Yes, my continued participation with SIM reflects my personal feelings about teaching science. It gives me an opportunity to offer lab lessons that otherwise I wouldn't be able to do. (John) 
Yes, my continued participation with SIM reflects my personal feelings about teaching science. It's a great resource for lab experiences. (Linda)

\section{Feelings about the Process of Instruction and Curriculum}

Feelings about the process of providing instruction as well curriculum surface as teachers discussed how their continue participation with SIM reflects their personal feelings about science teaching. Teachers feel that teaching is a dynamic process in a constant state of renewal and change, and as such, so too is their curriculum:

SIM allows me to keep instruction relevant. SIM was the gateway to supplying these things to keep my students connected with current events. (Chuck)

There is a day I dream about, but you know how you do all this extra stuff and you're like, someday I'm just going to stop, but doing all these extra things it's good, we need it. (Brian)

Curriculum should be adaptable to keep with the changes and current trends in society:

I am not teaching anymore, but definitely, I would use SIM more today than I did originally, and I thought I was using it a lot. I think that science is changing so fast. And there is so much stuff out there. (Lucy)

I'm always looking for something new to keep myself and students on the cutting edge. (Kevin)

\section{Feelings about being a Professional Educator}

During question four discussions, teachers reveal feelings about themselves as professionals. Teachers have a desire to continue to grow professionally and network with other science educators. Participating in professional networks such as SIM reflects and supports these feelings: 
Teaching is very isolating. SIM gives us a chance to talk about science and teaching. It helps with the isolation, making connections and hearing what other teachers are doing. (Chuck)

During the all-day SIM seminars, you're just talking with each other. It's a great way to get new ideas, just being able to talk to someone who's already worked out those bugs. That just kind of makes teaching go a little bit more smoothly. (Barbie)

Just being a part of something and, in particular when you were having the SIM workshops sort of on a regular basis, there was a crew of people that, you saw them a couple of times a year and you were able to get some ideas from them and say, 'What are you doing for this and how did you use this in your classroom?' So that does, I think, help out a lot because you can talk to them. (Laurie)

\section{Feelings about Student Readiness to Learn}

Teachers, specifically those in FG1, speak of their feelings that students are coming into their classroom ill prepared to learn science. These teachers express their desire to provide opportunities, such as those provided through SIM, in order for their students to overcome these obstacles:

I still think my students are disadvantaged in that they don't have the outside experiences, literally, in the environment that I had when I was growing up. We want to be their foundation and give them what they need. We want to see them go places. (Marcy)

During this discussion Sue and Leslie shares their thoughts:

They don't come with much background, and you're giving them that experience, you're giving them that experience in the lab. (Sue) 
Yeah, I know at my school my kids don't have that at home, so we all try to be as approachable as we can be and give them what they need without overstepping boundaries. (Leslie)

Lucy shares how the experiences she provided in her classroom, helped her students later in life: They were asking me why, why, why last year. It just made me realize that the kids do not get to do the actual physical exploring stuff. I'll even talk to my son (former student) and he'll say something that we did in class that has made such an impact on him, and I'll go like, well, that's because you lived this way. He says, no, even when I'm talking to my friends, and we remember doing this or that and how much that has helped us later on. (Lucy)

\section{Feelings about Student Learning and Motivational Experiences}

Teachers share their personal feelings about their desire to provide engaging

opportunities for their students that will motivate and inspire. Their continued participation with SIM enable teachers to provide these opportunities for their students:

The Science in Motion materials spark the students' interest in science. (Marcy)

Students are excited on lab days but become increasingly excited when they know I am borrowing materials from SIM. (Mary)

You just got to love those aha moments where they're like, 'Oh!' and you can see the light bulb coming on. It's not coming from notes. It's something that they actually did. It's like, 'Oh, that's how it really works!' so that is very satisfying. (Barbie) Barbie's comments about the "aha moments" were followed by Brian's comment: And Jason described it as he saw nothing but teeth and gums, and you don't have to do any management, you know. The kids are $100 \%$ engaged and you're just kind of 
scooching them along. So it is a lot easier when they are engaged like that. It's fun. I mean, it's really good. (Brian)

Barbie then responds to Brian's comment with:

Yeah, where you have the students, who, you know, they just want to keep going and going and going, and it's like, 'We're on a time limit. We can't do this.' I feel bad, but we have to stop. (Barbie)

\section{Feelings about Teaching Goals: Science Literacy and Life beyond Classroom}

Teaching goals were frequently brought to the table as participants share their thoughts regarding the SIM project and ways in which their continued participation reflects their feelings about the teaching of science. Teaching goals include aspects of science literacy, with the ultimate goal for their students to have real world connections that last beyond the classroom experience. Teachers want their students to develop science literacy skills because they feel these skill will enable them to participate as productive, informed citizens in society:

I want my students to be prepared for the twenty-first century. (Tessa)

I think until the day I die, I will have my personal feelings about why I taught science; for the betterment of humanity. (Barbie)

SIM helps students to make connections with their everyday lives. It's the skills they learn that they might be able to use. (Marcy)

So now, when they read something, or like they hear something on TV, they're going, oh, yeah, I have that connection. (Sue)

I want to teach students about science. I want to teach them what science is and how it works. I want them to understand that whenever they read something that deals with science, they'll understand it. So I guess one of my personal goals as well, is to make sure 
that the kids understand what science is. SIM supports that and I will continue to use it for that reason. (Laurie)

I continue to utilize resources that will empower the students to understand how these disciplines can be integrated and how these disciplines can pave a path to a more scientific/technological world. (Leslie)

\section{Question Four Summary}

Teacher participants share specific feelings about their teaching of science as they address question four: Does your continued participation with SIM reflect your personal feelings about your teaching of science? Teachers feel inquiry instructional practices are important for student learning. For these teachers, the process of instruction and curriculum are both dynamic and as such are in a constant state of change and renewal as advances are made in science and technology. Reflective of their feelings of the dynamics within curriculum and instruction, teachers have a desire to continue to grow professionally, and make connections with other science educators to facilitate this process. Teachers also express their feelings that their students are ill-prepared for science instruction due to the lack of experiences they have encountered before they step into their classroom, both inside and outside of school. Teachers feel that in order to learn, in order to have a desire to learn, students need opportunities to be inspired and motivated. And finally, teachers want to prepare students for life beyond the classroom. Teachers feel it is important for students to develop science literacy skills that will prepare them for the real world, and perhaps make the world a better place for future generations.

Science in Motion is viewed as a resource which provides opportunities necessary to be the kind of science teachers they want to be. SIM provides resources for inquiry instructional practices. With the constant updating of equipment and laboratory activities, teachers are able to 
maintain dynamic instructional practices and curriculum reflective of changes and advances in science and technology. The professional development opportunities provide avenues for teachers to continue to learn, and network with other science teachers. Through SIM, teachers have the opportunities to motivate, and inspire students which in turn helps to develop science literacy and prepare students for life beyond the classroom. 


\section{Question Five: What is it about yourself that you believe causes you to continue to use the}

\section{SIM project?}

As teachers share and discuss question five, they reveal their personal beliefs and how SIM helps them to nurture and realize these personal attributes. Teachers share specific personal beliefs about student learning, beliefs about themselves as educators, and their curriculum. They also shared they believe the SIM project is user friendly, and as a result they have embedded SIM lab resources and activities within their curriculum. As this process has taken shape over the years, teachers have developed a personal connection with the project, sharing they feel a sense of ownership, empowerment and community.

\section{Beliefs about Learning: Personal Enjoyment}

Teachers believe learning should be engaging so that students experience personal enjoyment which in turn facilitates motivation and excitement about what they are learning. Below are some of the comments related to beliefs about student personal enjoyment of the learning experience, and their continued use of the SIM project:

SIM workshops and materials are the hook I can use to motivate students to learn science. (Marcy)

I want my kids to come in and you know, be excited. I just want them to be excited to come to class, you know, not feel like it's a drag. (Barbie)

Grades don't matter in the long run. I'm more concerned about students and inspiring them. (Chuck)

\section{Beliefs about Learning: Life beyond the Classroom}

Teachers ultimately believe student learning should last beyond the classroom experience. Teachers want to prepare students for their future, and believe learning should 
include engaging experiences that help students make connections with the real world. SIM does this by providing resources otherwise out of reach for these teachers and their students. Below are comments from teachers regarding beliefs about providing learning experiences that connect learning with the world beyond the classroom which can have a positive impact on students and their future:

I continue to use the project because I want the students to get the best experience possible. (John)

SIM provides a supplement that can be used to give my students a richer experience in science. (Kevin)

I want to make my class more applicable and do things that the kids haven't done before, and they think it is really cool. (Laurie)

SIM reflects the subject matter by keeping with current events and it keeps kids connected. (Chuck)

I want to provide my students with experiences that properly prepare them for their future. I think it is important that they know how to properly conduct an investigation.

It is equally important to understand how to use the required lab equipment. (Mary)

\section{Belief about being an Educator: Learning is a Life Long Process}

Throughout the interview, teachers discuss their desire to be life-long learners. This trend continues as they share what it is about themselves that causes them to continue using the SIM project:

I enjoying learning and using the equipment myself. (Patty)

There was a personal interest for me with the materials provided through SIM. (Chuck) 
The SIM workshops that I have participated in have helped me professionally to become a better teacher. I am committed to life-long learning. SIM can give me materials for the hands on practice that enables me to continue to learn and bring new approaches to my students. (Marcy)

I just want to try to be the best teacher that I can be and give my kids the best. (Barbie)

\section{Beliefs about Teaching: Curriculum is Dynamic}

Maintaining a dynamic curriculum is associated with life-long learning as teachers discuss what it is about themselves that keep them with the SIM project. Below are teacher comments regarding life-long learning and maintaining a dynamic curriculum:

I was always interested in new ideas and laboratories. (Linda)

I always want to continue to make my class better. (Laurie)

Below, Brian relates an analogy which eloquently expresses a desire to improve, and maintain a dynamic curriculum:

I read an analogy about a farmer and it was talking about why farmers plants seeds, you know, why they plow, till and fertilize. I mean, they do all this... with the expectation that they're going to get something. So I think basically what it comes down to is that we do it because we expect that we can be better. We expect that we can always yield some better results from our teaching. You just never arrive there because every year there's something you do better, or re-figure something out because you have a better perspective. So I think that's the biggest reason why I continue, because I know I can do better. (Brian) 


\section{SIM: Personal Connections}

As teachers share what it is about themselves they believe causes them to continue using the project, the user friendly nature of the project, and personal connections with SIM surface. One teacher sums up the user friendly nature of the project:

I'm all about the user friendliness. SIM is very user friendly. (Tessa)

During FG1, a discussion as question five was brought to the table begins with how the SIM resources have become embedded within their curriculum, in part because of the user friendly nature of the project. As this discussion evolves, teachers share about their sense of ownership and association with the SIM project and community at large:

I continue to utilize SIM because I know how to use it, the stuff that I keep bringing in, I've chosen to use because I'm familiar with it. I know it exists. It is part of what I do. I'd hate to think that I couldn't function without it, but... (Sue)

You wouldn't want to have to. (Lucy)

Yeah, I don't want to have to. And we change up something every year, and I change up some follow-up questions. What my kids do with that information, or what research they might do from that, but it's the guts of what I do. (Sue)

It's really easy to use and be familiar with it. It makes it easy to use. And I think it becomes your comfort zone. The more you use it, the more comfortable you are with it. (Lucy)

I feel like I'm part owner. You know it's weird to think, no, I'm not owner, like it's mine, but I feel like I'm a part of it because I use it so much. (Leslie) And it's like you're part of a clique or a fraternity or sorority that knows something that's really good, and like you're part of that group. (Lucy) 
During this conversation, teachers share how the user friendly nature of the project has encouraged them to embed the project resources within their curriculum. And as they embed the resources they still maintain a dynamic curriculum. With their frequent and long term use of the project, they have a sense of ownership and belonging to a professional community that facilitates preferred instructional practices. Along a similar thread of ownership, and belonging to a professional community, a PPQ teacher shares about how the project was an empowering resources while he was a classroom teacher as he shares his thoughts regarding question five: It was a resource I could access without going to my administration and hearing, 'Sorry, we don't have the money for that.' And that's powerful. When a teacher gets told no a few times, they tend to stop asking, and when they stop asking they start settling and loose interest, and that does not keep anyone on the cutting edge. So, I kept using SIM because it enhances the experience for my students and myself and I hear 'Yes' when I need a resource. (Kevin)

In addition to the SIM project being empowering, Kevin also speaks of the enhancing experience for his students as well as himself. The mutual benefit for teacher and students was mentioned by other teachers as well as they share their thoughts regarding question five:

It was good for the kids. It was good for me. I don't care about anything else. (Lucy) I enjoy learning and using equipment myself. My excitement is then transferred to students which affects student learning. (Patty) I love it when they say, 'I feel like a scientist!' (Laurie) Similar sentiments were also shared throughout the entire interview process. 


\section{Question Five Summary}

Teachers who participated in this research project believe student learning should last well beyond the classroom experience and believe in order to make a lasting impression learning should be engaging, and meaningful. This includes making real world connects to help facilitate interest which ultimately prepares them for their future. Teacher participants report they are lifelong learners and they believe the act of teaching is a dynamic process. As life-long learners, and the act of teaching being a dynamic process, teachers constantly strive to be better educators, continually improving their instructional practices. Teachers also share about the personal connection they feel with the SIM project as it has become embedded in their curriculum, and as they have become a member of the SIM community. Teachers share how this connection has given them a sense of ownership and empowerment. 


\section{Chapter V}

\section{Discussion of Data, Further Study and Concluding Thoughts}

\section{Introduction}

The purpose of this study is to seek an understanding which explains why teachers chose to initiate and then continue to use Science in Motion (SIM) services in the Clarion University of Pennsylvania (CUP) service area. A complete description of the CUP SIM project is detailed in Chapter One. The SIM project at CUP is a resource for secondary science teachers to enhance instructional practices. The project is funded through a state grant and is based on three goals: 1) provide state of the art scientific equipment, 2) provide curriculum aligned with state science standards and, 3) provide professional development for teachers to learn how to use the equipment and find ways to implement the laboratory activities provided through the project into their existing curriculum. The project provides three levels of service for the science classroom: 1) a teaching visit, 2) a team-teaching visit, and 3) a lab loan. Teacher professional development is offered through summer workshops. In addition, the teaching and team teaching visits offer a level of embedded PD as teachers develop a comfort and knowledge of the labs and equipment while in their own classroom. Over the years, several studies have been conducted to examine student achievement impact of the project, as well as student and teacher attitude surveys. However, an in-depth understanding regarding initial and sustained use from the perspective of the teachers in the CUP SIM service area who use the project on a regular basis was unknown. The project is not a top-down or required resources for teachers to use in their classroom, nor was it created at CUP as a grassroots initiative. Research shows us that a top down approach to innovations can be met with teacher resistance (Oloruntegbe, 2011; Richardson, 1998), while a 
"grassroots" bottom-up approach where teachers play an active role leads to teacher implementation (Ellis, 1995; Jones \& Eick, 2007; McCarthy, 2009, Richardson, 1998). Why then, do project users choose to use SIM?

Chapter Two details current challenges faced within K12 science education. Science education partnerships provide viable solutions to some of these challenges. In the case of SIM, resources typically out of reach for many school districts are provided so that students can experience science. This is especially true for schools in rural NWPA where budgets are limited and resources are few and far between. But ultimately, it is the teacher who decides what is taught in the classroom and the instructional method of delivery. Research shows us that teacher instructional decisions are heavily influenced by personal beliefs and values (Bandura, 1986; Ertmer; 2005; Hargraeaves, 1998; Nespor, 1987; Pajares, 1992). In order to understand what motivates a teacher to adopt and implement teaching and learning goals, as well as pedagogical styles, we need to uncover their beliefs about the teaching and learning process. This too is true if we are to understand how and why teachers select resources to enhance teaching and learning.

This study is based on the following research question: what are the reasons for project use reported by teachers who use the project on a regular basis in the CUP SIM service area? Sub questions are: 1) what was it about the teacher that encouraged her/him to become involved with the project, and 2) what is it about the teacher that encourages her/him to continue using the project? To examine these research questions, a qualitative research design was used. Details regarding the research design, interview questions and participant selection is detailed in Chapter Three. Two focus group interviews as well as a paper/pencil questionnaire were used to collect data. Twenty teachers were contacted to participate in this study. A total of fourteen teachers agreed to participate in this study representing $36 \%$ of the population of teachers who meet the 
criteria for this study. It is noted that the self-selection of these teachers may have created a bias in the research. Questions asked are: 1) what was it about you that encouraged you to initiate SIM services, 2) what are the factors that have encouraged you to continue using the SIM project, 3) does SIM help you to meet your personal goals as a science teacher, 4) does your continued participation with the SIM project reflect your personal feelings about your teaching of science, and 5) what is it about yourself that you believe causes you to continue to use the SIM project? Interview question one directly relates to research sub question one. Question two directly relates to research sub question two. Interview questions three, four and five solicit further personal information regarding teacher goals, feelings and beliefs which impact their professional decision making regarding the use of resources, such as SIM to enhance teaching and learning. Questions one through five are used to address the main research question for this study.

Data was micro-analyzed, and coded. Hyper Research software was used to organize codes into categories. A grounded theory approach was used to develop themes from the categories and codes. Chapter Four presents the data. Chapter Five includes a discussion of data as it relates to the research questions and review of relevant literature. Sub research questions are discussed first, which then lead into the main research question. This is followed by suggestions for further study and final thoughts.

\section{Research Sub Question One}

\section{What was it about the teacher that encouraged initial project use?}

Teachers provide a wealth of information with explicit thoughts regarding why they initiated SIM services revealing their perceptions of the SIM project, teaching, learning, as well 
as themselves. The following paragraphs provide a discussion which addresses research sub question one.

Teacher Perception of the SIM Project. Teachers initially were interested in the project because they perceived SIM to be a resource that could help them reach their teaching goals, their professional goals, and student learning goals. In addition to being perceived as a valuable resource, the project was user friendly making access to the resources easy. The laboratory activities are already aligned with state science standards, the materials are prepared and delivered to the teacher, and come with a mobile educator to set up and teach the lab if the teacher so desires. Accessing these resources only takes a request from the teacher, which is usually done via the internet and email exchanges. This is important because the literature does tell us that in order for teachers to implement new activities, they must not perceive the activity as an additional task (Lester, 2003). Other literature supports the notion that time is a limiting factor and can inhibit the implementation of new materials (Mitchell, 1998; Rogers, 2000; Luehmann, 2002). For some teachers, being familiar with the SIM staff encouraged them to use the project, as they had already established a positive working relationship with these individuals.

Beyond the user friendly nature, goals of the project are to provide research grade laboratory equipment and laboratory activities that are relevant to current "real world" science practices, aligned with science education standards and curriculum. Burruss also reported teachers who participate in the Alabama SIM project, a sister project modeled after SIM in Pennsylvania, found the labs made the learning experience more realistic for students (Burruss, 2011). By tapping into these resources free from any budget restraints, teachers saw an opportunity to provide these engaging learning experiences that otherwise were inaccessible, 
essentially providing learning and teaching opportunities which allowed them to "level the playing field" for themselves as educators as well as their students. Indeed the literature tells us that most successful schools are affluent and have access to resources (Martin et al., 2012) while socio-economically disadvantaged schools have limited resources and are left to teach with mostly didactic modes of instruction (Thadani et al., 2010). The school districts served by CUP SIM are relatively rural and economically disadvantaged. On average, approximately $43 \%$ of the students who attend schools within the CUP SIM service area are eligible for free or reduced lunch programs (PDE, 2012). While the CUP SIM schools are not affluent, the SIM project provides resources which socio-economically advantaged school districts are able to provide, in essence giving SIM school districts a level of equal opportunity. This "leveling of the playing field" is expressed by Laurie during the interview:

... our students in little rural western PA can have some of the same experiences and opportunities as somebody who lives in a rich school district. (Laurie)

One teacher shares that by using the SIM project resources she was able to effectively stretch her allotted school budget using the monies she saved on other materials. Herring also found similar sentiments from teachers who use the Alabama SIM project (Herring, 2009).

The professional development component of the project was attractive which facilitated initial use. The project provides workshops free of charge for teachers to learn about equipment and labs. The embedded professional development offered through teaching visits made the project especially attractive for teachers as they grapple with the challenges associated with learning new technology, and as they implement new activities into their curriculum. The embedded PD helps teachers more able to step into the unknown with a sense of comfort. Sue shares how the teaching visits enabled her to reach out and use the project: 
...The great thing about SIM is that there are people there that support you and teach you. (Sue)

The workshops along with the embedded PD together provided a professional learning community forum for teachers to share with their colleagues. This experience is supported by Darling-Hammond and Richardson who provide evidence that professional learning communities and job embedded PD does in fact encourage teachers to try out new instructional practices and develop self-confidence for sustained instructional changes (Darling-Hammond \& Richardson, 2009). Emo reported in her study that teachers need to be part of a socialprofessional outlet as they implement something new in the classroom (Emo, 2010). Chuck makes a statement about the need to connect with other science teachers:

Teaching is very isolating. Science in Motion gives me a chance to talk about science and teaching. SIM helps with the isolation - making connections and hearing what other teachers are doing. (Chuck)

Ultimately teachers perceived the project had potential to provide engaging inquiry experiences that could make learning personal and relevant, igniting interest and motivation. Research does show teachers are more willing to try new instructional practices if they believe it will benefit their students (Emo, 2010; Guskey, 2002; Richardson, 1998, Mouza, 2006). These engaging activities then could be used to develop a depth of understanding and science literacy skills. And, the laboratory experiences were viewed as relevant learning opportunities that could expose students to possible career interests in science.

Beyond the practical nature of the project as an attractive resource, teachers share about personal feelings and beliefs about teaching and learning which encouraged them to begin using SIM. 
Teacher Beliefs about Teaching and the Teaching Process. SIM teachers hold explicit as well as tacit beliefs about teaching and the teaching process. Their primary teaching goal is to prepare students for their future. This goal extends well beyond the confines of secondary education, encompassing life beyond the classroom. These teachers want their students to learn a set of skills they can take with them and use to function well in society. While this study did not focus on measuring these student skills, a study conducted on the Alabama SIM project did find that students who participate in the project did in fact have high science process skills (Lott, 2003). Teachers, first and foremost want to teach their students science literacy skills so that they can participate and make informed decisions as citizens as they become adults. This teaching goal is in line with the Benchmarks for Science Literacy (Rutherford, Ahlgren, et al., 1989) and the National Science Education Standards (NRC, 1996) and more recently the Next Generation Science Standards (NRC, 2013). These teachers want to give their students experiences that will prepare them for the "real world." Tessa states:

I want my students to be prepared for the $21^{\text {st }}$ century. (Tessa)

They want to teach students about the opportunities that exist in the realm of science and society, so that they can make informed decisions about possible career paths in science.

(SIM allowed me to) keep the kids knowing. They're going to be competing in the world... (SIM) made them aware of things.... (Lucy)

With limited resources and budgets, this primary teaching goal leads them to access resources outside the classroom. The literature does call for all stakeholders to find ways in which to overcome these obstacles (NRC, 1996). SIM is a vehicle for change these teachers believe can make a difference in their instructional practices. 
In addition to science literacy goals and possible science career opportunities teachers want to model behavior they believe is important for their students to adopt as they move through life. Passion, life-long learning, organizational skills, and moving beyond a comfort zone to solve problems are explicitly stated as teachers discuss their desire to be role models for their students. Below is an example where Leslie shares about her desire to model her passion and moving beyond her comfort zone for her students:

Part of the reason I use SIM is so the kids know my passion for the content and I can show them that I am going outside the school and what our school provides... so that they aren't afraid to pull from different resources. (Leslie)

Indeed, Hargreaves recognizes teaching as an act full of passion and where emotions are inseparable from moral purpose (Hargreaves, 1998). By accessing SIM resources these teachers model behaviors that enable them to reach their personal goals.

As teachers strive to reach their teaching goals, SIM teachers have clear ideas about the process of teaching. This process includes inquiry methods of instruction as a preferred pedagogical style. They believe is that inquiry invites their students to make personal connections with the learning process. Patty's comment clearly shows this belief:

I personally believe that students should experience science... SIM allows me to do just that. I truly believe that these types of experiences are much better ways for students to learn and appreciate science. My goal as an educator is for my students to develop a love for science that will make them want to learn more. (Patty)

For these teachers, hands-on instruction that includes up-to-date laboratory materials, and relevant science topics are preferred. Teachers who participate in the Alabama SIM project also report a positive attitude towards inquiry teaching and use technology frequently in their 
classrooms (Lott, 2003). In addition to up-to-date science materials, realistic or authentic science experiences are preferred to bring together science literacy with real world relevancy in a constantly changing environment:

I want to provide my students with authentic classroom investigations. (Mary) These teaching strategies are reflective of those encouraged in education reform documents such as the NSES and NGSS (NRC, 1996; NRC, 2013). While these documents call for such teaching strategies, research also shows us that teachers who embrace such pedagogical beliefs are more willing to select instructional resources that support these beliefs (Becker, 2001; Niederhauser \& Stoddart 2001; Squire, 2003).

In order to achieve these teaching goals, the SIM teachers who took part in this study believe curriculum and instruction should be dynamic. Bringing in new classroom resources is somethings these teachers actively seek to implement. Teachers with the Alabama SIM project also report the project is important for their curriculum as well (Herring, 2009). The dynamic nature of curriculum is to keep up with current trends and keep teaching relevant, but it also serves to maintain interest for both teacher and student:

I get excited when I see something new and I like to take that back to my students and hopefully the excitement will be there for them as well. (Laurie)

These CUP SIM teachers believe that being excited about the teaching process, and bringing excitement and a personal connection into their instructional practices helps to facilitate excitement and a personal connection for their students. Green and Palmer argue that these types of teaching practices are necessary to initiate change within the teacher and to inspire and motivate students (Green, 1971; Palmer, 1998). Emo found teachers who initiate instructional change did so out of a need to add to their own enjoyment of their work suggesting a need to 
keep instructional practices exciting and engaging for them and in turn for their students (Emo, 2010).

SIM teachers display a strong sense of professionalism and determination to achieve their teaching and learning goals. Teaching isn't just a job for them. It's viewed as something very important and taken very seriously. They greet obstacles such as restrictive curriculum due to standardized testing, and limited resources due to restrictive budgets with a sense of determination, creativity, and a positive attitude, remaining focused on their teaching and learning goals. Courson also found teacher implementers of a grant funded project which provided instructional resources were driven to explore new teaching tools because of their deep sense of professionalism (Courson, 2002).

Teacher Beliefs about Students and the Learning Process. Ultimately, the primary goal for these teachers focuses on their students and student learning. The literature is reflective of this, indicating teachers are in fact more willing to try new instructional practices if they believe it will benefit their students (Emo, 2010; Guskey, 2002; Richardson, 1998; Mouza, 2006). SIM teachers want to find ways to invite students to willingly participate in the learning process. For them learning, like teaching, is a personal endeavor. Hargreaves would agree as she presents teaching as emotional labor (Hargreaves, 1998). In order to invite students into their learning space, these teachers believe it is important to provide engaging experiences where students can make personal connections. They do this through inquiry instructional practices and when possible, lab activities that relate to the real world, and have relevance for the student. Once students are interested and motivated and willingly participating in the learning process, these experiences can lead to a depth of understanding: 
You have hands on where you sling things out and the kids are like, 'Whoa!' they are so engaged. The students are just into the learning activities, but to take that and then move into the direction of the content.... (Brian)

These CUP SIM teachers want the learning process to prepare students for their future as informed citizens capable of making decisions using science literacy skills, and by providing opportunities and knowledge of what may be available in terms of science career choices as they become adults. These teachers are concerned about their students and life beyond the classroom. Truly, the ultimate goal for these teachers is to leave a lasting positive impression upon their students:

(I want my students to know I) cared. (I) care about their future. (I) care that they are going to be a productive part of society. (Lucy)

With SIM in line with their teaching goals and a belief that the experiences could help them provide positive learning experiences for their students, coupled with the user friendly nature of the project, teachers decided to initiate SIM use.

\section{Research Sub Question Two}

\section{What was it about the teacher that encourages her/him to continue using the project?}

SIM is a Valuable User-Friendly Resource. Many of the stated reasons for initiating SIM use were restated as reasons for continued use. Mainly, the resources available are aligned with personal feelings and beliefs regarding their personal teaching goals. First and foremost, teachers have continued to use SIM over the years because it has proven to be a valuable resource that enhances the educational experience and helps them meet their teaching, professional development and student learning goals. The practical, user friendly nature of the 
project proved to be convenient and easy to access for teachers, facilitating and encouraging continued use. SIM brings the equipment to the teachers, provides embedded PD by request, and the labs are aligned with state science standards and aligned with existing curriculum. We also know from previous research that in order for teachers to sustain usage of an innovative practice, they need an opportunity to learn within the context of their teaching setting (Plummer \& Zahn, 2010). The teaching and team-teaching available through SIM does just that. The literature suggests varying amounts of time are needed for teachers to master new practice and sustained usage (Brinkerhoff, 2006; Darling-Hammond \& Richardson, 2009; Huziak-Clark et al., 2007; Sandholtz et al., 1997). Due to the nature of the SIM project, teachers are able to request teaching visits as often as they would like. The embedded PD is available for them on a continual basis.

SIM Expands the Curriculum. The project allows the teachers who participated in this study to expand their existing curriculum, and provide upper level science courses previously out of reach due to lack of resources. Teachers specifically state the variety and updating of equipment kept them coming back to the project for classroom resources. Some of the teachers specifically note the project has allowed them to teach advanced placement courses, previously out of reach for their school districts:

There's no way I could possibly buy the equipment for some of those labs that you need to do, that you are required to do. SIM has allowed me to have AP Biology. (Laurie) And, with an increase in student interest due in part to the lab experiences made available through SIM, there is a demand for advanced science course. Other science outreach partnership projects experienced increased student interest and motivation due to their participation in the 
projects (Craney, Mazzeo \& Kaye, 1990; Felix et al., 2004; Krieble \& Salter, 2008; Long, 2004; Peyrot \& Ziolo-Royer, 2006).

Ownership and Empowerment. Over the years the project has become embedded within their curriculum and instructional practices. And, the practical nature of the project coupled with the teachers and their strong commitment to reach their educational goals lead to something else which teachers described as empowering. While the teachers were not part of the development of the project, they have been given a voice and part ownership by actively participating in the selection process of new labs and equipment, and professional development opportunities. This voice and ownership is greatly appreciated by the teachers and strongly encourages them to continue tapping into this resource.

SIM would ask teachers in the spring what new equipment they would like to have SIM purchase. I always thought that was great. It empowered me to think of really cool things I wanted for me and my students and put that forward. (Kevin)

Over the years, their continued participation has deepened their sense of ownership:

I feel like I'm part owner. You know it's weird to think, no, I'm not owner, like it's mine, but I feel like I'm a part of it because I use it so much. (Leslie)

The aspect of ownership is key to teachers being willing to participate in a project designed for curricular innovations (Careless, 1999; Ellis, 1995; Jones \& Eick, 2007; McCarthy, 2009; Richardson, 1998). The project became personal for these teachers. This may be linked to their beliefs and feelings regarding their instructional decision making process, which the literature suggest has a considerable impact upon teachers (Bandura, 1986; Ertmer, 2005; Hargreaves, 1998; Nespor, 1987; Pajares, 1992). 


\section{Over-Arching Research Question: What is it about the Teachers that Encourages Use?}

The SIM resources and ease of use make it an attractive enhancement tool for teachers. Teacher goals, beliefs and feelings about teaching, the learning process, and what they want for their students are important for teachers as they initiate reaching out and implementing new resources in their classroom. But, there is more to this story. At the core of the over-arching research question and sub questions one and two, there was an attempt to develop a deep understand about this group of teachers, to uncover the characteristics these teachers possess which provides the fortitude and inspiration to go beyond what is necessary and expected. It is the, "What is it about these teachers?" which provided the impetus to initiate as well as continue using SIM. Discussing teacher goals are certainly valid reasons for initiating and continuing use of a teacher resource, but Green would argue there is a distinction between explaining behavior and giving reason for behavior. Explanations are such things as teacher goals, and provide justifications and reasons for a behavior, which in this case is teacher use of SIM. But to understand at a greater depth the cause of a behavior, we need to understand beliefs (Green, 1971). The following paragraphs address the over-arching research question: What are the reasons for project use reported by teachers who use the project on a regular basis in the CUP SIM service area? The paragraphs include assertions made about these teachers through data analysis.

\section{Reflective Nature of the SIM Frequent User Teachers}

One could argue that the teaching and learning goals of the SIM teachers who took part in this study are not unique. But there is something unique about the teachers that encourages them to reach beyond what is expected and available in the classroom to achieve their goals. Some of the teachers who participated in this study openly discussed personality characteristics they 
believe provides the impetus to reach out and include resources such as SIM as question one was brought forward regarding initial use of the project. Some teachers talk about not being afraid to show their weakness:

I really think it's your personality, that you're not afraid. You're willing to show your weakness. (Lucy)

Here, Lucy is speaking of being willing to show her weakness in front of another professional educator as well as her students. Another teacher shares she is willing to accept help via the embedded PD offered through the project, but specifies she is not comfortable showing her weakness in front of her students:

I would not have done that on my own because I don't like to fail in front of my students. (Barbie)

There exists varying levels of comfort with perceived weaknesses, but what does surface as we examine teacher responses is a reflective nature about their role as educators. There exists a level of reflection about themselves and their teaching. Both teachers here take their reflections and understandings and then find ways to grow and develop professionally, building on their strengths and improving upon their weaknesses. This type of reflectiveness was also reported in the literature as an impetus for a teacher seeking new instructional practices (Ritchie \& Rigano, 2002). The teacher, Mr. Volker, who took part in the research by Ritchie and Rigano (2002) was reflective of his teaching practices and was motivated to change in order to meet his professional goals. This reflective nature may also be linked to their commitment to life- long learning for themselves and a desire for their students to adopt this personal value. Research does show that what teachers believe and feel has a considerable impact on their instructional decision making process (Bandura, 1986; Ertmer, 2005; Hargreaves, 1998; Nespor, 1987; Pajares, 1992). 


\section{Teachers and Their Professional Attitudes}

These teachers share ideas which lead to the understanding that it is their strong sense of professionalism, which, in part, drives them to access resources for instruction:

I want to be the best teacher I can be and use things that have evidence they work...

When it comes down to it, I feel like we're at the front line and what we do is not the most glamorous job, but it is really important, and so I want to do the best I can. (Laurie) SIM frequent users time and time again share their commitment to grow professionally to meet their teaching and learning goals. In fact, throughout both focus group interviews, aside from addressing interview questions, these teachers were networking and sharing professional ideas with each other, demonstrating their desire to continue to grow professionally. Other research findings also show teacher professional attitudes impact implementation of instructional practices (Emo, 2010; Voogt, 2010). Their strong desire to make a lasting positive impression upon their students, and their resourceful nature woven together lead them to find ways to meet their goals in spite of the obstacles they may encounter within the confines of their classroom. Many of the teaching characteristics these teachers demonstrate align with what is recommended by science education reform documents, suggesting these teachers exemplify what good science teaching should embrace (NRC, 1996; NRC, 2013). And, many of them have been teacher leaders within their school districts, and have been involved with professional organizations.

\section{Life- Long Learning}

The study participant's drive for continued growth is for personal reasons, professional reasons, and to be a role model for their students: 
I think as a teacher you have to be willing to continue to learn and that was the opportunity that SIM provided. And, I think in some ways that provides a good role model for my students. (Marcy)

Teachers want to be life-long learners and hope to model that for their students so that they and their students can overcome obstacles, recognize and develop strengths and improve upon their weaknesses, knowing and understanding that learning is a continuous process that does not end with compulsory education. Not only do these teachers model this behavior and value for their students, they invite them to embrace these behaviors and values by showing their students their care and concern about them as individuals, because truly, these teachers aspire to leave a lasting positive impression on their students.

\section{Resourceful Problem-Solvers}

SIM teachers, time and time again through conversation and written word, demonstrate resourcefulness and problem solving characteristics which provide the fortitude to continue to strive and meet their personal goals as educators:

If I thought a lab was really cool that you had brought in, I would share it with all my classes just to give them the experience. Those days are done. If it doesn't match the curriculum map, I can't do it. That's why I do a lot of after school activities. It doesn't matter what curriculum I'm doing after school, I can do it. (Barbie)

They find ways to achieve their goals in spite of the external obstacles they encounter. During both focus group interviews, question two, where probing questions regarding external issues teachers may grapple with as they implement a teaching resource were brought forward, these teachers indicate administration, school culture, and parents had mild, little, or no impact on their decisions to use SIM. The literature suggests that these external factors may serve as barriers for 
teacher implementation if the innovation is not aligned with external goals such as school district appointed curriculum (Spitzer, 2004). However, Howard found that teachers who embrace student-centered instructional practices also exhibit risk-taking behaviors (Howard, 2009). Perhaps the fortitude exhibited by these teachers encourages them to be risk-takers. It is important to note that SIM activities are aligned with state science curriculum standards. Other studies found evidence that teachers use resources that support their curriculum (ChanLin et. al., 2009; Sonmez \& Haury, 2011). SIM teachers simply find ways to support and achieve external curricular goals set forth by their school districts, as well as their personal teaching goals.

Part of the resourceful nature of these teachers encourages them to seek outside resources for their instructional practices. In fact, SIM was found to be one of many instructional resources many of these teachers access on a regular basis. SIM is just one tool in their teacher tool box. This group of teachers is involved with other grant projects, and they often tap into other resources and teacher support systems to reach their goals.

\section{Teacher Beliefs about Students and Student Learning}

Palmer speaks of identity and integrity in teaching, where teacher, students, and subject are connected, where the teacher is truly present and engaging as to inspire and motivate their students (Palmer, 1998). There is a recognition and adoption of this philosophy by the study participants. They believe they must be truly engaged, and excited so that their students can become engaged and excited as well:

I enjoy learning... My excitement is then transferred to students which affects student learning. (Patty)

These teachers reflect upon learning goals, science literacy, and opportunities to level the playing field. Reflection and strong determination lead them to provide opportunities which expose 
students to real world connections, making learning relevant for their student in order to spark interest. But, for these teachers there seems to be a greater sense of responsibility towards their students. Repeatedly they talk about their strong desire to make a lasting positive impression. They discuss the lack of readiness to learn when their students step into their classrooms. They talk about care and concern about their students as individuals. There is a strong sense of commitment to the nature of being human and the need to make personal connections that permeates their teaching goals.

It's important that they understand they could be passionate about something. I mean, truly, that we are all passionate.... (Sue)

Perhaps this is what Nespor was suggesting when she states, "To understand teaching from teachers' perspective we have to understand the beliefs with which they define their work" (Nespor, 1987, p. 323). From their perspective their responsibility is truly to prepare their students for life beyond the classroom, leaving a lasting positive impression for them to draw from as they move through life. Science literacy and possible science careers are important, but so too is the personal positive connection to learning and growing as individuals. They care deeply for their students, and they want to help their students make meaningful connections with the learning experience.

\section{Summary}

What is it then, about these teachers that encourages them to use the resources and tap into the professional development offered through the SIM project? It appears to be the dynamics which exist between the project itself in regards to being user friendly, the empowerment and ownership that has been created between the project and the teachers, in conjunction with teacher goals and beliefs and their fortitude to meet these goals that provides the impetus for project use. 
These teachers are highly motivated to find ways to meet their goals and purpose as educators. The SIM project provides a positive experience which facilitates many aspects regarding what they value as educators.

There also exists tacit beliefs which these teachers possess that help us to develop a deeper understanding of the "What is it about these teachers" that encourages them to go above and beyond what is expected. These teachers are reflective about their teaching practices and strive to continue to grow and learn in order to be better teachers. They maintain strong professional attitudes, and are focused on achieving their goals. Life-long learning is something they practice so that they can reach their professional goals and constantly improve their teaching practices. These teachers are determined, and focused finding ways to meet their professional goals in spite of obstacles they may encounter. They don't take "no" for an answer. And all of these characteristics are to support what they want for their students and their beliefs regarding how to achieve their goals. Maintaining a dynamic curriculum and continual professional growth and learning keep teaching exciting for them, and they believe that excitement can then be there to spark interest for their students. For these teachers, ultimately they want their students to have experiences that will have a lasting positive impact that includes not only learning science literacy skills, but validates their human nature, and encourages them to find their passion in life.

\section{Further Study}

There are topics which surfaced during data analysis that warrant further study. The following paragraphs explore possible research questions and avenues of study which were gleaned from this research. 


\section{Teacher Users verses Non-Users}

Interesting to note, both focus groups initiated unsolicited conversation regarding teachers who do not use the SIM project within their schools. Teacher thoughts in FG1 indicate they are puzzled why their colleagues do not use the project:

It's not that time consuming to use the project. Maybe it's just that some people think that it's too much. (Sue)

I don't know how many times I've said, this is my best resource. I don't know if they think it requires too much time.... (Leslie)

They also share their disappointment and provide thoughts which may shed some light regarding non-use:

I'm so disappointed in the ones that don't use it. You know in your own building you have teachers who have taught the same thing over and over. You know they have the same lesson plans. Some of them are so stagnant. (Lucy)

I think maybe they get stuck and want to keep doing what they are doing. (Leslie)

One teacher provides her insight which she believes might be part of the reason why some teachers in her building don't use SIM:

It's just what they believe is more important. Because, they believe they are doing a good job. But they aren't really stretching themselves in certain ways. Their belief is that using something different is invasive or it's not going to be any better than what they're already doing. I think it's their inability to try to achieve something different verses the kids have to know this. (Sue) 
Sue provides additional possible reasons for non-use suggesting perhaps these teachers have not had experiences using the resources such as those available through SIM, or that their teacher preparation programs were lacking.

In FG2 a similar conversation takes place:

I'm always trying to get those teachers that are lacking in enthusiasm to get involved with things, so I'll say, 'Don't forget to call SIM.' (Barbie)

Why do you think they don’t use SIM? (Interview)

Well, I think they have a different mindset. I'm goal oriented and I want to make these kids successful. I don't care that much about what that standardized test does. I just want to make it better for the kids... The other teachers are definitely very test oriented. (Barbie)

These conversations with the teacher frequent users of the SIM project in regards to their teacher non-user counterparts lead to questions for further study. It would be interesting to seek an understanding which explains why teachers do not use SIM. What are their teaching and student learning goals? And, how do their teaching and learning goals compare to SIM frequent users?

\section{Teacher Users}

As the data regarding teacher users was analyzed, it was discovered that these teachers possess qualities and characteristics often described as "exemplar" in well-respected science education documents and other literature. It would be worth further study to attempt to understand if these characteristics are learned through experiences, are personality characteristics, or both? If they are personality characteristics, perhaps a survey could be developed to recognize pre-service teachers with similar characteristics to recruit into science 
education programs. If the characteristics can be learned through experiences, what are those experiences and how do we embed them in the teacher preparatory programs as well as professional development opportunities for in-service teachers?

\section{Student Achievement}

The literature indicates partnership projects such as SIM, can and do have a positive impact on student achievement (Burress, 2011; Felix et al., 2004; Herring, 2009; Lott, 2002; Mitchell, 1998; PDE, 2006; PDE, 2008; Thandani et al., 2010). This is in addition to positive effects on science literacy skills (Bell et al., 2003; Colley, 2001; Lott, 2002; PDE, 1998; PDE, 2008; Spuck, 2005) and interest and motivation (Craney, Mazzeo, \& Kaye, 1996; Felix et al., 2004; Long, 2004; Peyrot \& Ziolo-Royer, 2006). While these teachers did discuss the importance of science literacy and student interest and motivation, what I found interesting was the absence of any discussion about student achievement per se. Teachers did not report achievement as something that motivates them to use the SIM project. However it was very clear they were deeply concerned about their students having real world connections and opportunities that could impact their learning in a positive manner, as well as their ability to function well in life. It was interesting what they had to say about student assessment when they did discuss it:

I definitely want my students to know that life is not all about just standardized testing. (Barbie)

There's this body of content that of course everybody loves to get assessed on, but we know it's only useful when you go and apply it. (Brian)

Grades don't matter in the long run. I'm more concerned about students and inspiring them. (Chuck) 
There is almost a palpable disdain regarding ways in which student achievement is measured and valued. However, it is very clear that these teachers possess qualities which the education arena would consider exemplar. How could these exemplar teachers have such a distaste for the commonly accepted and used means of student assessment? Further, do we as an educational system measure what we value? Or, are we coerced in some fashion to place unwarranted value on a test score? What is a better indicator of student achievement, a standardized test score, or the impact and knowledge the student takes with them after the classroom experience is over? It would be interesting to explore what we as an educational system consider to be valuable experiences and then find meaningful ways in which to measure those experiences. It would be a safe assumption based on the comments from these teachers that what is currently in place is only minutely valuable and meaningful at best.

Aside from the philosophical questions generated regarding standardized testing, and the absence of student achievement as a reason for SIM use reported by frequent SIM users, further study is warranted in this area. Both Lott and Herring found the Alabama Science in Motion program has a positive impact on student achievement (Lott, 2002; Herring, 2009). Several studies have been conducted by the SIM consortia demonstrating a positive impact on student achievement as a result of participating in SIM labs (PDE, 2006; PDE, 2008). It would be interesting to examine achievement comparing students from different socio-economic backgrounds serviced by SIM. What is the impact on student achievement from SIM sites that service schools in more affluent areas compared to SIM sites in socio-economically challenged areas? 
Further, SIM frequent users in this study identified life beyond the classroom as a reason for SIM use. This sort of student achievement could be examined through longitudinal studies on former SIM students who select a science major in college and career choices in science.

\section{The Role of the Mobile Educator}

During the interviews, the mobile educator was often mentioned as an important factor for project use:

Really, it was the enthusiasm of the mobile educator that got me involved. (Barbie) There is evidence that embedded PD, which is provided by SIM via the mobile educator, is an important factor which encourages teachers to implement new technology and learning experiences in the classroom (Darling-Hammond \& Richardson, 2009). It would be of value to understand at a greater depth the qualities of the mobile educator which encourage teachers to reach out. It would also be valuable to examine the roles and perceptions of the mobile educators at the other SIM sites in Pennsylvania regarding their role in the SIM program.

\section{The SIM Consortia in Pennsylvania}

And, finally, the CUP SIM project is only one SIM site within the SIM Consortia in Pennsylvania. To paint a complete picture of the PA SIM program, this study should be conducted at each SIM site.

\section{Final Concluding Thoughts}

We know what is necessary to provide a solid education in science which leads to science literacy. The reality is, many school districts are unable to provide the instructional resources necessary to provide students with the opportunities and experiences which lead to a depth of understanding and appreciation of science. Reform documents provide viable solutions to meet the challenges of these short comings, which include the idea of science outreach partnerships in 
order to bridge the gap. Many partnership models can and do facilitate what is necessary to provide a quality science education. The SIM project at CUP is one such project. However, we know that it is the teacher who ultimately decide what sort of instructional practices happen in their classroom. Due to the nature of the project design, teacher participation is voluntary. The successful implementation of the project into the secondary science classrooms in NWPA is largely due to something special about the teachers who use the project. It is also due to the user-friendly nature of the project coupled with easy access and the support teachers need to implement new technologies in their classroom. Over the years these teachers have an established voice and ownership within the CUP SIM project. And most importantly, it is the teachers themselves that lead us to a depth of understanding regarding project use. It is their teaching and learning goals, their commitment to life-long learning, their strong sense of professionalism, and ultimately their desire to leave a lasting positive impact on their students which drives them to reach beyond what is necessary and expected to achieve something better, worthwhile and long lasting.

\section{A Letter to Stakeholders and Policy Makers in the U.S.}

Based on years of professional experience and formal education within the science education arena, coupled with my examination of the relevant literature, and conducting this study, it is the conclusion of this study that the positive impact upon students, due to the opportunities provided by SIM coupled with the fortitude these teachers possess is worthy of recognition, merit and ultimately support. The project is an example of an innovative approach to solving and overcoming inequalities in the education system, and SIM is a cost effective way to provide these resources. Evaluations, and studies conducted over the years have demonstrated program worth time and time again (Mitchell, 1998; Mulfinger, 2004; PDE, 1998; PDE 2006; 
PDE. 2008; Spuck, 2005). However, the program exists as a political pawn subject to the whims of elected officials. While most outreach and grant funded programs have a life expectancy, what would it take to elevate successful programs to a permanent status? What does it take at the state legislative level to ensure such programs are provided the necessary funding on a continual basis so that students across the commonwealth have equal access to quality, meaningful educational experiences? It is my hope this study demonstrates even more evidence and support to persuade state officials and politicians to find ways to ensure the SIM program continues on a permanent, fully funded basis. 


\section{References}

Bandura, A. (1986). Social foundations of thought and action: A social cognitive theory. Englewood Cliffs, NJ: Prentice Hall.

Beamer, T., Van Sickle, M., Harrison, G., \& Temple, G. (2008). Lasting impact of a professional development program on constructivist science teaching. Journal of Elementary Science Education, 20(4), 49-60.

Becker, H. (2001). Computer use by teachers: Are Cuban's predictions correct? Paper presented at the annual meeting of the American Educational Research Association, Seattle, WA.

Bell, R., Blair, L., Crawford, B., \& Lederman, N. (2003). Just do it? Impact of a science apprenticeship program on high school inquiry. Journal of Research in Science Teaching 40(5), 487-509.

Burruss, L. (2011). Exploring professional development experiences: Teachers' and facilitators' perceptions of Alabama science in motion. (Doctoral Dissertation) University of Alabama, Tuscaloosa, Alabama. (3478678)

Brinkerhoff, J. (2006). Effects of a long-duration professional development academy on technology skills, computer self-efficacy, and technology integration beliefs and practices. Journal of Research on Technology Education, 39(1), 22-43.

Bybee, R. (1991). Science-Technology-Society in science curriculum: The policy-practice gap. Theory Into Practice, XXX(4), 294-302.

Bybee, R. (2010). Advancing STEM education: A 2020 vision. Technology and Engineering Teacher, September, 30-35.

Carless, D. (1999). Factors affecting classroom implementation: Task-based curriculum renewal in Hong Kong. International Journal of Educational Reform, 8(4), 374-382.

ChanLin, L., Hong, J., Horng, J., Chang, S., \&Chu, H. (2006). Factors influencing technology integration in teaching: a Taiwanese perspective. Innovations in Education and Teaching International, 43(1), 57-68.

Charmaz, Kathy (2006). Constructing Grounded Theory A Practical Guide Through Qualitative Analysis. Thousand Oaks, CA. Sage Publications Inc.

Craney, C., Mazzeo, A., \& Lord, K. (1996). A high school-collegiate outreach program in chemistry and biology delivering modern technology in a mobile van. Journal of Chemical Education, 73 (7), 646-650. 
Cochran-Smith, M., \& Lytle, S. (1990). Research on teaching and teacher research: The issues that divide. Educational Researcher, 19(2), 2-11.

Cole, D., Buehner-Brent, L., Dollhopf, W., Laux, L., (1991). Collaborative agencies efforts: An essential ingredient for successful science programs. Education, 111(3), 313-324.

Colley, K. (2001). Technology based learning: Using water studies as the basis for an alternative teaching strategy. The Science Teacher, 49-52.

Courson, K. (2002). Stories of teaching biotechnology: A case study of volitional curriculum implementation. Annual conference of the National Association for Science Teaching, New Orleans, L.A.

Cuban, L. (1986). Teachers and machines: The classroom use of technology since 1920. New York, NY, Teachers College Press.

Darling-Hammond, L., \& Richardson, N. (2009). Teacher learning: What matters? Educational Leadership. 66(5), p46-53.

Dawkins, K. (2002). Earth-view: Using high tech and low tech in a field course for teachers. Paper presented at the Conference on K-12 Outreach from University Science Departments, hosted by The Science House, NCSU, Raleigh, NC.

Ellis, J.D. (1995). Fostering change in science education. In innovating and evaluating science education: NSF evaluation forums 1992-94 (NSF 95-162). Washington, DC: National Science Foundation.

Emo, W. (2010). Teachers who initiate curriculum innovations: Motivations and benefits. (Unpublished doctoral dissertation) University of York, York, United Kingdom.

Ertmer, P. (2005). Teacher pedagogical beliefs: The final frontier in our quest for technology integration? Educational Technology Research and Development, 53(4), 25-39.

Ertmer, P. \& Ottenbreit-Leftwich, A. (2010). Teacher technology change: How knowledge, confidence, beliefs, and culture intersect. Journal of Research on Technology in Education, 42(3), 255-284.

Felix, D., Hertle, M., Conley, J., Washington, L., \& Bruns, P. (2004). Assessing precollege science education outreach initiatives: A funder's perspective. Cell Biology Education, 3, 109-195.

Fullan, M.G. with Stiegelbauer, S. (1991). The new meaning of educational change, $2^{\text {nd }}$ ed. New York; Teachers College Press.

Gaff, J., Ratcliff, J. \& Associates (1997). The Handbook of the Undergraduate Curriculum. John Wiley \& Sons, San Francisco, CA, 476-492. 
Garet, M., Porter, A., Desimone, L., Birman, B., \& Yoon, K. (2001). What makes professional development effective? Results from a national sample of teachers. American Educational Research Journal, 38(4), 915-945.

Gay, L., \& Airasian, P. (2000). Educational research competencies for analysis and application, sixth edition. Von Hoffmann Press, Inc.

Green, T. (1971). The activities of teaching. New York: McGraw-Hill.

Guskey, T. (2000). Evaluating professional development. Thousand Oaks, CA: Corwin Press.

Guskey, T. (2002). Professional development and teacher change. Teachers and teaching: theory and practice, $8(3 / 4)$

Hargreaves, A. (1998). The emotional practice of teaching. Teaching and Teacher Education, 14(8), 835-854.

Herring, P. (2009). An assessment of the impact of a science outreach program, science in motion, on student achievement, teacher efficacy, and teacher perception. (Doctoral Dissertation) University of Southern Mississippi, Hattiesburg, Mississippi. (3367174)

Howard, Sarah K. (2011). Affect and acceptability: exploring teachers' technology-related risk perceptions. Educational Media International, 48 (4), 261-272.

Hurd, P.D. (1991). Issues linking research to science teaching. Science Education, 75(6), 723732.

Huziak-Clark, T., Van Hook, S. J., Nurnberger-Haag, J., \& Ballone-Duran, L. (2007). Using inquiry to improve pedagogy through k-12/university partnerships. School Science and Mathematics, 107(8), 311-324.

Jones, M. \& Eick, C. (2007). Providing bottom-up support to middle school science teachers'reform efforts in using inquiry-based kits. Journal of Science Teacher Education, 18, 913-934.

Klieger, A., \& Bar-Yossif, N. (2011). Professional development of science teachers as a reflection of large-scale assessment. International Journal of Science and Mathematics Education, 9, 771-791.

Krieble, K., \& Salter, C. (2008). Promoting science via an equipment loan outreach program. The Physics Teacher, 46, 296-299.

Lester, J. (2003). Planning effective secondary professional development programs. American Secondary Education, 32(1), 49-61. 
Long, G. (2004). Mobile chemistry laboratory: Outreach to high schools. Proceedings of the conference on k-12 outreach from university science departments. The Science House, North Carolina State University, 50-55.

Lott, K. (2002). Evaluation of a statewide science inservice and outreach program: Teacher and student outcomes. (Doctoral Dissertation) Auburn University, Auburn, Alabama. (3057153)

Loucks-Horsely, S., Hewson, P., Love, N., \& Stiles, K. (1998). Designing professional development for teachers of science and mathematics. Thousand Oaks, CA: Corwin Press.

Lowther, D., Inan, F., Strahl, D., \& Ross, S. (2008). Does technology integration "work” when key barriers are removed? Educational Media International, 45(3), 195-213.

Luehmann, A. (2002). Understanding the appraisal and customization process of secondary science teachers. Paper presented at the annual meeting of the American Educational Research Association: New Orleans, LA.

Luehmann, A. (2007). Urban Students and School Science: Out-of-School Inquiry as Access. Paper presented at the annual meeting of the National Association for Research in Science Teaching, New Orleans.

Luehmann, A. \& Markowitz, D. (2007). Science teachers' perceived benefits of an out-ofschool enrichment programme: Identity needs and university affordances. International Journal of Science Education, 29(9), 1133-1161.

Martin, M, Mullis, I.V.S., Foy, P., \& Stanco, G. (2012). TIMSS International Results in Science. Chestnut Hill, MA: TIMSS \& PIRLS International Study Center, Boston College.

Mazuzan, G. (1994). NSF 88-16 A Brief History. www.nsf.gov/pubs/stis1994/nsf8816/nsf8816.txt - 89k - 1998-10-15.

McCarthy, T. (Ed.). (2009). Implementing curriculum change: A "bottom-up" approach. In A.M. Stoke, JALT2008 Conference Proceedings. Tokyo: JALT.

Mitchell, D. (1987). Central Pennsylvania Chemistry Teachers Science Education Improvement Project. Juniata College, Huntingdon, PA.

Mitchell, D. (1998). Juniata college science outreach program. Council on Undergraduate Research Quarterly, 15-20. 
Moskal,B., Skokan,C., Kosbar, L., Dean, A., Westland, C., Barker, H., Nguyen, Q., \& Tofoya, J., (2007). K-12 Outreach: Identifying the Broader Impacts of Four Outreach Projects. Journal of Engineering Education, 173-189.

Mouza, C. (2006). Linking professional development to teacher learning and practice: A multicase study analysis of urban teachers. Journal of Educational Computing Research, 34(4), 405-440.

Muijs, D., \& Reynolds, D. (2002). Teachers' beliefs and behaviors: What really matters? Journal of Classroom Interaction, 37(2), 3-15.

Mulfinger, L. (2004) What is Good Science Education, and Whose Job Is It to Support It? Conference on K-12 Outreach from University Science Departments: 2004. The Science House, NCSU, Research Triangle Park, NC.

Mulfinger, L. and D. Mitchell (2005). Science in motion and advancing science 2004-2005 program report. Huntingdon, Juniata College.

Murnane, R., \& Raizen, S. (1988). Improving indicators of the quality of science and mathematics education in grades K-12. Washington, DC: National Academy Press.

National Academy of Science (2007). Rising above the gathering storm: Energizing and employing America for a brighter economic future. Washington DC: National Academies Press.

National Academy of Science (2010). Rising above the gathering storm, revisited; Rapidly approach category 5. Washington DC: National Academies Press.

National Center for Education Evaluation (1983). A Nation at risk: An imperative for educational reform. http://datacenter.spps.org/uploads/SOTW_A_Nation_at_Risk_1983.pdf accessed 12/6/2012.

National Center for Educational Statistics. Digest of Educational Statistics: 2009. http://nces.ed.gov accessed 1/24/2013.

National Center for Educational Statistics. U.S. Department of Education. http://nces.ed.gov

National Research Council (1996). National science education standards. Washington, DC: National Academies Press.

National Research Council (2011). A framework for k-12 science education: Practices, crosscutting concepts, and core ideas. Washington, DC: National Academies Press.

National Research Council (2013). Next generation science standards: For states, by states. Washington, DC: The National Academies Press. 
National Science Foundation (1999, February 18). Graduate Science, Math, Engineering, and Technology Students Can Become K-12 Teaching Fellows. http://www.nsf.gov/news/news_summ.jsp?cntn_id=102973

Nespor, J. (1987). The role of beliefs in the practice of teaching. Journal of Curriculum Studies, 19(4) 317-328.

Nelson, G., \& Landel, C. (2006). Chapter 14: The Importance of Partnerships in Science Education Reform. Teaching in the $21^{\text {st }}$ Century. NSTA press.

Niederhauser, D.S., \& Stoddart, T. (2001). Teachers' instructional perspectives and use of educational software. Teaching and Teacher Education, 17, 15-31.

No Child Left Behind (NCLB) Act of 2001, Pub. L. No. 107-110, § 115, Stat. 1425 (2002).

Oloruntegbe, K. (2011). Teachers' involvement, commitment and innovativeness in curriculum development and implementation. Journal of Emerging Trends in Educational Research and Policy Studies, 2(6), 443-449.

Pajares, M. F. (1992). Teachers' beliefs and educational research: Cleaning up a messy construct. Review of Education Research, 62, 307-332.

Palmer, P. (1998). The courage to teach: Exploring the inner landscape of a teacher's life. San Francisco: Jossey- Bass.

Patton, M. (2002). Qualitative research \& evaluation methods $3^{\text {rd }}$ edition. Thousand Oaks: Sage Publications Inc.

Pennsylvania Department of Education (1998). Pennsylvania's Science Partnership Feasibility Study. PDE, 333 Market Street, Harrisburg, PA.

Pennsylvania Department of Education (2002). Academic Standards for Science and Technology Education. http://pde.state.pa.us/stateboard_ed/cwp/view.asp?Q=76716.

Pennsylvania Department of Education (2006). Science in motion annual program report 20052006.

Pennsylvania Department of Education (2008). Science in motion annual program report 20072008.

Pennsylvania Department of Education (2009). Academic standards for science and technology and engineering education. http://pde.state.pa.us. 
Pennsylvania Department of Education (2012). National school lunch program. http://pde.state.pa.us.

Peyrot, M., \& Ziolo-Royer, M. (2006). Impact of a hands-on science outreach program on student interest in science. Paper presented at the MSP Evaluation Summit II. Minneapolis, MN.

Powell, J., \& Anderson, R. (2002). Changing teachers' practice: curriculum materials and science education reform in the USA. Studies in Science Education, 37, 107-136.

Reinhart, J., Thomas, E., \& Toriskie, J. (2011). K-12 Teachers: Technology use and the second level digital divide. Journal of Instructional Psychology, 38(3), 181-193.

Richardson, V. (1998). How Teachers Change: What will lead to change that most benefits student learning? http://www.ncsall.net/index.html@id=395.html accessed 10/9/2013

Ritchie, S. \& Rigano, D. (2002). Discourses about a teacher's self-initiated change in praxis: storylines of care and support. International Journal of Science Education, 24(10), 10791094.

Robblee, K. (2000). Quantum science in secondary chemistry: Influence of teachers' beliefs and knowledge on the use of interactive computer models. (Doctoral Dissertation). Boston, University, Boston, MA. (9953776)

Roerig, G. \& Garrow, S. (2007). The impact of teacher classroom practices on student achievement during the implementation of a reform-based chemistry curriculum. International Journal of Science Education, 29(14), 1789-1811.

Rogers, P. (2000). Barriers to adopting emerging technologies in education. Journal of Educational Computing Research, 22, 456-472.

Ruby, A. (2006). Improving science achievement at high-poverty urban middle schools. Wiley InterScience. www.interscience.wiley.com.

Rutherford, F., Ahlgren, A., Warren, P., Holmes, C., \& McCutchoen, G. (1989). Project 2061: Science for all Americans. Washington, D.C.: American Association for the Advancement of Science.

Sandholtz, J., Ringstaff, C., \& Dwyer, D. (1997). Teaching with technology: Creating studentcentered classrooms. New York: Teachers College Press.

Shulman, L. (1986). Those who understand: Knowledge growth in teaching. Educational Researcher, 15(2), 4-14. 
Sonmez, D., Haury, D. (2011). The bridge between motivation and implementation; An inside look at professional development. A.U. Journal of Education, 40, 353-362.

Spitzer, B., \& Stansberry, S. (2004). Public school teacher use of instructional technology from an organizational culture perspective: An explanatory case study of two middle schools. Paper presented at the Association for Educational Communications and Technology.

Spuck, K. (2005). Successful implementation of the Pennsylvania science in motion program: Exploring the impact of the PA science in motion program in the Clarion University service area. Proceedings of the Conference on K-12 Outreach from University Science Departments: 2005, NC State University, pp. 45-50.

Steyn, G. (2005). Exploring Factors that influence the effective implementation of professional development programs. Journal of Invitational Theory and Practice, 11, 7-34.

Steyn, G. (2006). A qualitative study of the aspects influencing the implementation of invitational education in schools in the U.S. Journal of Invitational Theory and Practice, $12,17-36$.

Squire, K. D., MaKinster, J. G., Barnett, M., Luehmann, A. L., \& Barab, S. L. (2003). Designed curriculum and local culture: Acknowledging the primacy of classroom culture. Science education, 87(4), 468-489.

Thadani, V., Cook, M, Griffis, K., Wise, J., \& A. Blakey (2010). The possibilities and limitations of curriculum-based science inquiry interventions for challenging the "pedagogy of poverty." Equity \& Excellence in Education, 43(1), 21-37.

Urban, W. (2004). American Education: A History ( $3^{\text {rd }}$ ed.). New York: The McGraw-Hill Companies, Inc.

Voogt, J. (2010). Teacher factors associated with innovative curriculum goals and pedagogical practices: differences between extensive and non-extensive ICT-using science teachers. Journal of Computer Assisted Learning, 26, 453-464.

Yu, H., Leithwood, K. \& Jantzi, D. (2000). The effects of trans-formational leadership on teachers' commitment to change in Hong Kong. Journal of Educational Administration, 40(4):368-389.

Zhao, Y., \& Cziko, G. A. (2001). Teacher adoption of technology: A perceptual control theory perspective. Journal of Technology and Teacher Education, 9(1), 5-30. 
APPENDIX A

\section{PARTICIPANT CONSENT LETTER}




\section{WestVirginiaUniversity。}

Dear Participant,

This letter is a request for you to take part in a research project that examines teacher usage and non-usage of the Science in Motion Program at Clarion University. This research project is being conducted by Karen Spuck, a doctoral student in Curriculum and Instruction under the supervision of Dr. Patricia Obenauf, a professor in the College of Education and Human Services. This research project is part of a dissertation that it is being conducted in partial fulfillment of the requirements of the Curriculum and Instruction Doctoral Program at West Virginia University. Your participation in this project is greatly appreciated.

Your involvement in this project will be kept as confidential as legally possible. All data will be reported in the aggregate. Your name as well as any other identifying factors will be altered in any reporting documentation to keep your identity confidential. Your participation is completely voluntary. You may skip any question that you do not wish to answer and you may discontinue at any time. West Virginia University's Institutional Review Board acknowledgement of this project is on file.

I know that you are very busy, but I hope that you will be able to participate in this research project. The focus group interview will take about an hour to complete. You will also be asked to complete a short questionnaire to provide demographic and teaching background information which will take approximately five minutes to complete. You will be provided with a gift card upon your completion of the interview as a token of appreciation. The results of this research could potentially be used to improve the Science in Motion program and add to the body of research concerning teachers and how they select instructional practices. Should you have any questions about this letter or the research project, please feel free to contact Karen Spuck at (814)758-7129 or kmspuck@gmail.com.

Thank you for your time and help with this project.

Sincerely,

Karen Spuck 
APPENDIX B

HUMAN RESEARCH PROTOCOL ONLY MINIMAL RISK CONSENT FORM 


\title{
W WestVirginiaUniversity.
}

Human Research Protocol Only Minimal Risk Consent Form Without HIPAA

\author{
Only Minimal Risk \\ Consent Information Form (without HIPAA) \\ Principal Investigator \\ Karen Spuck \\ Department \\ Education \\ Protocol Number \\ TBA
}

Study Title Understanding Teachers as Gatekeepers: Examining Reported Teacher Reasons for Program Usage of the Science in Motion Program at Clarion University of Pennsylvania.

Co-Investigator(s) none

Sponsor (if any) none

\section{Contact Persons}

For information regarding your rights as a research subject, to discuss problems, concerns, or suggestions related to the research, to obtain information or offer input about the research, contact the Office of Research Integrity \& Compliance at (304) 293-7073.

In addition if you would like to discuss problems, concerns, have suggestions related to research, or would like to offer input about the research, contact the Office of Research Integrity and Compliance at 304-293-7073.

\section{Introduction}

You have been asked to participate in this research study, which has been explained to you by Karen Spuck. This study is being conducted by Karen Spuck, a doctoral student in the Department of Education at West Virginia University.

\section{Purpose of the Study}

The purpose of the study is to understand why teachers decide to use, or not use Science in Motion resources.

\section{Description of Procedures}

This study involves focus group interviews to gain an understanding about teacher usage of the Science in Motion Program at Clarion University. The focus group interview will take approximately one hour. You will be asked to fill out a questionnaire providing information regarding your teaching background and other demographic information. This will take approximately five minutes to complete. You do not have to answer all the questions.

\section{Discomforts}

There are no known or expected risks from participating in this study.
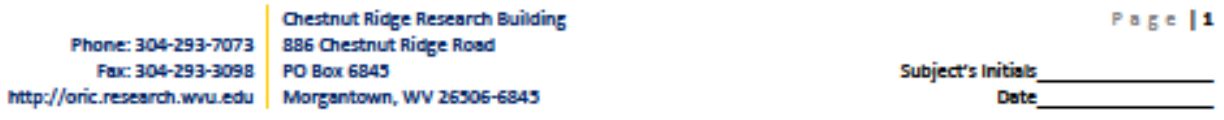


\section{WesthiginiaUniversity.}

Human Research Protocol Only Minimal Risk Consent Form Without HIPAA

\section{Benefits}

You may not receive any direct benefit from this study. The knowledge gained from this study may eventually benefit others.

\section{Financial Considerations}

There are no special fees for participating in this study.

\section{Confidentiality}

Any information about you that is obtained as a result of your participation in this research will be kept as confidential as legally possible. Your research records, just like hospital records, may be subpoenaed by court order or may be inspected by the study sponsor or federal regulatory authorities (including the FDA if applicable) without your additional consent.

In addition, there are certain instances where the researcher is legally required to give information to the appropriate authorities. These would include mandatory reporting of infectious diseases, mandatory reporting of information about behavior that is imminently dangerous to your child or to others, such as suicide, child abuse, etc.

Audiotapes or videotapes will be kept locked up and will be destroyed as soon as possible after the research is finished. In any publications that result from this research, neither your name nor any information from which you might be identified will be published without your consent.

\section{Voluntary Participation}

Participation in this study is voluntary. You are free to withdraw your consent to participate in this study at any time.

Refusal to participate or withdrawal will involve no penalty to you. Refusal to participate or withdrawal will not affect your future care, or your employee status at West Virginia University.

In the event new information becomes available that may affect your willingness to participate in this study, this information will be given to you so that you can make an informed decision about whether or not to continue your participation.

Phone: $304-293-7073$ Fax: 304-293-3098 nttp://oric. research.wwu.ed
Chestnut Ridge Research Building

886 Chestnut

Morgantown, WV 26505-6845
$P a g e \mid 2$

Subject's Initia:

Dote 


\title{
W. WestVirginiaUniversity,
}

Human Research Protocol Only Minimal Risk Consent Form Without HIPAA

\begin{abstract}
You have been given the opportunity to ask questions about the research, and you have received answers
\end{abstract} concerning areas you did not understand.

Upon signing this form, you will receive a copy.

I willingly consent to participate in this research.

Signatures

Signature of Subject

Printed Name

Date

Time

The participant has had the opportunity to have questions addressed. The participant willingly agrees to be in the study.

Signature of Investigator

\begin{tabular}{lll}
\hline Printed Name & Date
\end{tabular}

Phone: 304-293-7073

Fax: 304-293-309 Inttp//oric.research.wwu.edu
Chestnut Ridge Research Building

886 Chestnut Ridge Rosd

PO Box 6845

Morgantown, WV 26505-6849
Page | 3

Subject's Initials

Dote 
APPENDIX C

STUDY PARTICIPANT DEMOGRAPHIC QUESTIONNAIRE 


\section{Study Participant Demographic Questionnaire}

Name:

Current status: actively teaching education administrator retired teacher

Years of science teaching experience:

Degrees earned:

Grade level(s) you have experience teaching science:

Science course(s) you have experience teaching:

Please list any science teaching grant funded projects you have participated in:

Do you have any experience doing research in science? If so, please elaborate:

Have you participated in other teacher outreach projects or professional development programs at Clarion University? If so, please elaborate:

Are you a member of any professional organization such as PSTA? If so, please list:

Have you received any awards or recognitions as an educator? If so please list:

Do you hold any leadership positions at your school, or extra duties such as class sponsor, or science club advisor? If so, please list: 
The purpose of this study is to understand what it is about you the encouraged you to initiate SIM services and continue using the program as you have done for an extended period of time. If you are no longer a classroom teacher, think of this in past tense.

Thoughtful, in-depth responses to each question will be extremely helpful, and provide rich data that will make this study more meaningful. Please let me know if you have any questions or concerns.

1. What was it about you that encouraged you to initiate SIM services?

2. What are the factors that have encouraged you to continue using the SIM project?

3. Does SIM help you meet your personal goals as a science teacher?

4. Does your continued participation with the SIM project reflect your personal feelings about your teaching of science?

5. What is it about yourself that you believe causes you to continue to use the SIM project? 
APPENDIX D

STUDY PARTICIPANT DEMOGRAPHIC DATA 
Table 1 Demographic Questionnaire Data

\begin{tabular}{|c|c|c|c|c|c|c|c|c|c|c|}
\hline Teacher & $\begin{array}{l}\text { Current } \\
\text { Status }\end{array}$ & $\begin{array}{c}\text { Years } \\
\text { Teaching } \\
\text { Experience }\end{array}$ & $\begin{array}{l}\text { Degrees } \\
\text { Earned }\end{array}$ & $\begin{array}{c}\text { Grade } \\
\text { Level } \\
\text { Taught }\end{array}$ & Subjects Taught & $\begin{array}{l}\text { Prev } \\
\text { CUP }\end{array}$ & $\begin{array}{l}\text { ious Ex } \\
\text { Grants }\end{array}$ & $\begin{array}{l}\text { perience } \\
\text { Research } \\
\end{array}$ & $\begin{array}{c}\text { Professional } \\
\text { Organizations }\end{array}$ & $\begin{array}{c}\text { Leadership/Extra- } \\
\text { Curricular } \\
\text { Responsibilities }\end{array}$ \\
\hline Marcy & $\begin{array}{l}\text { Actively } \\
\text { Teaching }\end{array}$ & 21 & BS Education & $9-12$ & $\begin{array}{l}\text { A.P.* Biology, } \\
\text { Biology, Chemistry, } \\
\text { Earth Science }\end{array}$ & Yes & Yes & No & Yes & Yes \\
\hline Mary & $\begin{array}{l}\text { Actively } \\
\text { Teaching }\end{array}$ & 14 & $\begin{array}{l}\text { BS Biology } \\
\text { M.Ed. }\end{array}$ & $6-12$ & $\begin{array}{l}\text { Life Science, Biology, } \\
\text { Chemistry, Environ. S }\end{array}$ & Yes & Yes & Yes & Yes & Yes \\
\hline Patty & $\begin{array}{l}\text { Actively } \\
\text { Teaching }\end{array}$ & 19 & BS Education & $6-12$ & $\begin{array}{l}\text { Life Science, Earth } \\
\text { Science } \\
\text { Environ Science, } \\
\text { Biology, } \\
\text { Physics }\end{array}$ & Yes & No & No & Yes & Yes \\
\hline Laurie & $\begin{array}{l}\text { Actively } \\
\text { Teaching }\end{array}$ & 24 & $\begin{array}{l}\text { BS Education } \\
\text { M.S. Biology }\end{array}$ & $7-12$ & $\begin{array}{l}\text { A.P. Biology, Biology, } \\
\text { Anatomy, Forensics, } \\
\text { Gen Science }\end{array}$ & Yes & Yes & Yes & Yes & Yes \\
\hline Lucy & Retired & 27 & $\begin{array}{l}\text { BS Chemistry } \\
\text { and Biology }\end{array}$ & $9-12$ & $\begin{array}{l}\text { A.P. * Chemistry, } \\
\text { Biology, } \\
\text { Chemistry, Gen } \\
\text { Science }\end{array}$ & Yes & Yes & No & Yes & Yes \\
\hline Sue & $\begin{array}{l}\text { Actively } \\
\text { Teaching }\end{array}$ & 25 & $\begin{array}{l}\text { B.S. Biology } \\
\text { Teacher } \\
\text { Certification } \\
\text { Bio/General } \\
\text { Science } \\
\text { M.Ed. }\end{array}$ & $7-12$ & $\begin{array}{l}\text { Biology, Chemistry, } \\
\text { Geology, Physical } \\
\text { Science, } \\
\text { Life Science }\end{array}$ & No & Yes & Yes & Yes & Yes \\
\hline Barbie & $\begin{array}{l}\text { Actively } \\
\text { Teaching }\end{array}$ & 21 & $\begin{array}{l}\text { BS Science } \\
\text { Education } \\
\text { MS Science } \\
\text { Education }\end{array}$ & $7-12$ & $\begin{array}{l}\text { A.P.* Biology, } \\
\text { Biology, } \\
\text { Earth Science, Life } \\
\text { Science, } \\
\text { Physical Science }\end{array}$ & Yes & Yes & No & Yes & Yes \\
\hline Brian & $\begin{array}{l}\text { Actively } \\
\text { Teaching }\end{array}$ & 17 & $\begin{array}{l}\text { BS Biology } \\
\text { MA Ed Tech } \\
\text { \& Leadership }\end{array}$ & $6-8$ & Integrated Science & Yes & Yes & Yes & Yes & Yes \\
\hline Tessa & $\begin{array}{l}\text { Actively } \\
\text { Teaching }\end{array}$ & 13 & $\begin{array}{l}\text { BS Biology } \\
\text { BS Secondary } \\
\text { Education }\end{array}$ & $7-12$ & $\begin{array}{l}\text { Biology, Life Science, } \\
\text { Earth Science, Gen } \\
\text { Science, }\end{array}$ & Yes & No & No & No & Yes \\
\hline
\end{tabular}




\begin{tabular}{|c|c|c|c|c|c|c|c|c|c|c|}
\hline & & & M.Ed. & & Physical Science & & & & & \\
\hline Leslie & $\begin{array}{l}\text { Actively } \\
\text { teaching }\end{array}$ & 12 & $\begin{array}{l}\text { BS Biology } \\
\text { BS Ed }\end{array}$ & $7-12$ & $\begin{array}{l}\text { Biology, Chemistry, } \\
\text { Earth Science, Life } \\
\text { Science, } \\
\text { Physical Science } \\
\end{array}$ & Yes & Yes & No & Yes & Yes \\
\hline Chuck & $\begin{array}{l}\text { Ed } \\
\text { Admin }\end{array}$ & 17 & $\begin{array}{l}\text { BS Biology } \\
\text { M.Ed. }\end{array}$ & $7-12$ & $\begin{array}{l}\text { Biology, Life Science, } \\
\text { General Science }\end{array}$ & Yes & Yes & Yes & Yes & Yes \\
\hline Kevin & $\begin{array}{l}\text { Ed } \\
\text { Admin }\end{array}$ & 23 & $\begin{array}{l}\text { BS } \\
\text { M.Ed. }\end{array}$ & $8-16$ & $\begin{array}{l}\text { Earth Science } \\
\text { Astronomy }\end{array}$ & Yes & Yes & Yes & Yes & Yes \\
\hline John & $\begin{array}{l}\text { Actively } \\
\text { Teaching }\end{array}$ & 18 & $\begin{array}{l}\text { BS Biology } \\
\text { MAT }\end{array}$ & $7-12$ & $\begin{array}{l}\text { A.P. * Biology, } \\
\text { Biology, } \\
\text { Life Science, } \\
\text { Chemistry }\end{array}$ & Yes & No & No & No & Yes \\
\hline Linda & Retired & 31 & $\begin{array}{l}\text { BS Biology, } \\
\text { Education } \\
\text { MS Biology }\end{array}$ & $7-16$ & $\begin{array}{l}\text { A.P. *Biology, } \\
\text { Biology, } \\
\text { Earth Science, General } \\
\text { Science }\end{array}$ & Yes & Yes & No & Yes & Yes \\
\hline
\end{tabular}

*Advanced Placement 
